DANILO RIBEIRO GUERRA

\title{
Estimulação elétrica transcutânea do nervo: analgesia preemptiva em colecistectomia por lapar otomia
}

\begin{abstract}
Dissertação de Mestrado apresentada ao Departamento de Biomecânica, Medicina e Reabilitação do Aparelho Locomotor da Faculdade de Medicina de Ribeirão Preto da Universidade de São Paulo para obtenção do Título de Mestre em Reabilitação.
\end{abstract}

Orientador: Prof. Dr. Luís Vicente Garcia

Ribeirão Preto

2005 
AUTORIZO A REPRODUÇÃO E DIVULGAÇÃO TOTAL OU PARCIAL DESTE TRABALHO POR QUALQUER MEIO CONVENCIONAL OU ELETRÔNICO, PARA FINS DE ESTUDO E PESQUISA, DESDE QUE CITADA A FONTE.

Guerra, Danilo Ribeiro

Estimulação elétrica transcutânea do nervo: analgesia preemptiva em colecistectomia por laparotomia./ Danilo Ribeiro Guerra; orientador: Prof. Dr. Luís Vicente Garcia. Ribeirão Preto - SP. Ribeirão Preto, 2005.

139 f.: fig.

Dissertação de Mestrado apresentada ao Departamento de Biomecânica, Medicina e Reabilitação do Aparelho Locomotor da Faculdade de Medicina de Ribeirão Preto da Universidade de São Paulo.

1. Dor. 2. Estimulação elétrica transcutânea do nervo. 3. Colecistectomia. 4. Analgesia preemptiva 


\section{DEDICATÓRIA}

Aos meus pais, Salvino Guerra Filho e Maria Luíza Ribeiro Guerra, por todo o amor, dedicação e lições de vida que possibilitaram a concretização desse trabalho. 


\section{AGRADECIMENTOS}

A Deus, ser superior que nos acompanha constantemente não apenas nos momentos de euforia e alegria, mas principalmente quando necessitamos de um passo maior para superar os obstáculos da vida.

Ao orientador Prof. Dr. Luís Vicente Garcia, por toda a confiança depositada em meu trabalho desde a época em que ainda era um graduando; e apoio e incentivo na realização dessa pesquisa, mesmo diante de tanto trabalho. Obrigado por tudo, professor. A minha gratidão por ti é imensa. Continua sempre com essa energia positiva e essa paz interior, que o teu caminho será sempre bem iluminado.

Aos meus pais - Salvino Guerra Filho e Maria Luíza Ribeiro Guerra; irmãos — Salvino Guerra Neto e Ticiana Ribeiro Guerra; e sobrinhos - Juliano Guerra de Castro e Letícia Guerra - por serem o meu grande alicerce. O meu amor por vocês será eterno.

A toda a minha família — tios e primos —, em especial ao Dr. Wagner da Silva Ribeiro e a Ivana Almeida da Silva Ribeiro.

Aos meus professores da graduação Dr. Francisco Prado Reis, Dr. José Aderval Aragão, Dr. Ronaldo Queiroz Gurgel e Dr. Walderi Monteiro da Silva Júnior, verdadeiros pais na minha vida acadêmica. As lições — científicas e de vida —, sempre tão válidas, proveitosas e essenciais para o processo de aprendizado científico, ficarão guardadas para todo o sempre. 
A todos os integrantes do Departamento de Biomecânica, Medicina e Reabilitação do Aparelho Locomotor da Faculdade de Medicina de Ribeirão Preto, pela disponibilidade e atenção fornecidas, em especial a Maria de Fátima Feitosa Lima.

Aos amigos Válter Joviniano de Santana Filho e Josimari Melo de Santana, que sempre me acolheram como verdadeiros pais nessa nova jornada que se processou em minha vida. Obrigado de coração a vocês pela amizade, incentivo, carinho e respeito.

Aos companheiros de pesquisa: Thaísa Barreto, Brenno Santiago, Jaqueline Lobão, José Nery, Marcelo Prata, Paulo Autran, Thaís Costa e Renata. Essa pesquisa é um dos frutos que colhemos ao longo de todos esses meses.

Aos amigos de longas datas pelas sábias palavras, conselhos, viagens e por saberem compreender o verdadeiro sentido da palavra Amizade: Valeska Dias, Andrei Ribeiro, Thiago Paulino, Tácito Leite, Murilo Araújo, Mariana Godoy, Alina, Alberto Ribeiro, Wylner Cardozo, Elisvânia Barroso e Larissa Sampaio.

Aos novos amigos que me acolheram em Ribeirão Preto: Badauê, Keka, Luquinhas, Mateus, Emílson, Ricardo, Márcio, Manuela, Carol e Mariana. Ainda temos muita estrada para compartilharmos juntos. Obrigado por tudo.

A todos os integrantes da Liga de Dor de Ribeirão Preto — professores e estudantes —, pelo profissionalismo e, sobretudo, pelo clima de amizade sempre presente. Poder compartilhar um mesmo ambiente com pessoas tão dedicadas e sábias tem sido um processo de aprendizado 
muito relevante para mim. Em especial ao Prof. Dr. José Geraldo Speciali e à Prof ${ }^{\mathrm{a}}$. Dr ${ }^{\mathrm{a}}$. Fátima Aparecida Emm Faleiros Souza.

À Prof ${ }^{a}$. Dr ${ }^{a}$. Cláudia Benedita dos Santos, pelo grande apoio na reta final e simpatia sempre presente. Desejo-lhe imenso sucesso nessa próxima etapa da sua vida profissional.

Às funcionárias do Hospital das Clínicas de Ribeirão Preto, em especial Rita e Sílvia, que sempre me atenderam e "socorreram" com um carinho e simpatia muito grandes.

A todos os funcionários do Hospital São Domingos Sávio - cirurgiões, anestesiologistas, enfermeiros, técnicas em enfermagem e porteiros - , que sempre se mostraram receptivos a nossa presença; e principalmente aos pacientes que se disponibilizaram a participar da nossa pesquisa. 
“Aprendemos, em decorrência de, literalmente, centenas de experiências, que existe um limite para a eficácia de qualquer terapia empregada; porém, felizmente, os efeitos de duas ou mais terapias, fornecidas em combinação, são cumulativos”.

Melzack e Wall, 1987. 


\section{RESUM 0}

GUERRA, D. R. Estimulação elétrica transcutânea do nervo: analgesia preemptiva em colecistectomia por laparotomia. 2005. 139 f. Dissertação de mestrado - Faculdade de Medicina de Ribeirão Preto, Universidade de São Paulo, Ribeirão Preto, 2005.

Introdução. O uso da Estimulação Elétrica Transcutânea do Nervo (TENS) vem sendo muito pesquisado em pós-operatórios, todavia os estudos não analisam se a TENS de baixa freqüência - que estimula a liberação de opióides endógenos - seria eficiente em promover analgesia preemptiva. Objetivo. Analisar se essa modalidade de TENS, aplicada antes de colecistectomias por laparotomia, poderia proporcionar analgesia preemptiva. Casuística e método. A pesquisa - clínica, controlada, randomizada e duplamente encoberta - foi realizada no Hospital São Domingos Sávio, e teve uma amostra de 50 pacientes, todas do sexo feminino: grupo preemptivo $(n=25)$ e placebo $(n=25)$. As pacientes do primeiro grupo foram submetidas à aplicação da TENS de baixa freqüência antes da cirurgia: e as do grupo placebo, a uma falsa estimulação. Houve a padronização do cloridrato de bupivacaína $(0,5 \%)$ como droga anestésica, associado ao fentanil $(2 \mathrm{ml})$ para a realização das colecistectomias; e da medicação analgésica utilizada no pós-operatório: dipirona, prescrita de 6 em 6 horas, e diclofenaco de sódio, como medicação de resgate. A intensidade de dor pós-operatória foi mensurada pela Escala Numérica de Mensuração da Dor (END), em 8 momentos (21/2, 31/2, $41 \frac{1}{2}, 5 \frac{1}{2}, 7,8$ e 16 horas após a indução do bloqueio anestésico, além de uma última verificação no momento da alta hospitalar), e pelo Questionário de Dor McGill (MPQ), aplicado 16 horas após a indução do bloqueio anestésico. Outrossim, o grau de satisfação das pacientes com o tratamento foi mensurado pela Escala de Satisfação do Paciente (ESP). Os dados foram analisados por meio de testes estatísticos descritivos, Teste de Mann-Whitney, Teste-t de Student para amostras não-pareadas e qui-quadrado, sendo o nível de significância de 5\%. Resultados. A intensidade de dor, mensurada pela END, foi significantemente menor no grupo preemptivo nas terceira e quarta coletas. Não houve diferença significante quanto aos índices obtidos pelo MPQ, e nem quanto à satisfação das pacientes, o consumo de drogas analgésicas no pós-operatório e o tempo para o primeiro requerimento de diclofenaco de sódio. Conclusão. A TENS de baixa freqüência proporcionou analgesia preemptiva após colecistectomia por laparotomia.

Palavras-chave: dor; estimulação elétrica transcutânea do nervo; colecistectomia; analgesia preemptviva. 
GUERRA, D. R. Transcutaneous Electrical Nerve Stimulation: preemptive analgesia in open cholecystectomy. 2005. $139 \mathrm{f}$. Master's dissertation - Faculdade de Medicina de Ribeirão Preto, Universidade de São Paulo, Ribeirão Preto, 2005.

Introduction. Transcutaneous Electrical Nerve Stimulation (TENS) has been searched in the postoperative period, however these studies don't analyze whether low frequency TENS that stimulates the release of endogenous opioids - could be efficient to provide preemptive analgesia. Objective. The aim of this study was to verify whether low frequency TENS, applied before open cholecystectomies, could provide it. Cases and method. It was a controlled, randomized and double-blinded trial, carried out at the Hospital São Domingos Sávio (Aracaju city, Brazil), and had a sample of 50 patients: preemptive group $(\mathrm{n}=25)$ and placebo $(n=25)$. The patients from the first group were submitted to the application of TENS before the surgery; and the placebo group to a false stimulation. There was the standardization of the bupivacaine $(0,5 \%)$ as anesthetic drug plus fentanyl $(2 \mathrm{ml})$ for the accomplishment of the cholecystectomies; and of the analgesic medication used in the postoperative period: dipyrone, prescribed for every 6 hours, and diclofenac, only if the patients complained about pain. Pain intensity was measured by the Numerical Rating Scale (NRS), in 8 moments (21/2, $3 \frac{1}{2}, 4 \frac{1}{2}, 5 \frac{1}{2}, 7,8$ e 16 hours after inducing the anesthesia besides one last verification at the hospital discharge), and by the Brazilian version of the McGill Pain Questionnaire (Br-MPQ), applied 16 hours after inducing the anesthesia. Patient satisfaction level in relation to the treatment was measured by the Patient Satisfaction Scale (PSS). The data were analyzed by Mann-Whitney Test, unpaired t-test and qui-square, being significant, those data with $\mathrm{p}<$ 0,05. Results. Pain intensity, measured by the NRS, was lower in the preemptive group in the third and fourth verifications. There was no difference neither in relation to the indexes obtained with the Br-MPQ, nor the PSS, consume of analgesics in the postoperative and time for the first request of diclofenac. Conclusion. Low frequency TENS provided preemptive analgesia after open cholecystectomy.

Keywords: pain; transcutaneous electrical nerve stimulation; cholecystectomy; preemptive analgesia. 


\section{LISTA DE ILUSTRAÇÕES}

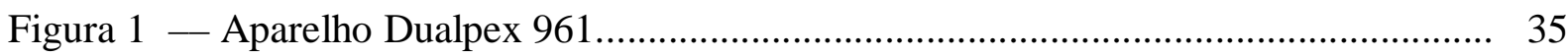

Figura 2 — Aparelho Physiotonus Four.......................................................................... 35

Figura 3 - Simulação da aplicação da TENS............................................................ 37

Figura 4 — Escala Numérica de Mensuração da Dor, numerada de 0 a $10 \mathrm{~cm}$.................... 39

Gráfico 1 Representação das idades das pacientes................................................... 46

Gráfico 2 - Representação dos pesos das pacientes.................................................. 47

Gráfico 3 — Representação das estaturas das pacientes.................................................. 47

Gráfico 4 — Representação dos Índices de Massa Corporal (IMC) das pacientes.............. 48

Gráfico 5 - Relato das pacientes sobre o período, em meses, em que vinham sentindo dor devido à doença da vesícula biliar...................................................... 50

Gráfico 6 - Estado físico das pacientes, de acordo com a classificação da Sociedade Americana de Anestesiologia.

Gráfico 7 - Relato das pacientes sobre o uso de analgésicos antes da colecistectomia, para o tratamento da dor decorrente da doença da vesícula biliar, ou de outras doenças crônicas.

Gráfico 8 - Representação do tempo decorrido desde o término da aplicação da Estimulação Elétrica Transcutânea do Nervo até a indução do bloqueio Anestésico nas pacientes.

Gráfico 9 - Representação da duração das cirurgias

Gráfico 10 - Representação da média da intensidade de dor incisional, por meio da END (Escala Numérica de Mensuração da Dor).

Gráfico 11 - Representação da média de satisfação das pacientes com o tratamento que estava sendo realizado, obtida pela ESP (Escala de Satisfação do Paciente).. 58

Gráfico 12 - Representação da média do Número de Palavras Escolhidas (NWC) total e em cada categoria do Questionário de Dor McGill, nos grupos preemptivo e placebo.

Gráfico 13 - Representação da média do Índice Quantitativo da Dor (PRI) total e em cada categoria do Questionário de Dor McGill, nos grupos preemptivo e placebo. 
Gráfico 14 - Representação do consumo de diclofenaco de sódio pelas pacientes nas primeiras 16 horas após a indução do bloqueio anestésico.

Gráfico 15 - Representação dos intervalos desde a indução do bloqueio anestésico até a solicitação do diclofenaco de sódio, nas pacientes que assim a fizeram nas primeiras 16 horas após tal indução.

Gráfico 16 - Número de vezes que as pacientes consumiram diclofenaco de sódio desde o início do período pós-operatório até o momento da alta hospitalar.....

Gráfico 17 - Número de vezes que as pacientes consumiram dipirona desde o início do período pós-operatório até o momento da alta hospitalar.

Gráfico 18 - Ocorrência de dor referida no ombro direito das pacientes, em algum momento do período pós-operatório, durante a internação hospitalar.

Gráfico 19 - Uso de metoclopramida pelas pacientes, durante o período de internação hospitalar.

Gráfico 20 - A aplicação da TENS:

Gráfico 21 - Em uma próxima cirurgia você iria preferir, para o tratamento da sua dor pós-operatória, usar:. 


\section{LISTA DE TABELAS}

Tabela 1 — Dados demográficos da amostra.

Tabela 2 - Distribuição da categoria de peso das pacientes, de acordo com os dados obtidos pelo índice de massa corporal (IMC).

Tabela 3 - Nível de escolaridade das pacientes

Tabela 4 - Diagnóstico clínico das pacientes.

Tabela 5 - Valores da média e Erro Padrão da Média (SEM) da intensidade de dor incisional, mensurada por meio da END (Escala Numérica de Mensuração da Dor.

Tabela 6 - Valores da média e Erro Padrão da Média (SEM) do grau de satisfação das pacientes com o tratamento que estava sendo realizado.

Tabela 7 - Relação dos descritores do Questionário de Dor McGill selecionados pelas pacientes

Tabela 8 - Número de pacientes que selecionou cada subcategoria do Questionário de Dor McGill.

Tabela 9 — Descritores do Questionário de Dor McGill mais freqüentemente selecionados pelas pacientes.

Tabela 10 - Índice do Número de Palavras Escolhidas (NWC) total e em cada categoria do Questionário de Dor McGill.

Tabela 11 - Relação do Número de Palavras Escolhidas nas categorias sensorial (NWC-S) e afetiva (NWC-Af), entre os grupos preemptivo e placebo.

Tabela 12- Índice Quantitativo da Dor (PRI) total e em cada categoria do Questionário de Dor McGill, nos grupos preemptivo e placebo

Tabela 13 - Valores da intensidade de dor incisional, obtidos pela Escala Numérica de Mensuração da Dor, das pacientes do grupo preemptivo.

Tabela 14 - Valores da intensidade de dor incisional, obtidos pela Escala Numérica de Mensuração da Dor, das pacientes do grupo placebo.

Tabela 15 - Valores do grau de satisfação das pacientes do grupo preemptivo com o tratamento que estava sendo realizado, obtidos pela Escala de Satisfação dos Pacientes.

Tabela 16 - Valores do grau de satisfação das pacientes do grupo placebo com o tratamento que estava sendo realizado, obtidos pela Escala de Satisfação dos Pacientes. 
Tabela 17 - Uso de diclofenaco de sódio nas primeiras 16 horas após a indução do bloqueio anestésico e tempo decorrido desde essa indução até a primeira solicitação dessa droga, nos grupos preemptivo e placebo

Tabela 18 - Presença de dor no ombro direito no período pós-operatório, nas pacientes dos grupos preemptivo e placebo.

Tabela 19 - Quantidade de vezes em que a metoclopramida, o diclofenaco de sódio e a dipirona foram administradas em cada paciente, durante todo o período pós-operatório em que elas estavam internadas. 


\section{LISTA DE ABREVIATURASE SIGLAS}

ACTH Adrenocorticotropina

AMPc Adenosina monofosfato

ASA American Society of Anesthesiology (Sociedade Americana de Anestesiologia)

â-LPH â-lipotropina

END Escala Numérica de Mensuração da Dor

ESP Escala de Satisfação do Paciente

IASP International Association for the Study of Pain (Associação Internacional para o Estudo da Dor)

IBA Início do Bloqueio Anestésico

IMC Índice de Massa Corporal

MPQ McGill Pain Questionnaire(Questionário de Dor McGill)

NMDA N-metil-D-aspartato

NWC Number of Words Chosen (Número de Palavras Escolhidas)

NWC-t Número de Palavras Escolhidas Total

NWC-s Número de Palavras Escolhidas na Categoria Sensorial

NWC-af Número de Palavras Escolhidas na Categoria Afetiva

NWC-av Número de Palavras Escolhidas na Categoria Avaliativa

NWC-m Número de Palavras Escolhidas na Categoria Miscelânea

PPI Present Pain Intensity (Intensidade de Dor Presente)

PRI Pain Rating Índex (Índice Quantitativo de Dor)

RNA Ácido Ribonucléico

SEM Standard Error Mean (Erro Padrão da Média) 
SN Sistema Nervoso

SUS Sistema Único de Saúde

TENS Transcutaneus Electrical Nerve Stimulation (Estimulação Elétrica Transcutânea do Nervo)

TNLs Terminações Nervosas Livres

VAS Visual Analogue Scale(Escala Analógica Visual) 


\section{LISTA DE SÍMBOLOS}

$\begin{array}{ll}\mathrm{cm} & \text { Centímetro } \\ \mathrm{g} & \text { Grama } \\ \mathrm{H}^{+} & \text {Íon hidrogênio } \\ \mathrm{K}^{+} & \text {Íon potássio } \\ \mathrm{h} & \text { Hora } \\ \mathrm{Hz} & \text { Hertz } \\ \mathrm{Kg} & \text { Kilograma } \\ \mathrm{m} & \text { Metro } \\ \mathrm{ml} & \text { Mililitro } \\ \mathrm{min} & \text { Minuto } \\ \mu \mathrm{s} & \text { Microsegundo } \\ \hat{\mathrm{a}} & \text { Beta } \\ \ddot{\mathrm{a}} & \text { Delta } \\ \leftarrow^{2} & \text { Qui-quadrado }\end{array}$




\section{SUMÁRIO}

I INTR ODUÇÃ O

2 OBJETIV O

3 CASUÍSTICA E MÉTODO

3.1 DESENHO DO ESTUDO........................................................................ 29

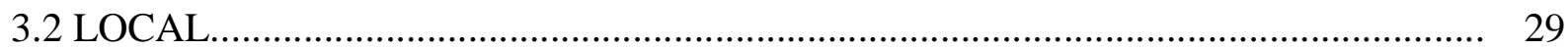

3.3 CASUÍSTICA E CRITÉRIOS DE INCLUSÃO E EXCLUSÃO..................................... 29

3.4 INTERNAMENTO DAS PACIENTES................................................................ 32

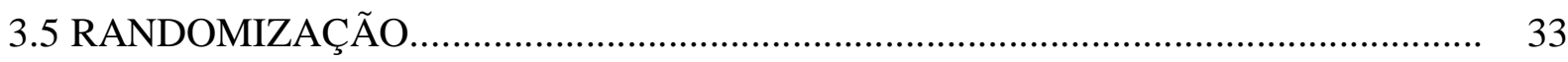

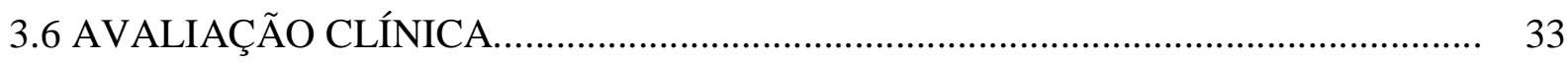

3.7 TERMO DE CONSENTIMENTO LIVRE E ESCLARECIDO...................................... 34

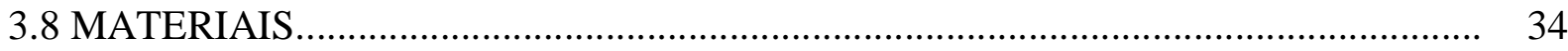

3.9 PROCEDIMENTOS METODOLÓGICOS......................................................... 35

3.9.1 Os grupos de pacientes da pesquisa.................................................................. 35

3.9.2 Técnica de aplicação da TENS............................................................................. 36

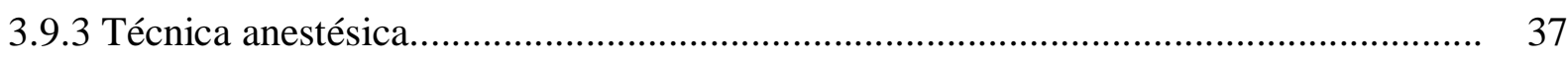

3.9.4 Cirurgia e prescrição de medicamentos................................................................. 38

3.9.5 Instrumentos de coleta de dados.......................................................................... 39

3.9.5.1 Escala Numérica de Mensuração da Dor (END) ..................................................... 39

3.9.5.2 Questionário de Dor McGill............................................................................ 40

3.9.5.3 Escala de Satisfação dos Pacientes......................................................................... 41

3.9.5.4 Ficha do consumo de fármacos....................................................................... 42

3.9.5.5 Questionário sobre a aplicação da TENS............................................................ 42

3.10 ANÁLISE E INTERPRETAÇÃO DOS DADOS................................................. 43

3.11 TÉCNICA UTILIZADA PARA A DEMONSTRAÇÃO DOS RESULTADOS.......... 43

4 RE SULTADO S

5 DISC USSÃ O

5.1 DADOS DEMOGRÁFICOS E CLÍNICOS............................................................. 76

5.2 ANÁLISE DA DOR PELA ESCALA NUMÉRICA DE MENSURAÇÃO DA DOR.. 79

5.3 ANÁLISE DA SATISFAÇÃO DAS PACIENTES COM O TRATAMENTO.............. 90 
5.4 ANÁLISE DA DOR PELO QUESTIONÁRIO DE DOR McGILL............................. 92

5.5 TEMPO PARA A PRIMEIRA ADMINISTRAÇÃO DO DICLOFENACO DE

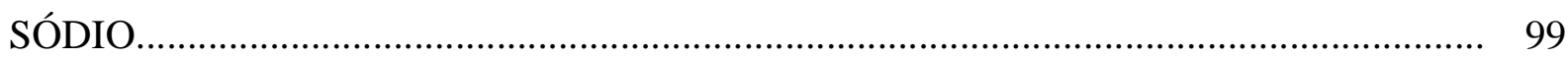

5.6 ANÁLISE DO CONSUMO DE ANALGÉSICOS NO PÓS-OPERATÓRIO............... 101

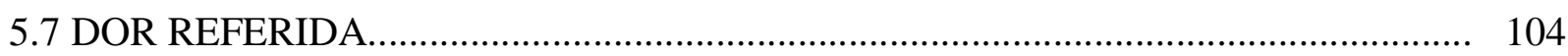

5.8 ANÁLISE DO CONSUMO DE METOCLOPRAMIDA ........................................... 105

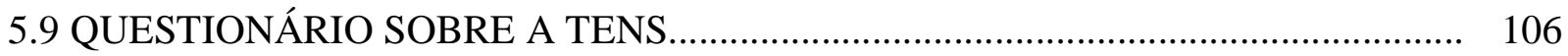

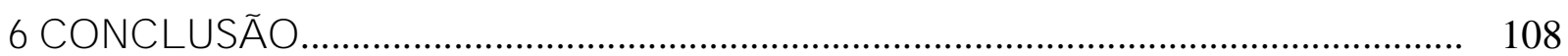

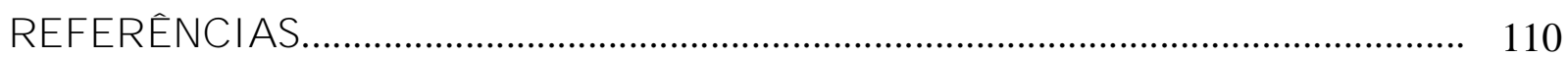

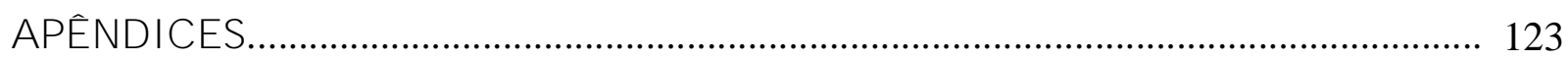


INTRODUÇÃO 


\section{INTRODUÇÃO}

A dor, um dos mais importantes mecanismos de defesa do corpo humano, propicia um sinal de alerta ao encéfalo de que os tecidos estão expostos a uma situação de perigo, mesmo que a dor ocorra antes de um real dano físico. Há longínquo tempo, o homem pesquisa maneiras para aliviar a dor, o que proporcionou vários avanços no campo das modalidades analgésicas, com destaque para os opióides — entre os fármacos; e, na fisioterapia, os estimuladores elétricos, como a Estimulação Elétrica Transcutânea do Nervo (Transcutaneus Electrical Nerve Stimulation - TENS), modalidade terapêutica que consiste na aplicação de corrente elétrica ao corpo humano com fins analgésicos (CHANDRAN; SLUKA, 2003; DuGAS, 1988; FORTH; BEYER; PETER, 1995; LOW; REED, 2001; STARKEY, 2001; TEIXEIRA; SOUZA, 2001; WOOD, 1998).

A tecnologia e a ciência deram suporte à TENS, não apenas pela criação dos modernos e práticos aparelhos eletroterápicos, mas também pelo conhecimento acerca do seu mecanismo de ação, possibilitando que essa técnica fosse amplamente difundida em vários países. De um modo geral, a TENS possui inúmeras indicações, podendo ser aplicada em qualquer síndrome dolorosa aguda ou crônica de causa diagnosticada, inclusive no período pós-operatório (ANTUNES et al. 2002; BUTTON; SAWYER, 1999; CREPON, 1996; DAMIANE, C.; DAMIANE, G., 1998; IMAMURA et al., 1995; ROBINSON, 2001; SANTIESTEBAN, 1993; SLUKA; WALSH, 2003).

Ultimamente, tem-se abordado bastante o uso da TENS para o tratamento de dores pós-operatórias, como as decorrentes de cirurgias cardíacas, colecistectomias, toracotomias, endoscopias microlaríngeas, cirurgias laparoscópicas, gastrectomias, entre outras. A TENS tem sido, na maioria das pesquisas, um recurso analgésico eficiente em pós-operatórios, na dependência do tipo de cirurgia, metodologia empregada, grau de dor gerado e medicação 
concorrente. Todavia, as pesquisas têm restringido seu uso somente ao período pós-cirúrgico, não a empregando antes de cirurgias com o intuito de tratar a dor antes mesmo do seu surgimento (BENEDETTI et al., 1997; CARROL; BADURA, 2001; LOMBARD et al., 1996; MARIANO; BEN, 1998; MARIN; CASTRO, 1986; TOYOTA; SATAKE; AMAKI, 1999; ZÁRATE et al., 2001).

Existem quatro modalidades de TENS: convencional, acupuntura, burst e breveintensa. A TENS acupuntura, muito conhecida como TENS de baixa freqüência, estimula a liberação pela glândula hipófise de ACTH (adrenocorticotropina) e â-lipotropina (â-LPH), que é a substância precursora da â-endorfina, ocorrendo, então, a ligação dessa com os receptores das fibras nervosas, bloqueando, assim, a passagem do impulso doloroso. As âendorfinas permaneceriam circulando pelo organismo durante algumas horas, promovendo analgesia prolongada. Outros autores relatam que há também, com o uso da TENS de baixa freqüência, a liberação de outros tipos de opióides endógenos (BISSCHOP, G.; BISSCHOP, É.; COMMANDRÉ, 2001; CHESTERTON et al., 2003; CREPON, 1996; DAMIANE, C.; DAMIANE, G., 1998; ROBINSON, 2001; SALGADO, 1999; SLUKA et al., 1999; SLUKA, 2000; STARKEY, 2001).

O uso da TENS para o tratamento da dor pós-operatória é estimulado pela tendência atual da analgesia multimodal, que se caracteriza pela combinação sinérgica de agentes analgésicos — farmacológicos e não-farmacológicos — com diferentes mecanismos de ação e vias de administração, proporcionando analgesia mais efetiva e com menor incidência de efeitos adversos, devido às menores dosagens empregadas (LABRADA; JIMÉNEZGARCIA, 2004; TORRE et al., 2002). Outros recursos não-farmacológicos também têm sido usados, como: acupuntura, eletroacupuntura, termoterapia, massoterapia, cinesioterapia, posicionamento, imobilização, outras correntes eletroanalgésicas e técnicas de relaxamento, meditação e imaginação (SOFAER, 1994; YENG et al., 2001). 
Seguindo esse conceito de analgesia multimodal, alguns experimentos clínicos têm analisado o efeito da analgesia preemptiva. O qualificativo, traduzido livremente do inglês para a língua portuguesa, tem origem da palavra preemptive e significa profilático. Assim, drogas analgésicas e anestésicas têm sido administradas antes mesmo do ato cirúrgico, com o objetivo de minimizar o quadro álgico no pós-operatório, por inibição dos fenômenos de hipersensibilidade central e periférica. Embora satisfatórios resultados já tenham sido obtidos com a utilização desse método, ainda existem muitas controvérsias sobre o tema, tendo em vista algumas tentativas frustradas de se obter esse tipo de estratégia de analgesia (AIDA et al., 1999; KONRAD; CORDEIRO; COELI, 2001; MCQUAY, 1995; MOINICHE; KEHLET; DAHL, 2002; ONG et al., 2005; PONTES; PRADO, 2002; SEKAR et al., 2004; SINATRA, 2002; WARNCKE; STUBHAUG; JORUM, 2000).

Uma das questões mais polêmicas sobre a analgesia preemptiva reside no seu próprio conceito e é relevante que esse seja bem definido para evitar interpretações erradas de resultados. Kissin (1994) afirma que constantemente há um errôneo uso do termo em questão, que deve ser restrito apenas à intervenção procedida antes da cirurgia com o objetivo de reduzir a dor pós-operatória. De acordo com Hepner (2000), algumas pesquisas, v.g., a de Motamed (2000), têm analisado o efeito de drogas antes do fechamento da incisão cirúrgica, o que não caracteriza a analgesia preemptiva, já que o procedimento não fora realizado antes da cirurgia (ONG et al., 2005).

Kissin (2000) criticou as 3 definições mais usadas de analgesia preemptiva: a) tratamento que começa antes da cirurgia; b) que previne o estabelecimento da hipersensibilidade central causada pela lesão incisional; e c) que previne a hipersensibilidade central causada pelas lesões incisional e inflamatória. A primeira seria errônea, pois a palavra preemptivo significa preventivo, e não somente antes da incisão cirúrgica. Assim, bloqueios ineficientes não podem ser considerados preemptivos. A segunda seria muito restrita, pois 
exclui a hipersensibilidade central causada pela inflamação que ocorre no período pósoperatório inicial, idéia ratificada por Ong et al. (2005). Contudo, essa é a mais utilizada, visto que as diferenças entre os resultados obtidos com as intervenções que se processam antes e após a cirurgia a evidenciam. A última é a mais ampla, pois também abrange a prevenção da hipersensibilidade provocada pelo processo inflamatório.

Inicialmente, seu conceito abrangia apenas o tempo de administração da droga para verificar seu efeito, comparando os momentos pré e pós-operatórios; porém, não englobava os estudos que comparavam tratamentos com uso de medicação analgésica pré-operatória versus aqueles que não a utilizavam (MOINICHE; KEHLET; DAHL, 2002). Esse é o conceito de analgesia preemptiva que estamos utilizando nessa pesquisa, em que iremos comparar o uso da TENS no período pré-operatório com um grupo placebo; e não comparar o seu efeito pré versus pós-operatório. Alguns autores consideram que esse desenho de estudo estabelecido em nossa pesquisa verificaria apenas uma analgesia preventiva, e não preemptiva; não obstante, nos detemos àqueles que também consideram esse desenho como método para verificar analgesia preemptiva.

A colecistectomia é a cirurgia realizada para extrair a vesícula biliar que se encontra enferma, seja devido a cálculos, inflamações e/ou infecções; tendo uma alta incidência, principalmente sobre a população mais idosa. Ela pode ser procedida por laparotomia ou laparoscopia. O primeiro método, que é mais agressivo, proporciona dor de caráter moderado a intenso no pós-operatório, em decorrência da incisão cirúrgica, manipulação da região, ocasional irritação da pleura pulmonar diafragmática e do nervo frênico e processo inflamatório (ANDRADE, 2002; BLUMGART, 1988; BRENTANO; 2003; GOFFI; GOFFI JÚNIOR; SORBELLO, 1996; MACHADO; RAIA, 1994; MARIANO; BEN, 1998; MERINO, 2001; PERÉZ-AYUSO, 2002; ROSLYN; ZINNER, 1996; WAY; DUNPHY, 1993). 
Quando ocorre a lesão tecidual periférica — decorrente, v.g., da cirurgia —, há dois tipos de respostas do Sistema Nervoso (SN): sensibilização periférica — que é a diminuição do limiar de excitabilidade dos nociceptores periféricos; e sensibilização central — aumento da excitabilidade dos neurônios da medula espinhal. Essas modificações determinarão o estado de hipersensibilidade dolorosa, característico de pós-operatórios, em que se verifica redução do limiar de dor e aumento da resposta aos estímulos nocivos, tanto no local da lesão, quanto nos tecidos adjacentes (VALE, 2000; WOOLF; CHONG, 1993).

Sabe-se que, após o trauma cirúrgico, altas concentrações de substâncias algiogênicas são liberadas de células lesadas, como os leucócitos, mastócitos e plaquetas; e de moléculas livres presentes no interior dos vasos sangüíneos. Dentre essas substâncias, destacam-se: prostaglandinas, leucotrienos, ácido araquidônico, bradicininas, $\mathrm{H}^{+}, \mathrm{K}^{+}$, histamina, substância $\mathrm{P}$, tromboxanos, serotonina, entre outras, que são capazes de sensibilizar os nociceptores das fibras Aä e C, amplamente distribuídos nos tecidos, facilitando a transmissão do impulso doloroso, fenômeno conhecido como hiperalgesia primária, caracterizado pela redução do limiar das terminações nervosas livres (TNLs) aos estímulos nocivos. Em algumas horas, a hiperalgesia secundária aumenta o tamanho da área dolorida à medida que substâncias químicas se difundem aos tecidos vizinhos, tornando-os hipersensíveis (BONICA et al., 1990; BRIDENBAUGH, 1994; KISSIN, 2000; ONG et al., 2005; SINATRA, 2002; STARKEY, 2001; WOOLF; CHONG, 1993).

Sob condições normais, os impulsos das fibras aferentes primárias e dos interneurônios espinhais ativam somente a zona de gatilho da célula, localizada no seu centro, não sendo suficiente para deflagrar o potencial de ação na região adjacente a este, sendo o estímulo, então, sublimiar. Todavia, quando essas células sofrem sensibilização, esses inputs, que eram sublimiares, são convertidos em estímulos supra-limiares. A maior excitabilidade dessas células é responsável pela expansão do número de receptores especializados, aumento 
da magnitude e duração da resposta aos estímulos supra-limiares, e redução do limiar, incluindo aumento da excitabilidade também dos mecanorreceptores de baixo limiar (WOOLF; CHONG, 1993).

Isso tudo ocorreria porque a repetida deflagração do potencial de ação nas fibras Aä e C acarretaria liberação na medula espinhal de ácido glutâmico e neuropeptídeos. A somação desses potenciais provoca progressivo aumento e duração da despolarização dos neurônios da coluna dorsal, que ocorre em consequiência à ativação de receptores N-metil-D-aspartato (NMDA), e possivelmente de receptores de taquininas, pela substância $\mathrm{P}$ e neurocinina A. Essa ativação seria resultado da entrada de cálcio através dos canais iônicos ligante e voltagem dependentes, e da ativação de proteínas guanosina trifosfato, e promoveria mudanças da concentração de mensageiros secundários nos neurônios espinhais. Esses mensageiros secundários, incluindo o AMPc (adenosina monofosfato) cíclico, alteram a ativação da proteína cinase, que, pela fosforilação de proteínas como canais iônicos e enzimas, podem alterar suas funções. A ativação da proteína quinase em resposta à substância P tem demonstrado exercer um efeito de feedback positivo nos receptores NMDA dos neurônios espinhais, aumentando a eficácia deles pela redução da sua suscetibilidade ao bloqueio de Magnésio (WOOLF; CHONG, 1993).

Mensageiros secundários podem também: dar origem a moléculas, de natureza ainda não bem elucidada, que penetram nos neurônios e alcançam o núcleo celular, provocando modificações em sua expressão genética, com subseqüente síntese de RNA mensageiro. Este estimula a produção de moléculas que atuam como receptores excitatórios e também está envolvido na síntese de neurotransmissores retrógrados, como óxido nítrico, monóxido de carbono e prostaglandinas, que se disseminam das células para o interstício, acarretando liberação de mais neurotransmissores excitatórios dos aferentes primários. O termo vind up tem sido empregado para descrever esse aumento da excitabilidade dos neurônios do corno 
posterior da medula espinhal. Parece existir também sensibilização neuronal das estruturas do sistema límbico e núcleos talâmicos (KELLY; AHMAD; BRULL, 2001; SINATRA, 2002; TEIXEIRA, 2001; WOOLF; CHONG, 1993).

Opióides — sistêmicos ou locais —, anestésicos locais, antiinflamatórios nãoesteroidais, antagonistas de receptores NMDA e antagonistas do receptor á-2 adrenérgico têm sido usados na tentativa de promover analgesia preemptiva por meio da inibição de alguns desses fenômenos citados anteriormente; contudo, o uso de recursos não-farmacológicos ainda não tem sido muito empregado para tal finalidade (AIDA et al., 1999; GOTTSCHALK; OCHROCH, 2003; MAESTRONI et al., 2002; MOINICHE; KEHLET; DAHL, 2002; ROSAEG et al., 2001; SINATRA, 2002; TAYLOR, 2002; WU et al., 2003).

Logo, a aplicação da TENS de baixa freqüência no momento imediatamente anterior à realização da colecistectomia por laparotomia tem o intuito de promover uma eletroanalgesia preemptiva - por meio da minimização da hipersensibilidade central — que poderia modular a dor pós-operatória nas suas propriedades mais marcantes: latência, duração, intensidade e remissão. Isso poderia ocorrer, pois a TENS poderia estimular a liberação de opióides endógenos que por sua vez iriam prevenir a sensibilização central.

O emprego da TENS de baixa freqüência para o tratamento da dor pós-operatória pode proporcionar uma diminuição da administração dos fármacos analgésicos habitualmente usados no pós-operatório, evitando alguns efeitos adversos decorrentes do uso dessas drogas, e.g.: náuseas; vômito; reações tóxicas e alérgicas; hipotensão; retenção urinária; sonolência; depressão respiratória; convulsão; constipação; e prurido. A TENS, além de não ocasionar esses problemas, é um método não-invasivo, de fácil aplicabilidade e que tem um pequeno número de contra-indicações (ANTUNES et al., 2002; CHEN et al., 1998; EISENBAUER; MURPHY, 1998; FRAMPTON, 1998; JAFFE; MARTIN, 1991; MARIANO; BEN, 1998; SILVA, 1998; SLUKA et al., 1999; TRIBIOLI, 2003). De acordo com a pesquisa de Silveira 
e Lima (2004), a TENS, utilizada como método analgésico no pós-operatório imediato de hernioplastia inguinal, foi economicamente mais viável do que o tratamento convencional, visto que houve significante redução das despesas hospitalares durante o período de internação dos pacientes, em virtude do menor consumo de analgésicos, seringas descartáveis, agulhas, álcool, algodão e luvas descartáveis - materiais não-biodegradáveis que podem proporcionar poluição ambiental, apresentar certo grau tóxico e ocasionar infecções. Ong et al. (2005) ressaltam sobre a relevância de se diminuir os custos com medicamentos, e que a analgesia preemptiva talvez possa contribuir para tal. 
OBJETIVO 


\section{OBJETIVO}

A presente pesquisa teve como objetivo analisar o efeito da TENS de baixa freqüência como recurso analgésico preemptivo em pacientes submetidas a colecistectomia por laparotomia. 
CASUÍSTICA E MÉTODO 


\section{CASUÍSTICA E MÉTODO}

3.1 Desenho do Estudo

Esse estudo foi uma pesquisa clínica prospectiva, controlada, randomizada e duplamente encoberta.

3.2 Local

A pesquisa foi procedida no Hospital São Domingos Sávio, privado, localizado na cidade de Aracaju, no período de dezembro de 2003 a abril de 2005, com a experimentação em pacientes que foram submetidos a colecistectomia por laparotomia, com incisão do tipo transversa subcostal direita, sendo utilizada a TENS de baixa freqüência.

\subsection{Casuística e Critérios de Inclusão e Exclusão}

Como critérios de inclusão, ficou estabelecido que só participariam da pesquisa os pacientes que:

- fossem submetidos à colecistectomia por laparotomia, em caráter eletivo, apenas com incisão transversa subcostal;

- tivessem sido operados por meio de financiamento do Sistema Único de Saúde (SUS), numa tentativa de "padronizar" a classe social dos pacientes;

- fossem operados no período da tarde, para evitar possíveis influências do ciclo circadiano (MORIN et al., 2000); 
- pertencessem ao sexo feminino somente, para evitar a possibilidade de influência do sexo na percepção do fenômeno doloroso. A escolha do sexo teve como fator preponderante a alta incidência de colecistectomias sobre as mulheres, implicando minimização da dificuldade em se obter uma casuística satisfatória. Ademais, até por fatores culturais, as mulheres da nossa sociedade são consideradas, no que se concerne aos seus relatos sobre dor, mais sinceras do que os homens, que muitas vezes não são tão fidedignos, por questões machistas, a esses relatos;

- possuíssem idade entre 21 e 65 anos;

- pertencessem aos estados físicos I e II da Sociedade Americana de Anestesiologia (ASA). ASA I é a classificação empregada para pacientes saudáveis que não tenham doença de base, e ASA 2 para os que possuem uma doença de base controlada, com ou sem drogas;

- fossem naturais do Brasil e que compreendessem bem a língua portuguesa, para evitar possíveis dificuldades durante a coleta de dados;

- não tivessem distúrbios de audição, visão ou fala;

- não tivessem distúrbios mentais e/ou intelectuais, para não somente compreender e aceitar participar da pesquisa, mas também não apresentar empecilhos durante a coleta dos dados (PIMENTA; TEIXEIRA, 1997);

- nunca tivessem sido submetidas a algum tipo de cirurgia abdominal alta, o que poderia influenciar na percepção da dor, visto que a percepção é influenciada por prévias experiências;

- e que não fossem portadoras de algum tipo de hepatopatia ou nefropatia diagnosticadas. 
Não participariam da pesquisa os pacientes:

- que tivessem diagnóstico de enfermidade maligna, pelas características diferenciadas das dores oncológicas (MINISTÉRIO DA SAÚDE DO BRASIL, 2001);

- em que a TENS fosse um recurso contra-indicado (e.g., feridas na região onde deveriam ser colocados os eletrodos);

- que fizessem, ou fizeram, uso crônico de opióides, pelo desenvolvimento de tolerância à TENS (SLUKA et al., 2000);

- que tivessem feito uso de drogas analgésicas em um período inferior a 7 dias;

- que já tivessem conhecimento sobre a TENS, ou sido submetidos a algum tratamento com o uso da mesma;

- que possuíssem alergia ou contra-indicação à dipirona ou ao diclofenaco de sódio, medicações que eram prescritas para o período pós-operatório;

- e que se recusassem, ou desistissem de participar do trabalho - mesmo após assinatura do Termo de Consentimento Livre e Esclarecido (apêndice B).

\subsection{Internamento das Pacientes}

Todas as pacientes foram internadas pelo turno da manhã e ficavam aguardando a cirurgia, que era sempre realizada no período da tarde, em um dos 3 apartamentos coletivos, com capacidade para até 4 pessoas, cada um. Os leitos — todos similares — eram os mesmos que as pacientes ocupavam no período pós-operatório. O hospital somente aceitava um máximo de 2 internamentos por dia, para a realização das colecistectomias por laparotomia. 


\subsection{Randomização}

Foram impressos em 32 pequenos papéis a informação "grupo preemptivo" e, em outros 32, "grupo placebo", que foram colocados em uma pequena caixa. O processo de randomização ocorreu com o auxílio de duas pessoas que não tinham conhecimento algum sobre a pesquisa, sendo solicitado às mesmas que retirassem cada um desses papéis da caixa e os colocassem dentro de envelopes — numerados de 1 a $64-$, opacos, que eram então lacrados e somente abertos após a concordância da paciente em participar da pesquisa.

\subsection{Avaliação Clínica}

Inicialmente era procedida uma avaliação clínica, realizada $2 \mathrm{~h}$ antes do horário previsto para a realização da cirurgia, com o propósito de verificar se a paciente se enquadrava, ou não, nos critérios de inclusão e exclusão estabelecidos pelo nosso protocolo. Dessa forma, era solicitado às pacientes que respondessem às questões presentes na Ficha de Identificação do Paciente (apêndice A), que possuía questionamentos sobre idade, sexo, peso, estatura, doenças associadas, diagnóstico clínico, entre outros. Caso a paciente atendesse a todos os pré-requisitos, era então rompido o lacre do envelope que correspondia ao seu

número na pesquisa e somente então se sabia a que grupo pertenceria tal paciente. $\mathrm{O}$ pesquisador que ficava ciente dessa informação acompanhava a paciente nas seguintes etapas: avaliação clínica, explicação sobre os instrumento de coleta de dados, aplicação da TENS e acompanhamento da paciente no centro cirúrgico. Ou seja, esse pesquisador não era responsável pela coleta dos dados no período pós-operatório, que era efetuada por outros pesquisadores que não sabiam a que grupo as pacientes pertenciam, pois eles não tinham 
acesso nem à Ficha de Aplicação da TENS e do Ato Cirúrgico (apêndice C) e nem aos envelopes.

Após a avaliação clínica, era efetuada a etapa de treinamento das pacientes sobre as escalas — posteriormente descritas — que seriam utilizadas após a cirurgia, para que as mesmas já se habituassem com elas e pudessem realizar os seus questionamentos sobre tais.

3.7 Termo de Consentimento Livre e Esclarecido

Todas as pacientes que fizeram parte dessa pesquisa autorizaram a sua participação por meio de assinatura ou impressão digital, em concordância ao que estava exposto no Termo de Consentimento Livre e Esclarecido (apêndice B), que constava de informações sobre a forma de tratamento que lhes estava sendo proposta, assim como seus benefícios e finalidades, explicando que o estudo não implicaria dano à saúde, informando-lhes também quanto ao direito de solicitar novas informações, esclarecer dúvidas e desistir de participar da pesquisa a qualquer momento. Logo, o estudo foi procedido de acordo com as normas expressas na resolução 196/96 do Conselho Nacional de Saúde de 10/10/1996. A coleta de dados só teve início após aprovação pelo comitê de ética e pesquisa.

\subsection{Materiais}

Foram utilizados 2 aparelhos para o fornecimento da corrente elétrica da TENS após prévia calibração no Laboratório de Física da Universidade Federal de Sergipe —, o Dualpex 961 e o Fisiotonus Four, cujas fotos estão apresentadas nas figuras 1 e 2, respectivamente. Entre os materiais de consumo utilizados, destacam-se: esparadrapos, gazes e gel condutor. Foram usados cabos que conectavam os aparelhos geradores de corrente elétrica aos eletrodos — de borracha, quadrangulares e com área de $9 \mathrm{~cm}^{2}$. A régua da Escala 
Numérica de Mensuração da Dor (END) foi utilizada para coletar a intensidade da dor, além do Questionário de Dor McGill e da Escala de Satisfação do Paciente. Algumas fichas, contidas no apêndice e descritas posteriormente, foram utilizadas para o registro de diversos dados.

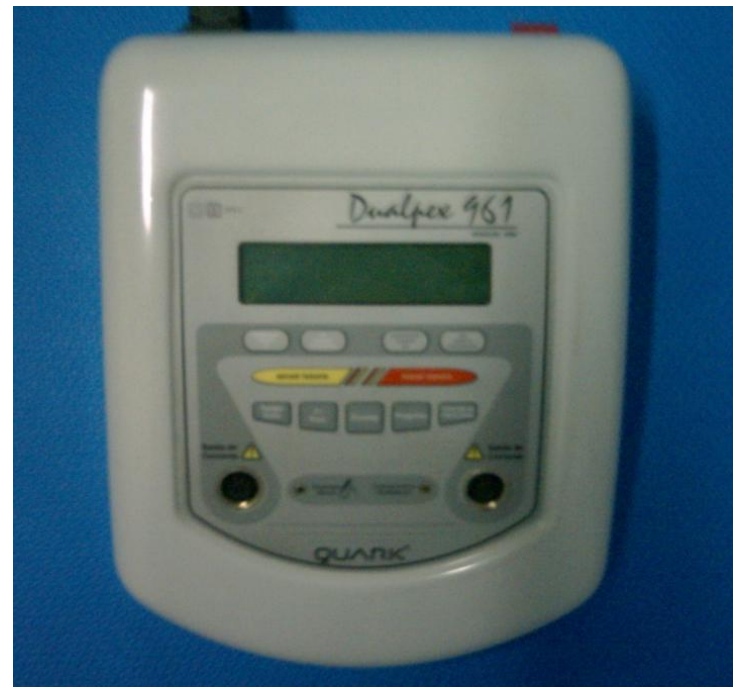

Figura 1. Aparelho Dualpex 961. Fonte: foto de Danilo Ribeiro Guerra.

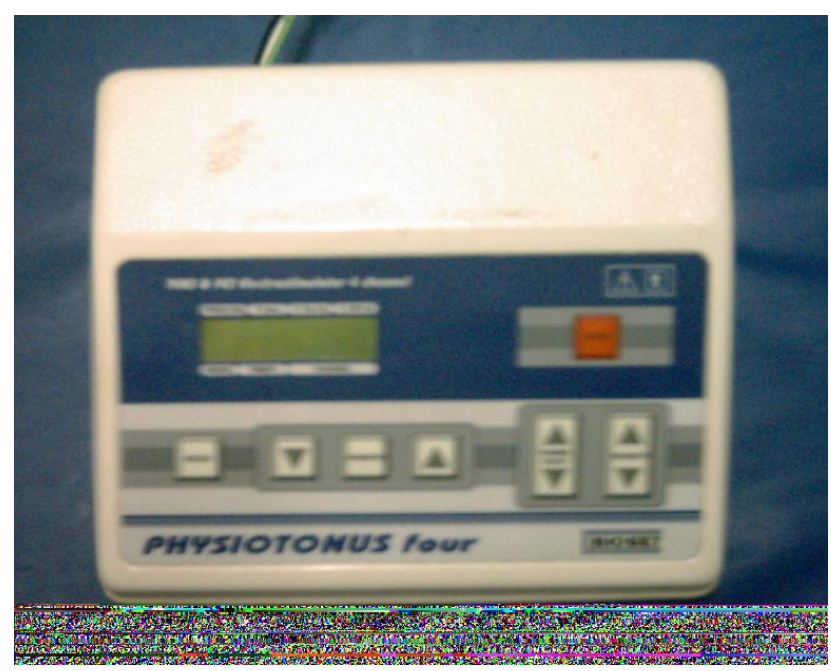

Figura 2. Aparelho Physiotonus Four. Fonte: foto de Danilo Ribeiro Guerra.

\subsection{Procedimentos Metodológicos}

\subsubsection{Os grupos de pacientes da pesquisa}

As pacientes foram alocadas, de forma aleatória, em dois grupos:

- Grupo preemptivo - sendo submetidas à aplicação da TENS de baixa frequiência durante 60 min, antes da cirurgia, com a utilização dos seguintes parâmetros: duração de pulso de $250 \mu$ s e freqüência de $4 \mathrm{~Hz}$. A intensidade utilizada foi a máxima suportada pela paciente, em nível motor. Esses parâmetros estão de acordo com as orientações de 
Johnson et al. (1989), Low e Reed (2001), Robinson (2001), Salgado (1999), Starkey (2001), Walsh et al. (1998) e Wang et al. (1997).

- Grupo placebo - os eletrodos eram colocados nas pacientes, porém, todos os parâmetros (duração de pulso, freqüência e intensidade) ficavam com referência zero, não possibilitando a passagem da corrente elétrica. O tempo da falsa aplicação também foi de $60 \mathrm{~min}$.

\subsubsection{Técnica de aplicação da TENS}

Antes da aplicação da TENS, era feita uma limpeza, com o uso de álcool, da região onde seriam colocados os eletrodos, a fim de diminuir a oleosidade da pele e remover sujeiras, facilitando, dessa maneira, a passagem da corrente elétrica.

A TENS de baixa freqüência foi aplicada nas pacientes, ainda em seus leitos, antes de serem encaminhadas ao centro cirúrgico, sendo utilizada a técnica quadripolar, com os eletrodos de borracha dispostos de maneira cruzada, abrangendo os dermátomos da região onde posteriormente seria realizada a incisão cirúrgica subcostal direita. Os dados sobre a aplicação da TENS, assim como as observações que se mostrassem relevantes, eram registrados na Ficha de Aplicação da TENS e do Ato Cirúrgico (apêndice C). A foto da figura 3 representa a simulação da aplicação da TENS no período pré-operatório. Após a aplicação da TENS, as pacientes eram preparadas para serem encaminhadas ao centro cirúrgico. 


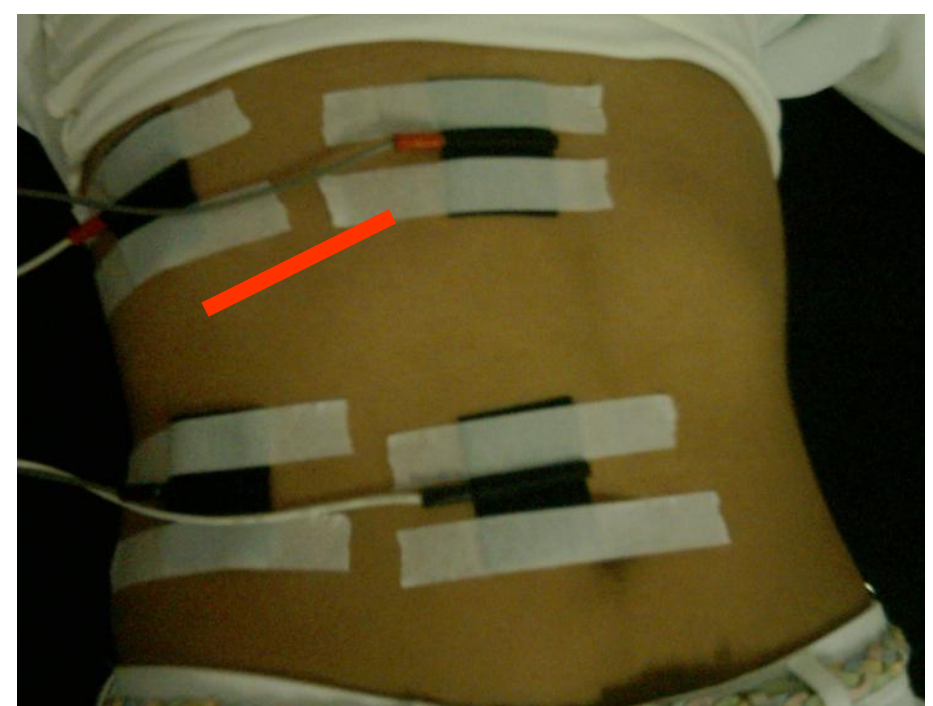

Figura 3. Simulação da aplicação da TENS.

A linha vermelha ilustra o local onde seria realizada a incisão subcostal direita.

Fonte: foto de Danilo Ribeiro Guerra.

\subsubsection{Técnica anestésica}

Em todas as pacientes houve administração de diazepam como medicação préanestésica. Houve padronização do método anestésico, tendo sido utilizadas como drogas anestésicas o cloridrato de bupivacaína $(0,5 \%)$ com vasoconstrictor, administrado via peridural, podendo ou não estar associado à xilocaína com vasoconstrictor $(2,0 \%)$, associação essa que não exercia influência na duração da analgesia; e o fentanil (2 ml), também administrado via peridural. A escolha dessas drogas deu-se por já fazer parte da rotina desse tipo de procedimento cirúrgico no Hospital São Domingos Sávio. Os dados sobre as drogas utilizadas, observações necessárias, classificação do estado físico da ASA, entre outros, eram registrados na Ficha de Aplicação da TENS e do Ato Cirúrgico (apêndice C). 
3.9.4 Cirurgia e prescrição de medicamentos

A equipe médica responsável pela realização de todas as intervenções cirúrgicas foi composta por 4 cirurgiões e 3 anestesiologistas, que se revezavam entre os dias da semana segunda a quinta-feira. Todas as cirurgias foram realizadas por laparotomia, sempre com incisão do tipo transversa subcostal direita.

Após a cirurgia, a prescrição médica foi padronizada da seguinte forma: a dipirona $(2 \mathrm{ml} ; 500 \mathrm{mg} / \mathrm{ml}$ ) era administrada de $6 \mathrm{em} 6 \mathrm{~h}$ (sendo a primeira administração efetuada $5 \mathrm{~h}$ após a indução do bloqueio anestésico, que era determinado como sendo o momento em que era introduzido o cloridrato de bupivacaína no espaço peridural), via intravenosa; diclofenaco de sódio ( $3 \mathrm{ml} ; 25 \mathrm{mg} / \mathrm{ml})$ prescrito como medicação de resgate, via intra-muscular, somente sendo administrado caso houvesse solicitação por parte da paciente; e a metoclopramida (2 $\mathrm{ml} ; 5 \mathrm{mg} / \mathrm{ml}$ ), também como medicação de resgate. Essa prescrição foi efetuada dessa maneira porque a dor gerada pela colecistectomia por laparotomia tem um nível de moderado a intenso, o que implicou a necessidade de algum fármaco analgésico prescrito em horário programado, nesse caso, a dipirona.

O estabelecimento dessa técnica de prescrição decorreu dos resultados obtidos com as 6 pacientes do estudo piloto - em que toda a medicação analgésica era administrada somente em caso de solicitação pelas mesmas. Percebeu-se analgesia insatisfatória, dado os relatos de altos índices de dor e desconforto. Dessa forma, objetivamos, nesse estudo, a utilização da TENS como um recurso analgésico coadjuvante; e não único. 
3.9.5 Instrumentos de coleta de dados

\subsubsection{Escala Numérica de Mensuração da Dor}

Como escala unidimensional para mensuração da intensidade da dor foi utilizada a END (figura 4), que consiste de uma régua, demarcada horizontalmente com valores em centímetros, de 0 a 10, representando, o primeiro valor, a ausência absoluta de dor, e o maior, a dor mais insuportável possível, sendo solicitado à paciente que indicasse aquele que melhor caracterizaria o seu nível de dor, estando a paciente em repouso. A dor leve estaria representada por números compreendidos no intervalo de 0 a 3; a moderada, pelos números 4 , 5 e 6; e a intensa por 7, 8, 9 e 10 .

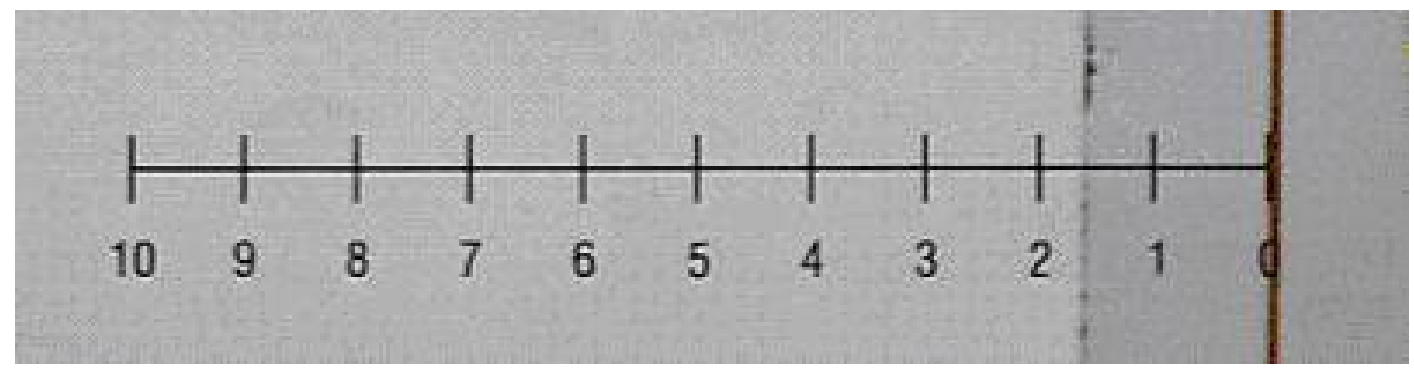

Figura 4. Escala Numérica de Mensuração da Dor, numerada de 0 a $10 \mathrm{~cm}$. Fonte: foto de Danilo Ribeiro Guerra.

Os dados foram registrados na Ficha de Avaliação da Dor pela Escala Numérica de Mensuração da Dor (apêndice D). A coleta da intensidade de dor era procedida, de acordo com o horário de indução do bloqueio anestésico, sendo investigada $2 \frac{1}{2} \mathrm{~h}$ (ENDa), 31/2 $\mathrm{h}$ (ENDb), 41/2 h (ENDc), 51/2 h (ENDd), 7 h (ENDe) , 8 h (ENDf) e 16 h (ENDg) após a sua indução, além de uma última coleta procedida no momento da alta hospitalar (ENDh), dois dias após a cirurgia, pela manhã. Optou-se em utilizar como referência o horário da indução 
do bloqueio anestésico, ao invés do horário de término da cirurgia, visto que grandes variáveis no tempo despendido para a realização das cirurgias poderiam influenciar nos níveis de dor relatados pelas pacientes, já que haveria, assim, discrepâncias no tempo decorrido desde a indução do bloqueio anestésico - momento de referência para a contagem do tempo de metabolização das drogas — até as averiguações da intensidade de dor.

É relevante salientar que o pesquisador responsável pela coleta do nível de dor não tinha conhecimento sobre o grupo a que pertencia a paciente e nem esta sobre em que grupo estava alocada, o que caracterizou um estudo do tipo duplamente encoberto.

\subsubsection{Questionário de Dor McGill}

O Questionário de Dor McGill (MPQ) é composto por 78 descritores, distribuídos em 4 categorias: sensorial, composta por 10 subcategorias, cujos descritores aí contidos traduzem a natureza somática e estão relacionados com a fisiologia da dor; afetiva, que contém 5 subcategorias, cujos descritores fornecem discernimentos sobre os aspectos psicológicos que acompanham a dor; avaliativa, com uma única, que descreve a intensidade global da dor; e, finalmente, a miscelânea, que é composta por 4 subcategorias. É solicitado ao paciente que circule ou sublinhe as palavras que melhor descrevem a sua dor, ou apenas as indique verbalmente (GRAHAM, 1980; MELZACK, 1975).

O MPQ possui três partes: a primeira serve para que o paciente indique, em um gráfico do corpo humano, a região onde está sentindo a dor — diagrama corporal da dor; a segunda é uma escala verbal para avaliar a intensidade de dor (Present Pain Intensity — PPI), utilizando-se de cinco palavras: leve, desconfortável, perturbadora, horrível e excruciante; e a última utiliza os 78 descritores, podendo-se daí se obterem dois índices, o Quantitativo da Dor (PRI - Pain Rating Index) e o do Número de Palavras Escolhidas (NWC — Number of 
Words Chosen). Cada descritor tem um correspondente número, que será utilizado para o estabelecimento do PRI. Por exemplo, em uma subcategoria que contenha 3 descritores, aos mesmos serão atribuídos, respectivamente, os valores 1, 2 e 3, de acordo com a ordem em que aparecem na lista dos descritores (FERNANDEZ; BOYLE, 2001; PEREIRA; SOUSA, 1998; PIMENTA, 1995; STARKEY, 2001; TEIXEIRA et al., 1999).

Em nossa pesquisa, foi utilizada a versão brasileira do MPQ (apêndice E) — validada pelos profissionais do Ambulatório de Dor da Clínica Neurológica do Hospital das Clínicas da Faculdade de Medicina da Universidade de São Paulo (PIMENTA; TEIXEIRA, 1997). Esse questionário, que é indicado por Graham et al. (1980) para dores imediatas, foi aplicado — sob a forma de entrevista — apenas uma vez, 16 h após a indução do bloqueio anestésico, dada a inviabilidade de utilizá-lo no mesmo dia do ato cirúrgico. Resolveu-se adaptar esse questionário e usar apenas uma parte dele, a dos 78 descritores, haja vista que não se achou necessária a utilização do PPI e do diagrama corporal da dor, por estarmos utilizando a END, e por já sabermos o local da dor incisional. Então, a partir desse questionário adaptado, pudemos analisar o PRI e o NWC. O primeiro, obtido por meio da soma dos valores atribuídos a cada descritor escolhido; e o segundo, pela soma do número de palavras escolhidas para qualificar a dor, segundo Fernandez e Boyle (2001) e Pereira e Sousa (1998).

\subsubsection{Escala de Satisfação dos Pacientes}

O grau de satisfação das pacientes com o tratamento que lhes estava sendo realizado foi avaliado por meio da Escala de Satisfação do Paciente (ESP), escala verbal que permite à paciente escolher um entre números que variam de 0 a 10, indicando, respectivamente, insatisfação completa com o tratamento e a maior satisfação possível. Os horários de coleta 
foram os seguintes: 311/2 h (ENDb), 51/2 h (ENDd), 8 h (ENDf) e 16 h (ENDg) após a indução do bloqueio anestésico, além de uma última coleta procedida no momento da alta hospitalar (ENDh). Os dados coletados eram registrados na Ficha de Avaliação da Satisfação dos Pacientes pela Escala de Satisfação do Paciente (apêndice F). Essa escala foi utilizada na pesquisa realizada por Melo e Santana Filho (2003), que tinha linha de trabalho semelhante.

3 9.5.4 Ficha do consumo de fármacos

O consumo de fármacos, analgésicos ou não, de cada paciente foi anotado na Ficha de Registro da Administração de Fármacos no Pós-operatório (apêndice G), que constou de campo para informações como o tipo de fármaco administrado, horário de administração, via de acesso e dosagem; além do tempo decorrido desde o horário da indução do bloqueio anestésico até a primeira administração, caso houvesse, do diclofenaco de sódio (prescrito como medicação de resgate).

\subsubsection{Questionário sobre a Aplicação da TENS}

Foram efetuados dois questionamentos para as pacientes: o primeiro sobre o desconforto promovido pela aplicação da TENS; e o segundo sobre a vontade da paciente em usá-la numa próxima cirurgia (Apêndice H). Em virtude da necessidade de esse questionário ter sido percebida somente no decorrer da coleta de dados, o mesmo fora empregado em 19 pacientes do grupo preemptivo e em 17 do placebo. 
3.10 Análise e Interpretação dos Dados

A análise estatística dos dados foi feita com a utilização dos programas GraphPad Prism 4.0 e Statistica 6.0. Inicialmente foram realizados testes estatísticos descritivos: média e erro padrão da média (SEM). Para a análise dos dados demográficos, de alguns dados clínicos e do tempo para a primeira administração de diclofenaco de sódio, foi utilizado o teste $\mathrm{t}$ de Student para amostras não pareadas (paramétrico). Para a análise de alguns dados clínicos e do uso de diclofenaco de sódio nas primeiras 16 h após a indução do bloqueio anestésico foi utilizado o teste do qui-quadrado. Para a análise da END, ESP, PRI, NWC e do número de vezes em que foram administrados o diclofenaco de sódio, dipirona e metoclopramida, foi utilizado o teste de Mann-Whitney (não-paramétrico). Em todos os testes, como nível de significância foi considerado o valor de $5 \%(\mathrm{p}<0,05)$.

3.11 Técnica Utilizada para a Demonstração dos Resultados

Para a exposição dos resultados, foram utilizados gráficos elaborados nos programas GraphPad Prism 4.0 e Statistica 6.0., além de tabelas elaboradas no Microsoft Word XP. Vários dados foram apresentados sob a forma de média \pm SEM. 
RESULTADOS 


\section{RESULTADOS}

Sessenta e quatro pacientes concordaram em participar da pesquisa e assinaram o termo de consentimento livre e esclarecido. Porém, 14 foram excluídas: seis por se tratarem de pacientes que pertenciam a um estudo piloto, cujo método foi posteriormente alterado; duas, por terem sido submetidas a anestesia geral; quatro, por erro na prescrição médica de analgésicos; uma, por não conseguir responder ao McGill Pain Questionnaire (MPQ); e uma, pela grande dificuldade em compreender a Escala Numérica de Mensuração da Dor (END). Destarte, a amostra ficou constituída por 50 pacientes: grupo preemptivo $(n=25)$ e grupo placebo $(n=25)$.

Os dados referentes à idade, peso, estatura e índice de massa corporal (IMC) das pacientes estão presentes na tabela 1 e ilustrados, respectivamente, nos gráficos 1, 2, 3 e 4, tendo sido analisados por meio do teste t de Student para amostras independentes. Não houve, em nenhuma das características demográficas, diferença significante entre os grupos.

A idade mínima foi de 25 anos no grupo preemptivo e de 21 anos no placebo; enquanto a máxima foi de 65 no preemptivo, e de 59 no placebo. Os pesos mínimo e máximo foram, respectivamente, iguais a $40 \mathrm{Kg}$ e $86 \mathrm{Kg}$ no grupo preemptivo, e $48 \mathrm{Kg}$ e $77 \mathrm{Kg}$ no placebo. As estaturas mínima e máxima foram, respectivamente, iguais a 1,49 m e 1,70 m (grupo preemptivo), e 1,51 m e 1,70 m (grupo placebo). E os valores mínimo e máximo do

IMC foram: $18,80 \mathrm{Kg} / \mathrm{m}^{2}$ e $35 \mathrm{Kg} / \mathrm{m}^{2}$ (grupo preemptivo), e $19,14 \mathrm{Kg} / \mathrm{m}^{2}$ e $28,90 \mathrm{Kg} / \mathrm{m}^{2}$ (grupo placebo). 
Tabela 1 - Dados demográficos da amostra.

\begin{tabular}{lccc}
\hline & Preemptivo & Placebo & \\
\hline & Média \pm SE M & Média \pm SE M & p \\
\hline Idade (anos) & $39,56 \pm 1,97$ & $38,52 \pm 2,38$ & 0,738 \\
Peso (K g) & $61,08 \pm 2,88$ & $63,48 \pm 1,72$ & 0,478 \\
E statura (m) & $1,57 \pm 0,01$ & $1,60 \pm 0,01$ & 0,168 \\
I M C (K g/: $\mathbf{m}^{\mathbf{2}}$ ) & $25,68 \pm 1,05$ & $24,75 \pm 0,59$ & 0,447
\end{tabular}

IMC — índice de massa corporal. SEM - erro padrão da média.

Teste t de Student para amostras não pareadas. á = 5\%.

Não houve diferença significante em nenhuma das variáveis analisadas.

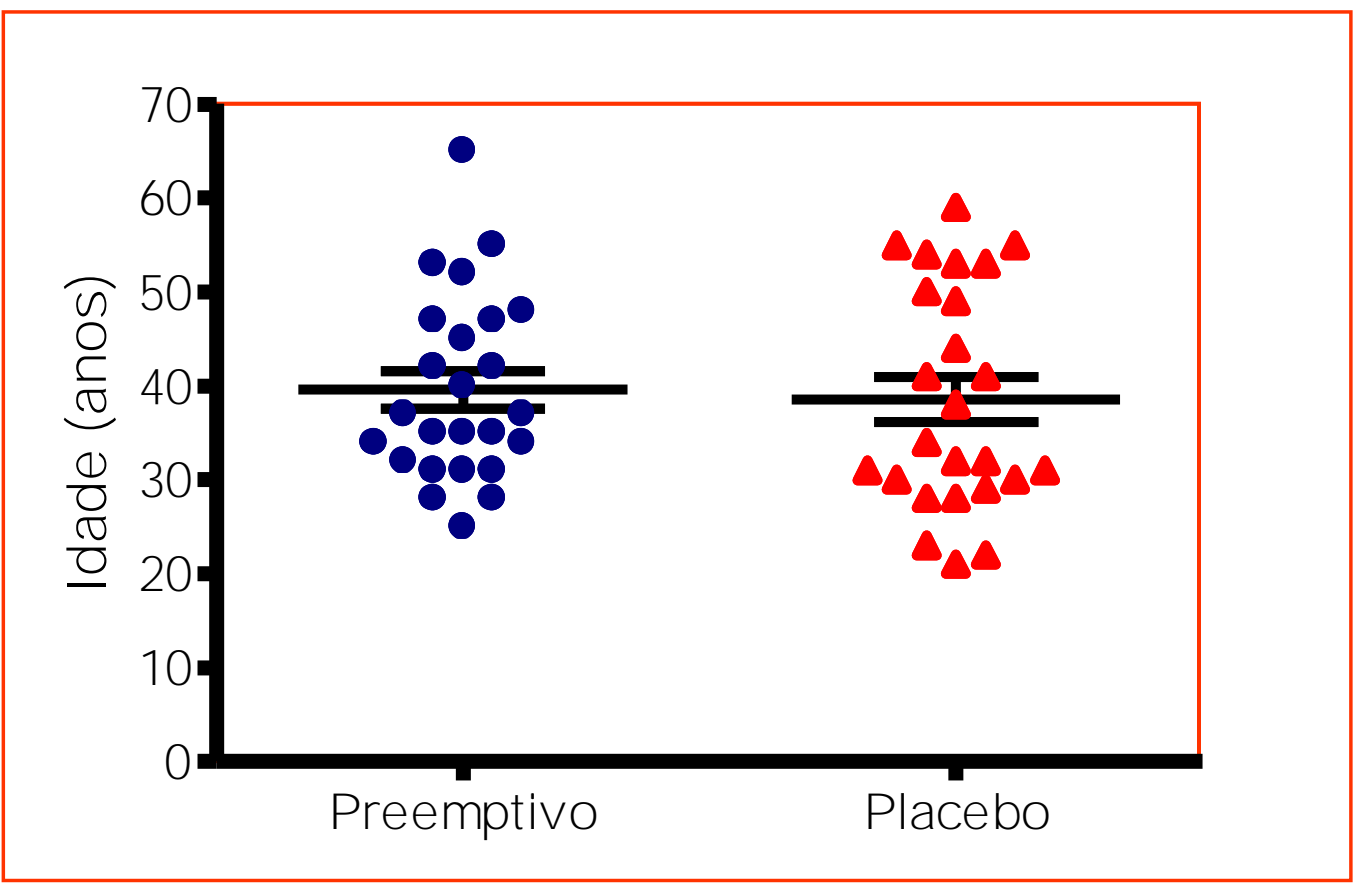

Gráfico 1. Representação das idades das pacientes.

A barra central indica o valor da média, em cada grupo, e as barras menores indicam o erro padrão da média. Teste $t$ de Student para amostras não pareadas. á $=5 \%$.

Não houve diferença significante entre os grupos $(p=0,738)$. 


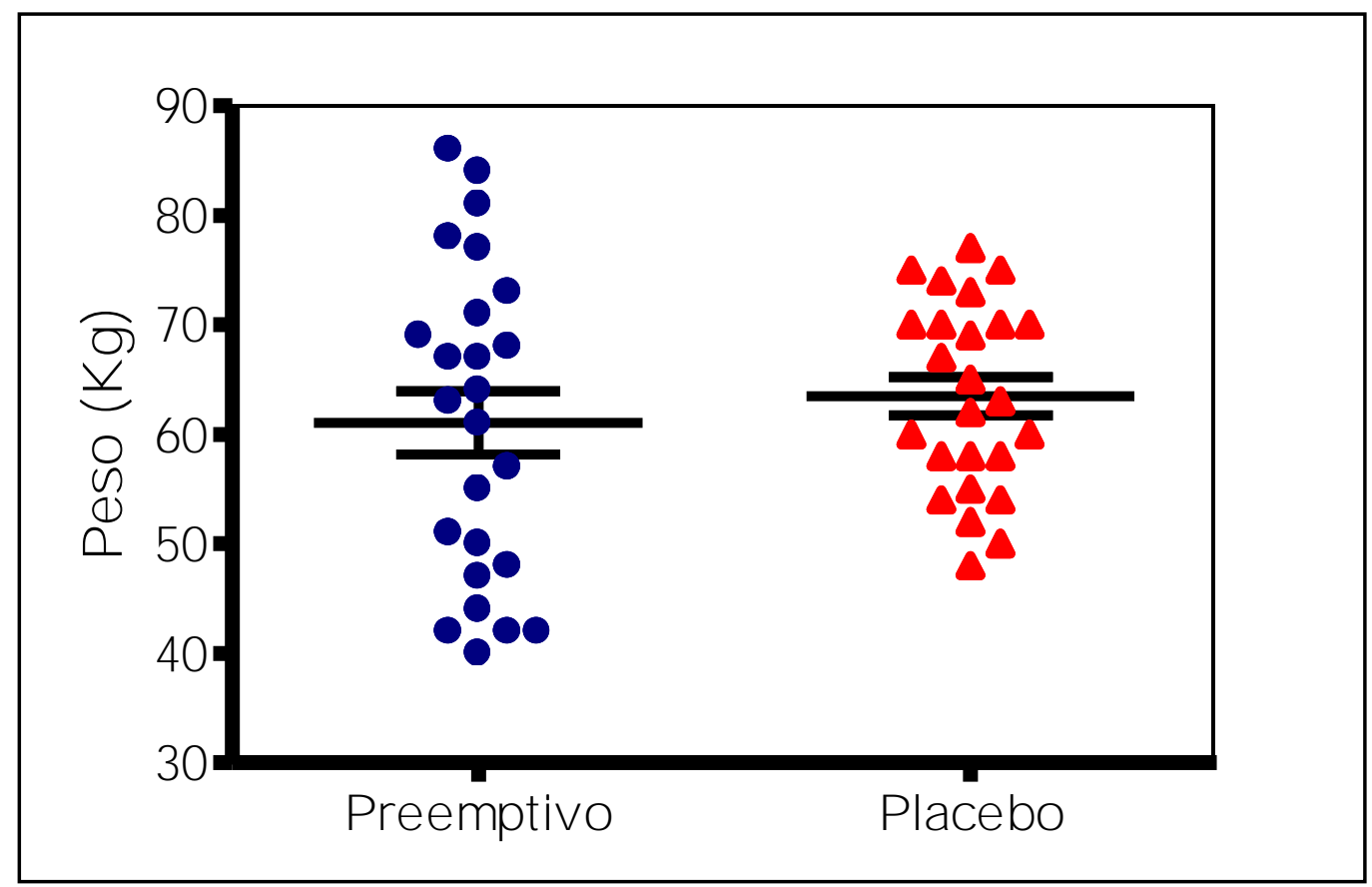

Gráfico 2. Representação dos pesos das pacientes.

A barra central indica o valor da média, em cada grupo, e as barras menores indicam o erro padrão da média. Teste t de Student para amostras não pareadas. á $=5 \%$.

Não houve diferença significante entre os grupos $(p=0,478)$.

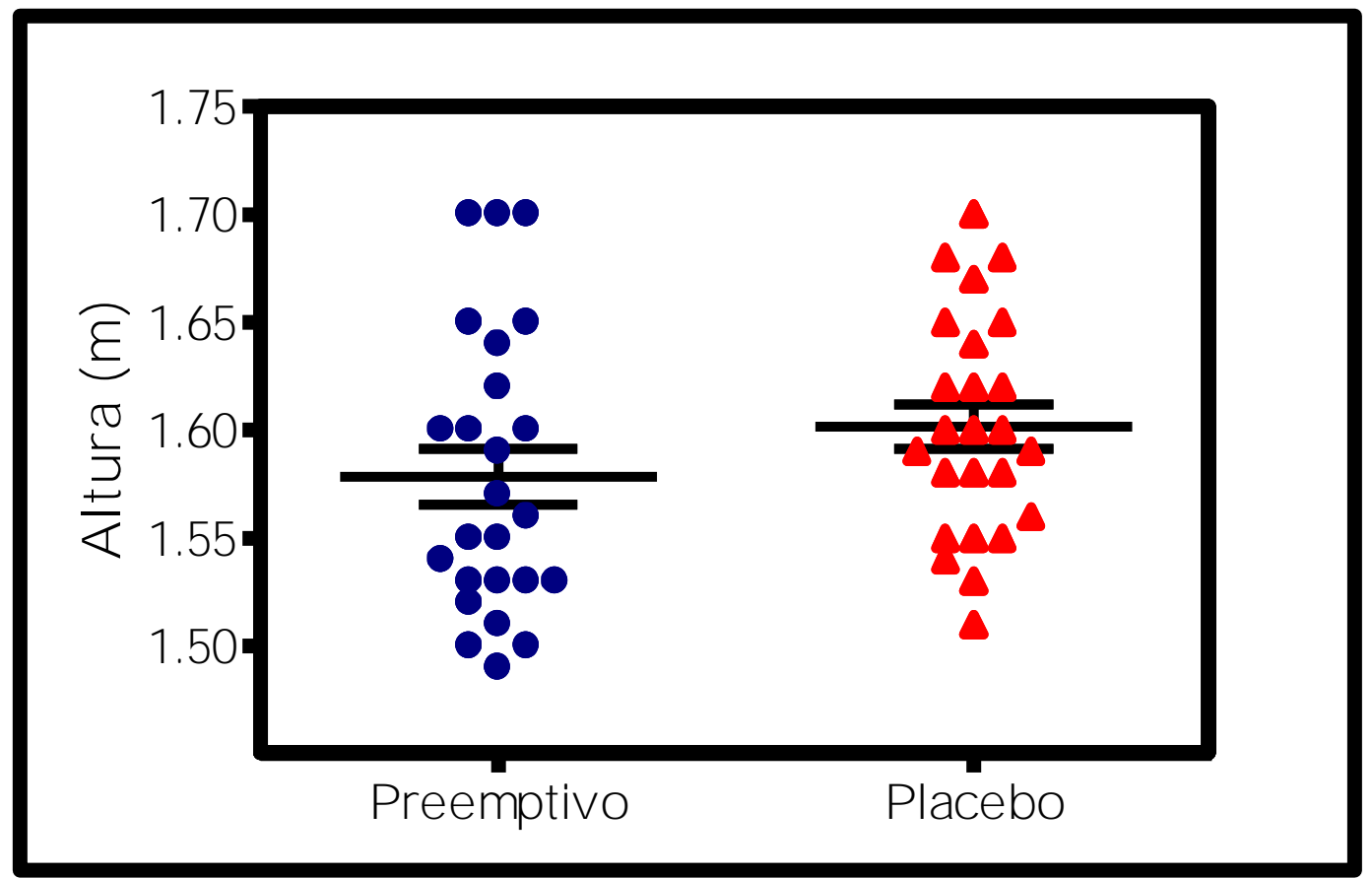

Gráfico 3. Representação das estaturas das pacientes.

A barra central indica o valor da média, em cada grupo, e as barras menores indicam o erro padrão da média.

Teste $\mathrm{t}$ de Student para amostras não pareadas. á $=5 \%$.

Não houve diferença significante entre os grupos $(p=0,168)$. 


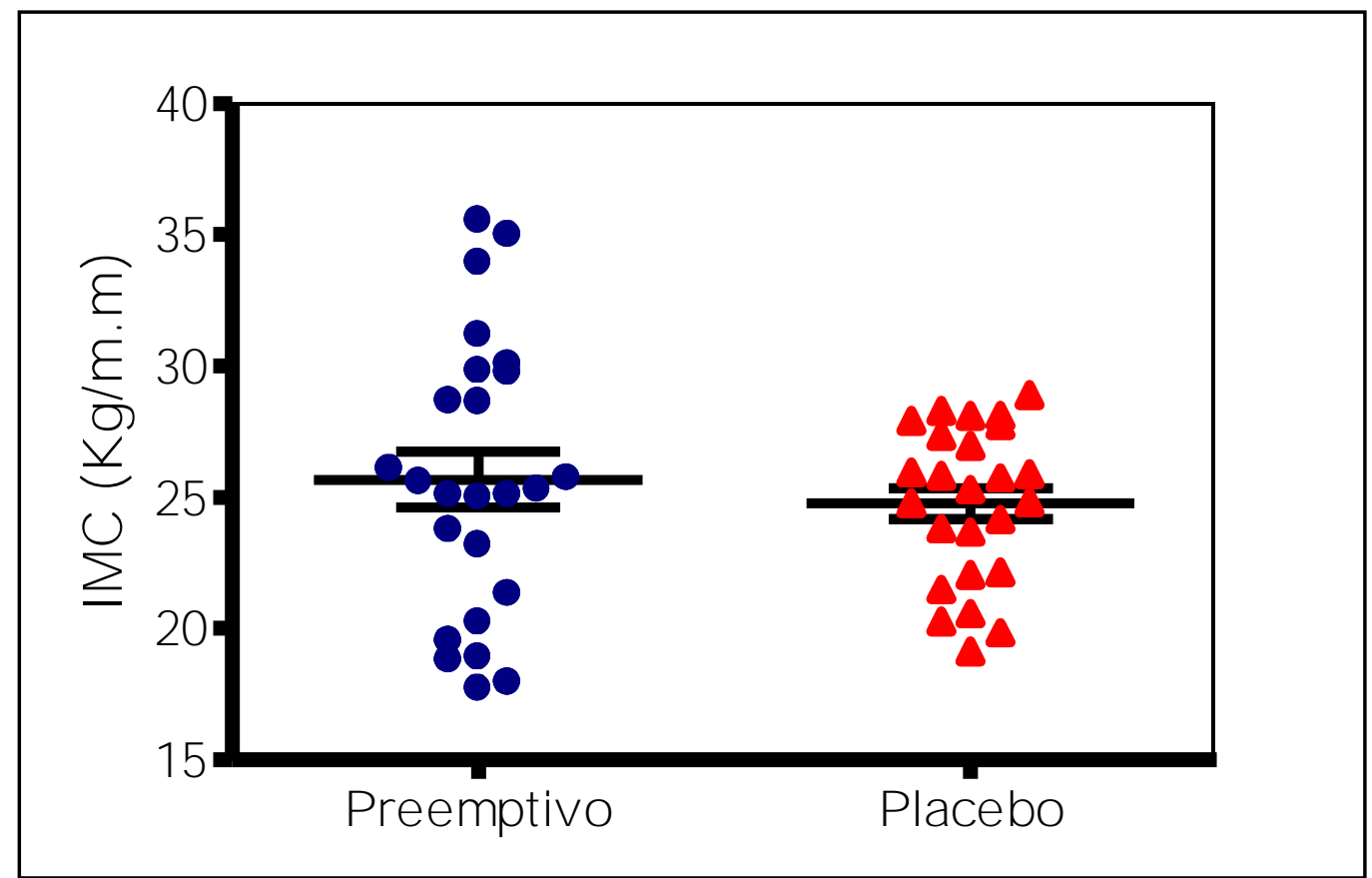

Gráfico 4. Representação dos Índices de Massa Corporal (IMC) das pacientes.

A barra central indica o valor da média, em cada grupo, e as barras menores indicam o erro padrão da média.

Teste $t$ de Student para amostras não pareadas. á $=5 \%$.

Não houve diferença significante entre os grupos $(p=0,447)$. 
A tabela 2 apresenta os dados referentes à categoria de peso das pacientes de ambos os grupos; a tabela 3, o nível de escolaridade das mesmas; e a tabela 4, o diagnóstico clínico. Não houve, de acordo com o teste do $\stackrel{2}{\div}^{2}$, diferença significante entre os grupos em nenhuma dessas variáveis analisadas.

Tabela 2 - Distribuição da categoria de peso das pacientes, de acordo com os dados obtidos pelo índice de massa corporal (IMC $-\mathrm{Kg} / \mathrm{m}^{2}$ ).

\begin{tabular}{lcccccc}
\hline \multicolumn{1}{c}{ Grupo } & $\begin{array}{c}\text { A baixo } \\
\text { do peso } \\
(<\mathbf{1 8 , 5 )}\end{array}$ & $\begin{array}{c}\text { Peso } \\
\text { normal } \\
(\mathbf{1 8 , 5 - 2 4 , 9 )}\end{array}$ & $\begin{array}{c}\text { Sobrepeso } \\
\mathbf{( 2 5}-\mathbf{2 9 , 9 )}\end{array}$ & $\begin{array}{c}\text { Obesidade } \\
\text { grau I } \\
\mathbf{( 3 0}-\mathbf{3 4 , 9 )}\end{array}$ & $\begin{array}{c}\text { Obesidade } \\
\text { grau II } \\
\mathbf{( 3 5}-\mathbf{3 9 , 9 )}\end{array}$ & $\begin{array}{c}\text { Obesidade } \\
\text { grau III } \\
\mathbf{( 4 0 )}\end{array}$ \\
\hline Preemptivo & 2 & 7 & 11 & 3 & 2 & 0 \\
Placebo & 0 & 12 & 13 & 0 & 0 & 0 \\
\hline
\end{tabular}

Os dados apresentados entre parêntesis referem-se aos parâmetros de referência do IMC que determinam aquela categoria de peso.

Teste do $\stackrel{2}{\div}$. á $=5 \%$.

Não houve diferença significante entre os grupos $(\mathrm{p}=0,075)$.

Tabela 3 - Nível de escolaridade das pacientes.

\begin{tabular}{lcccccc}
\multicolumn{1}{c}{ Grupo } & $\begin{array}{c}\text { Nunca } \\
\text { estudou }\end{array}$ & $\begin{array}{c}\mathbf{1}^{\circ} \text { } \text { grau } \\
\text { incompleto }\end{array}$ & $\begin{array}{c}\mathbf{1}^{\circ} \text { grau } \\
\text { completo }\end{array}$ & $\begin{array}{c}\mathbf{2}^{\circ} \text { grau } \\
\text { incompleto }\end{array}$ & $\begin{array}{c}\mathbf{2}^{\circ} \text { grau } \\
\text { completo }\end{array}$ & $\begin{array}{c}\mathbf{3}^{\circ} \text { grau } \\
\text { incompleto }\end{array}$ \\
\hline Preemptivo & 3 & 8 & 3 & 4 & 5 & 2 \\
Placebo & 3 & 11 & 2 & 6 & 1 & 2 \\
\hline
\end{tabular}

Teste do $\stackrel{2}{\div}^{2}$ á $=5 \%$.

Não houve diferença significante entre os grupos $(p=0,587)$.

Tabela 4 - Diagnóstico clínico das pacientes.

\begin{tabular}{lccccc}
\multicolumn{1}{c}{ Grupo } & Colelitíase & $\begin{array}{c}\text { Colecistite } \\
\text { aguda }\end{array}$ & $\begin{array}{c}\text { Colecistite } \\
\text { crônica }\end{array}$ & $\begin{array}{c}\text { Colecistite } \\
\text { (sem descrição) }\end{array}$ & $\begin{array}{c}\text { Colelitíase } \\
\text { + colecistite }\end{array}$ \\
\hline Preemptivo & 12 & 6 & 2 & 1 & 4 \\
Placebo & 10 & 2 & 4 & 5 & 4 \\
\hline
\end{tabular}

Teste do $\stackrel{2}{\div}^{2}$ á $=5 \%$.

Não houve diferença significante entre os grupos $(p=0,238)$. 
O gráfico 5 apresenta os dados sobre o período compreendido entre a época em que as pacientes relataram ter iniciado as primeiras dores devido à doença da vesícula biliar e a realização da colecistectomia. Não houve diferença significante entre os grupos, por meio de análise realizada pelo teste do $\div^{2}$.

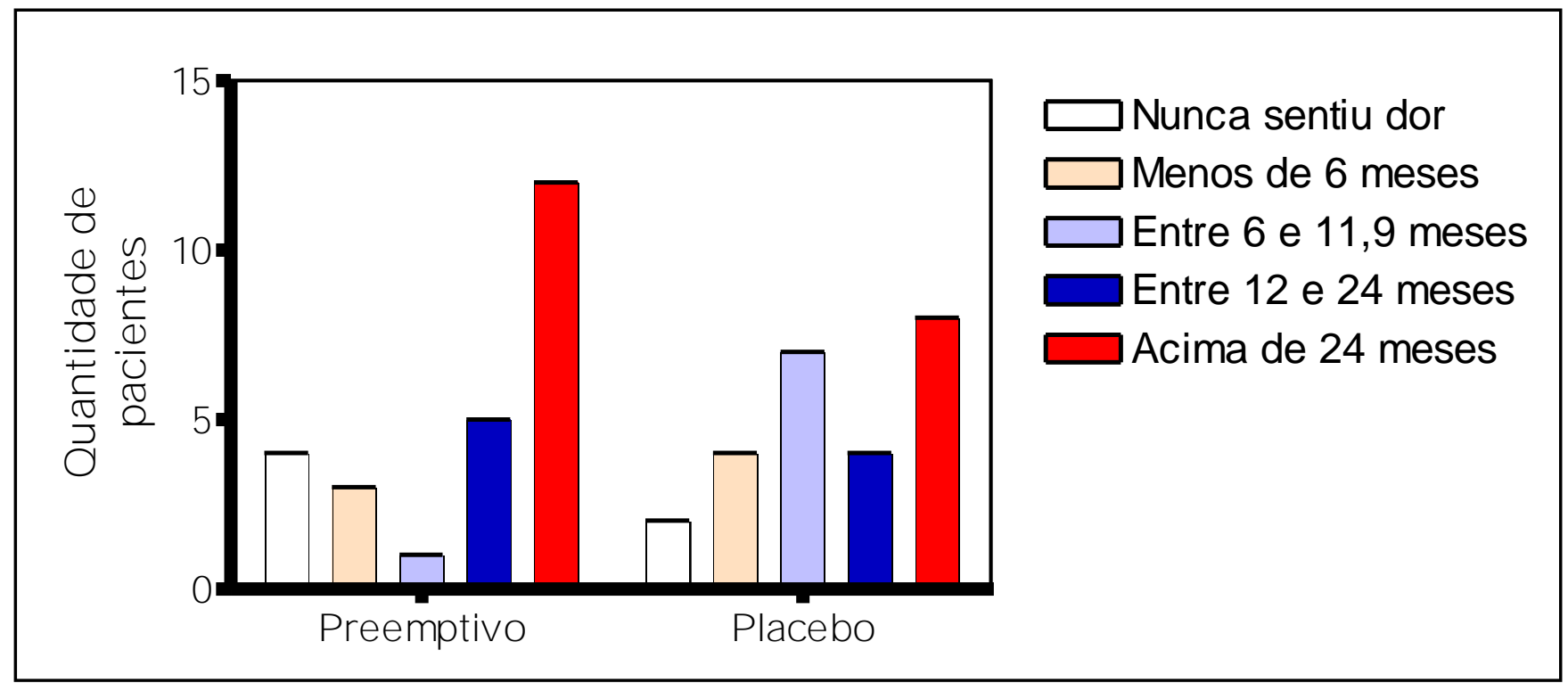

Gráfico 5. Relato das pacientes sobre o período, em meses, em que vinham sentindo dor devido à doença da vesícula biliar.

Teste do $\stackrel{\circ}{\circ}^{2}$ á $=5 \%$.

Não houve diferença significante entre os grupos $(\mathrm{p}=0,183)$. 
O estado físico das pacientes dos dois grupos, segundo o critério de classificação da Sociedade Americana de Anestesiologia (ASA), está expresso no gráfico 6. Não houve diferença estatística significante entre os grupos $(p=0,479)$, de acordo com o teste do $\div^{2}$.

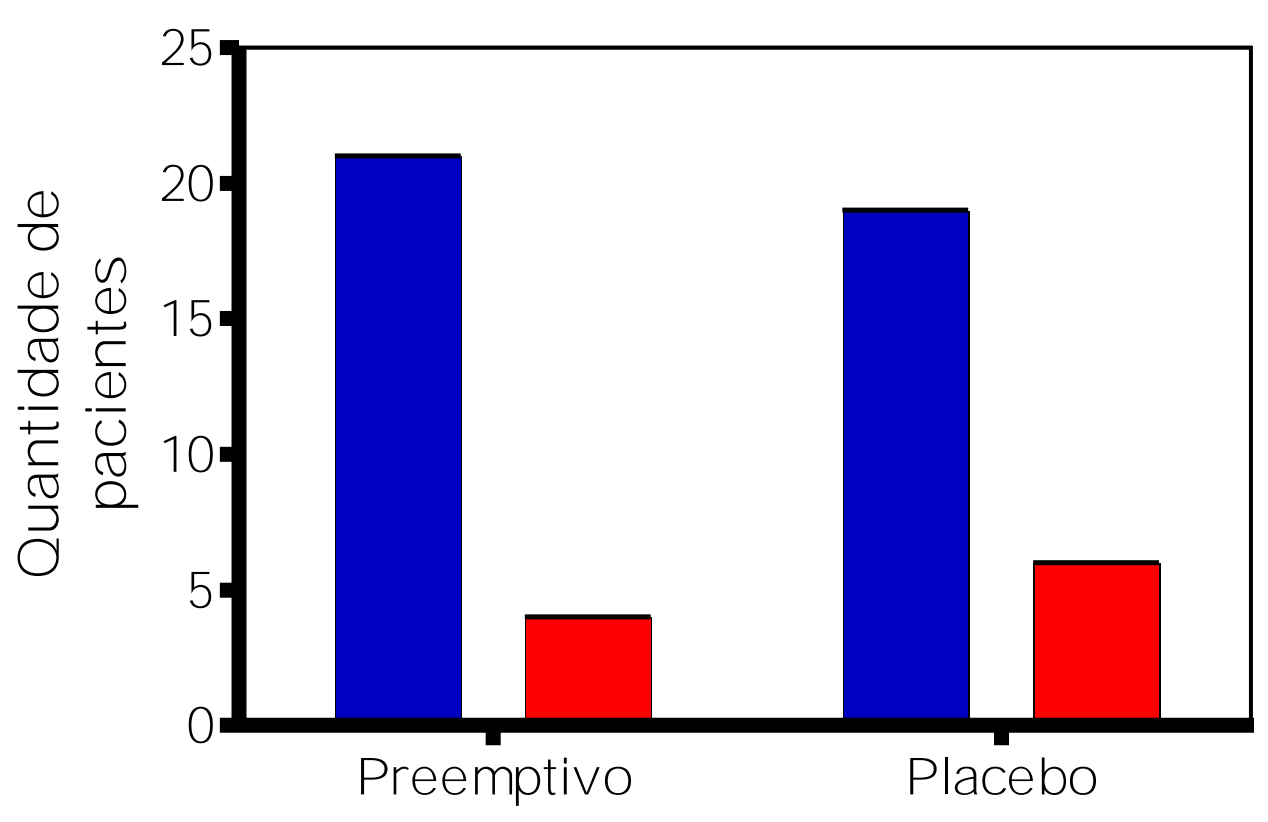

$\square$ ASA 1 $\square$ ASA 2

Gráfico 6. Estado físico das pacientes, de acordo com a classificação da Sociedade Americana de Anestesiologia.

Teste do $\check{\div}^{2}$. á $=5 \%$.

Não houve diferença significante entre os grupos $(\mathrm{p}=0,479)$. 
O relato das pacientes sobre o uso de analgésicos para o tratamento da dor decorrente da doença da vesícula biliar, ou de outra dor devido a doenças crônicas, estão

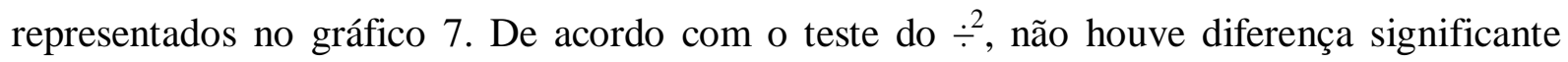
entre os grupos preemptivo e placebo $(\mathrm{p}=0,765)$. É importante considerar que as pacientes que relataram ter usado tais drogas, somente as utilizaram até no máximo uma semana antes da data da cirurgia, haja vista que foi previamente estabelecido como critério de exclusão o uso de drogas analgésicas dentro do período de 7 dias que antecedia a realização da colecistectomia.
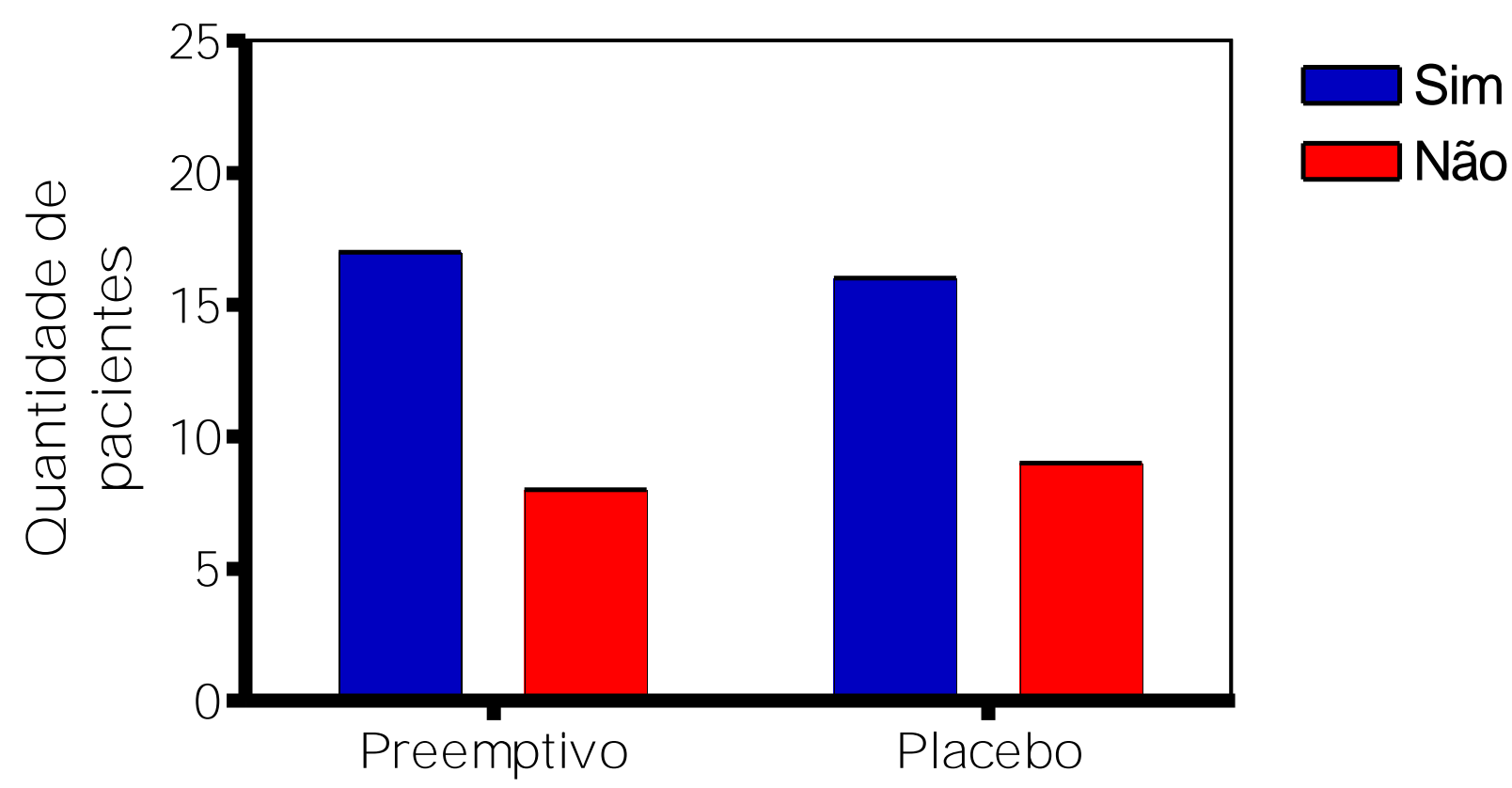

Gráfico 7. Relato das pacientes sobre o uso de analgésicos antes da colecistectomia, para o tratamento da dor decorrente da doença da vesícula biliar ou de outras doenças crônicas. Entende-se por "antes da colecistectomia" o uso de analgésicos em um prazo superior aos 7 dias que antecediam a realização do procedimento cirúrgico.

Teste do $\stackrel{2}{\circ}^{2}$ á $=5 \%$.

Não houve diferença significante entre os grupos $(p=0,765)$. 
Em todas as pacientes, o aparelho de TENS foi colocado durante $60 \mathrm{~min}$; e o intervalo médio entre o término da sua aplicação — verdadeira ou não — e a indução do bloqueio anestésico foi de 74,72 \pm 10,46 min no grupo preemptivo, e de 60,28 \pm 7,23 min no placebo, não havendo diferença significante $(\mathrm{p}=0,261)$ entre os grupos, de acordo com o teste t de Student para amostras não pareadas (gráfico 8). O menor e maior intervalos foram, respectivamente, iguais a: $10 \mathrm{~min}$ e $195 \mathrm{~min}$ (grupo preemptivo), e $15 \mathrm{~min}$ e $115 \mathrm{~min}$ (grupo placebo).

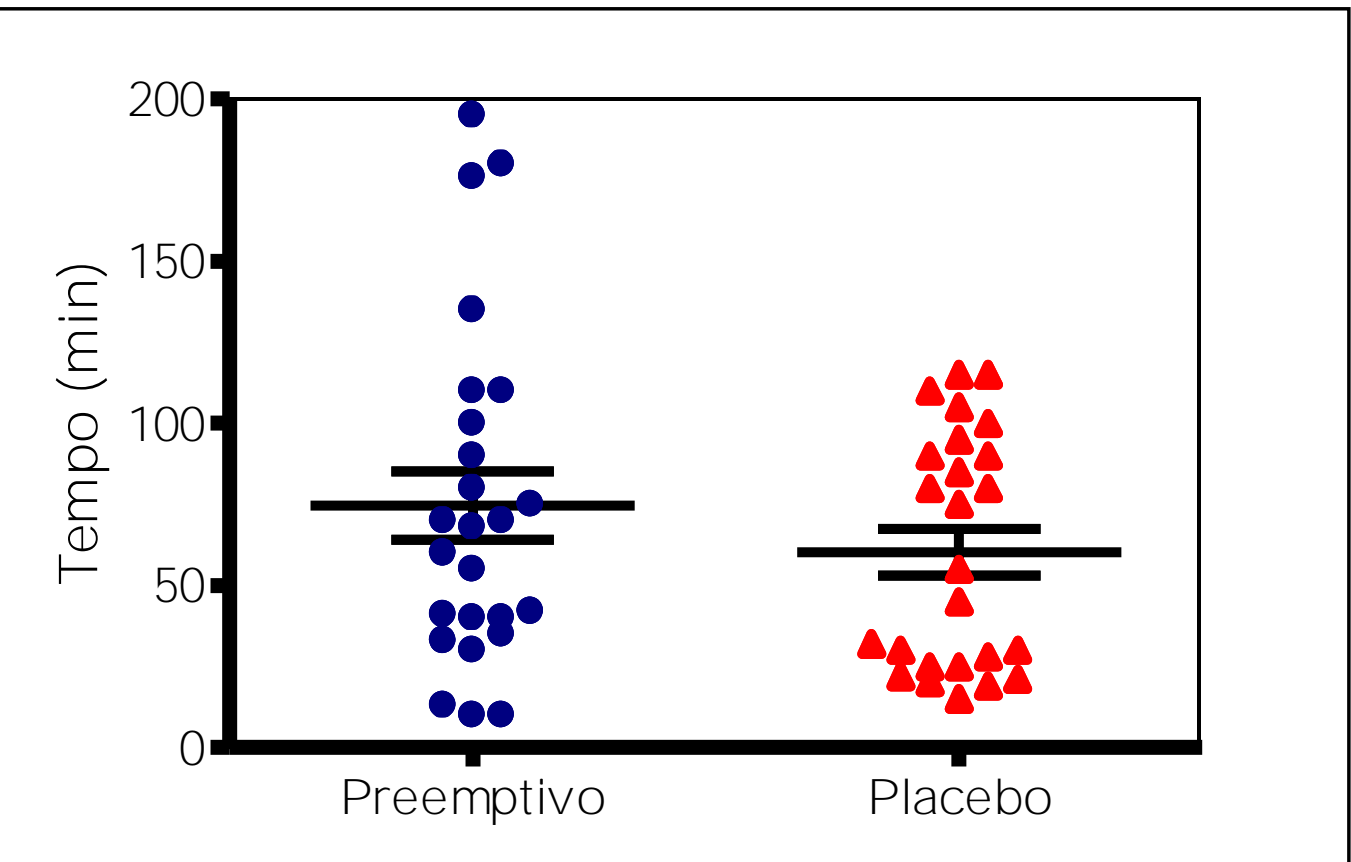

Gráfico 8. Representação do tempo decorrido desde o término da aplicação da Estimulação Elétrica Transcutânea do Nervo até a indução do bloqueio anestésico nas pacientes.

A barra central indica o valor da média, em cada grupo, e as barras menores indicam o erro padrão da média.

Teste $t$ de Student para amostras não pareadas. á $=5 \%$.

Não houve diferença significante entre os grupos $(p=0,261)$. 
A média de duração das cirurgias (gráfico 9) no grupo preemptivo foi de 38,12 \pm 1,94 min, e no placebo, 35,40 $\pm 1,84 \mathrm{~min}$, não havendo diferença significante $(\mathrm{p}=0,315)$. Não houve complicação cirúrgica em nenhum procedimento; todas as pacientes receberam alta hospitalar 2 dias após o ato cirúrgico, no turno da manhã; e o índice de mortalidade foi, em ambos os grupos, igual a zero. As cirurgias mais rápidas e mais prolongadas tiveram, respectivamente, duração de 21 min e 58 min (grupo preemptivo), e de 20 min e 50 min (grupo placebo).

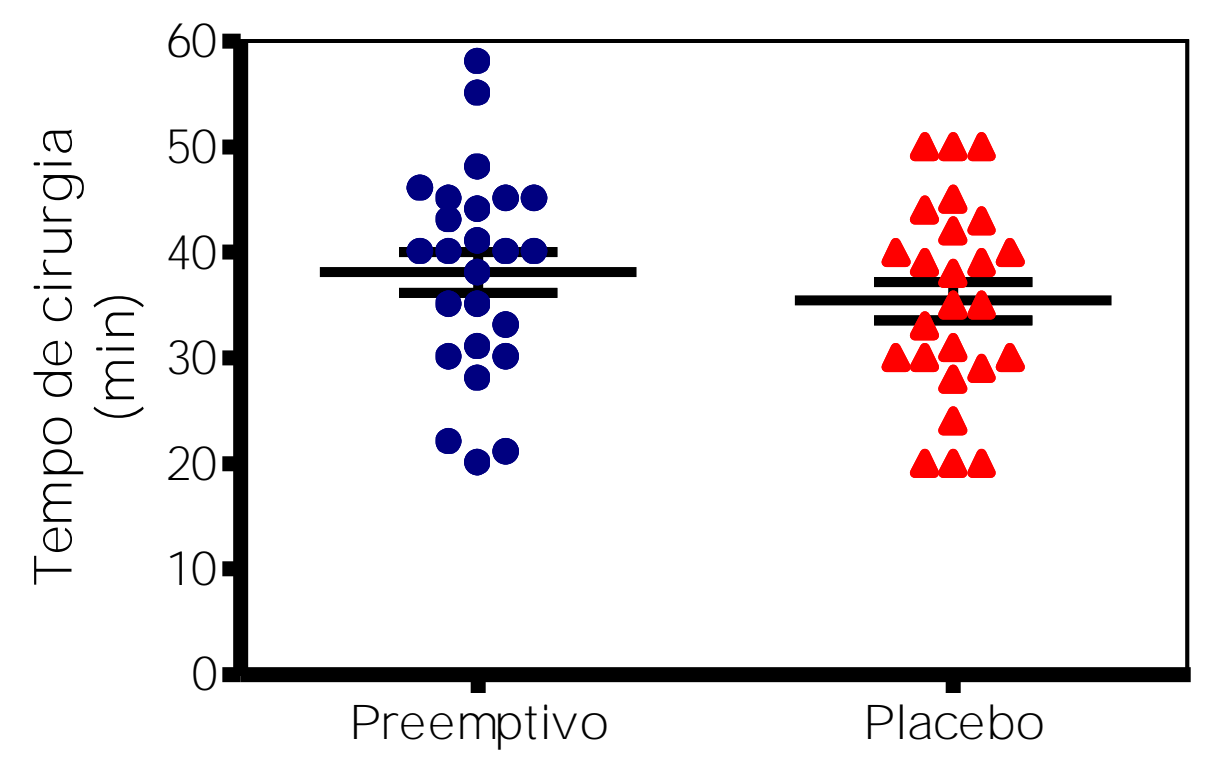

Gráfico 9. Representação da duração das cirurgias.

A barra central indica o valor da média, em cada grupo, e as barras menores indicam o erro padrão da média.

Teste t de Student para amostras não pareadas. á $=5 \%$.

Não houve diferença significante entre os grupos $(\mathrm{p}=0,315)$. 
Ao analisar a dor incisional por meio da END, pôde-se perceber que o grupo preemptivo apresentou nível de dor significantemente menor que o do placebo nas terceira (ENDc) e quarta coletas (ENDd), que representam 41/2 h e 51/2 h após a indução do bloqueio anestésico. O teste utilizado para tal análise foi o de Mann-Whitney. A tabela 5 apresenta os valores da média e erro padrão da média em todas as verificações do nível de dor, nos dois grupos; e o gráfico 10 ilustra tais valores.

Tabela 5 - Valores da média e Erro Padrão da Média (SEM) da intensidade de dor incisional, mensurada por meio da END (Escala Numérica de Mensuração da Dor).

\begin{tabular}{cccc}
\hline & Preemptivo & Placebo & \\
\hline M omento & Média e SE M & Média e SE M & p \\
\hline a & $0,84 \pm 0,34$ & $0,72 \pm 0,29$ & 0,756 \\
b & $1,16 \pm 0,39$ & $2,24 \pm 0,56$ & 0,171 \\
C & $2,02 \pm 0,53$ & $3,84 \pm 0,66$ & $0,042^{*}$ \\
d & $2,78 \pm 0,56$ & $4,8 \pm 0,67$ & $0,029 *$ \\
e & $3,22 \pm 0,56$ & $4,74 \pm 0,59$ & 0,068 \\
$\mathbf{f}$ & $3,42 \pm 0,50$ & $4,88 \pm 0,66$ & 0,135 \\
$\mathbf{g}$ & $3,56 \pm 0,61$ & $3,64 \pm 0,50$ & 0,497 \\
$\mathbf{h}$ & $0,96 \pm 0,33$ & $1,76 \pm 0,42$ & 0,145 \\
\hline
\end{tabular}

a (21/2 $\mathrm{h}$ após a indução do bloqueio anestésico - IBA); b (31/2 h após a IBA); c (41/2 $\mathrm{h}$ após a IBA); d (51/2 h após a IBA); e (7 h após a IBA); $\mathrm{f}$ ( 8 h após a IBA); $\mathrm{g}$ (16 h após a IBA); e $\mathrm{h}$ (momento da alta hospitalar, que corresponde ao $2^{\circ}$ dia pósoperatório). SEM - erro padrão da média.

Foi utilizada a END $(0-10 \mathrm{~cm})$.

Teste de Mann-Whitney. á $=5 \%$. $*$ p $<0,05$ 


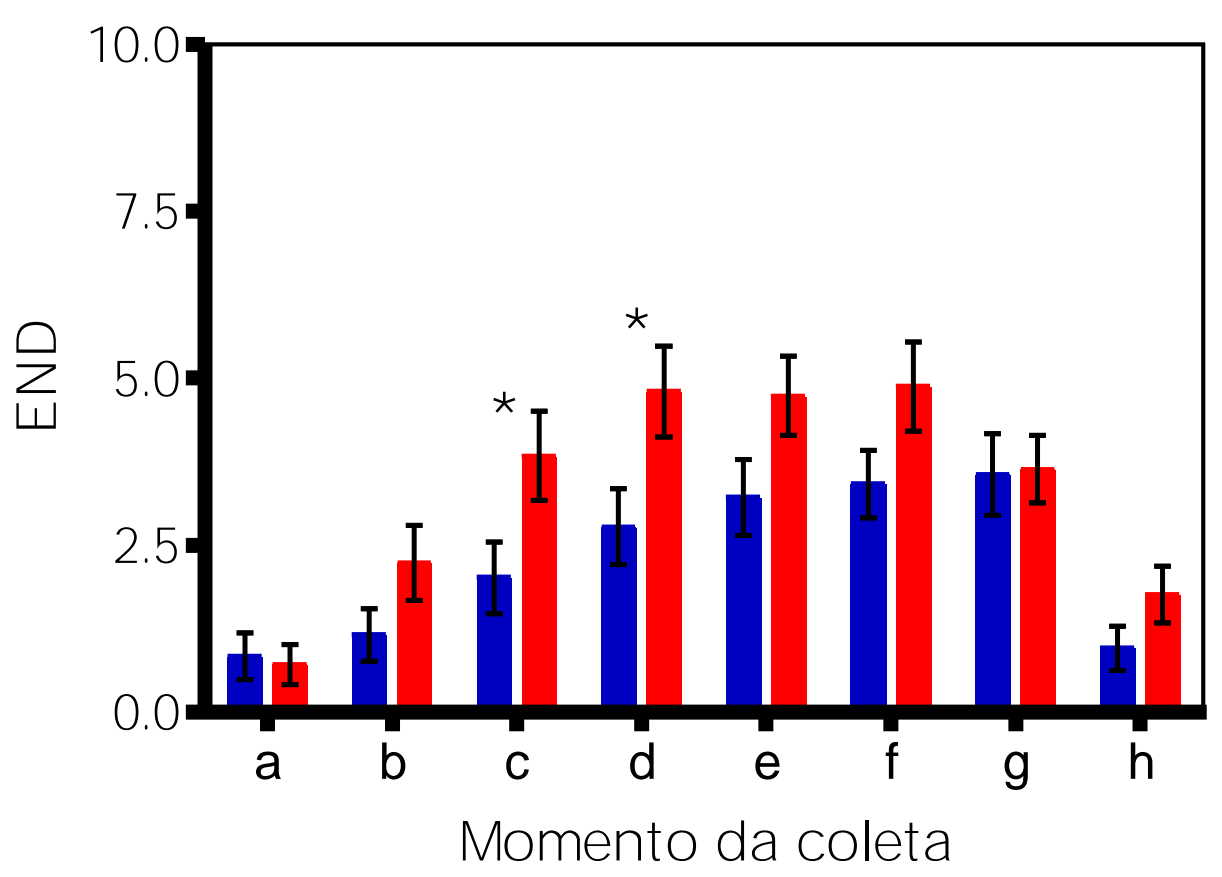

Preemptivo Placebo

Gráfico 10. Representação da média da intensidade de dor incisional, por meio da END (Escala Numérica de Mensuração da Dor).

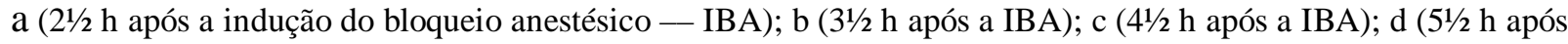
a IBA); e (7 $\mathrm{h}$ após a IBA); $\mathrm{f}$ ( $\mathrm{h}$ após a IBA); $\mathrm{g}$ (16 h após a IBA); e h (momento da alta hospitalar).

Foi utilizada a END $(0-10 \mathrm{~cm})$.

As colunas indicam os valores da média; e as barras, o erro padrão da média.

Teste de Mann-Whitney. á $=5 \%$. ${ }^{*} \mathrm{p}<0,05$. 
Na tabela 6, estão expressos os valores da média e erro padrão da média do grau de satisfação das pacientes com o tratamento que estava sendo realizado. $O$ instrumento de mensuração utilizado foi a escala numérica do grau de satisfação dos pacientes (ESP). Não se verificou, pelo Teste de Mann-Whitney, diferença estatística significante entre os dois grupos. Para a obtenção desses dados, a amostra foi composta por 49 pacientes, tendo em vista que uma paciente do grupo placebo não conseguiu compreender a ESP. O gráfico 11 ilustra tais dados.

Tabela 6 - Valores da média e Erro Padrão da Média (SEM) do grau de satisfação das pacientes com o tratamento que estava sendo realizado.

\section{Preemptivo}

Placebo

\begin{tabular}{cccc}
\hline M omento & Média e SE M & Média e SE M & $\mathbf{p}$ \\
$\mathbf{b}$ & $9,44 \pm 0,17$ & $9 \pm 0,26$ & 0,312 \\
$\mathbf{d}$ & $9,56 \pm 0,15$ & $9 \pm 0,31$ & 0,389 \\
$\mathbf{f}$ & $9,52 \pm 0,15$ & $9,12 \pm 0,27$ & 0,435 \\
$\mathbf{g}$ & $9,62 \pm 0,17$ & $9,25 \pm 0,32$ & 0,756 \\
$\mathbf{h}$ & $9,92 \pm 0,05$ & $9,33 \pm 0,35$ & 0,406
\end{tabular}

$\mathrm{b}\left(3 \frac{1}{2} \mathrm{~h}\right.$ após a indução do bloqueio anestésico - IBA); d (51/2 h após a IBA); f ( $\mathrm{h}$ após a IBA); g (16 h após a IBA); e h (momento da alta hospitalar).

Foi utilizada a ESP (Escala de Satisfação do Paciente, de 0 a 10). SEM — erro padrão da média.

Teste de Mann-Whitney. á = 5\%.

Grupo preemptivo $(\mathrm{n}=25)$ e grupo placebo $(\mathrm{n}=24)$. 


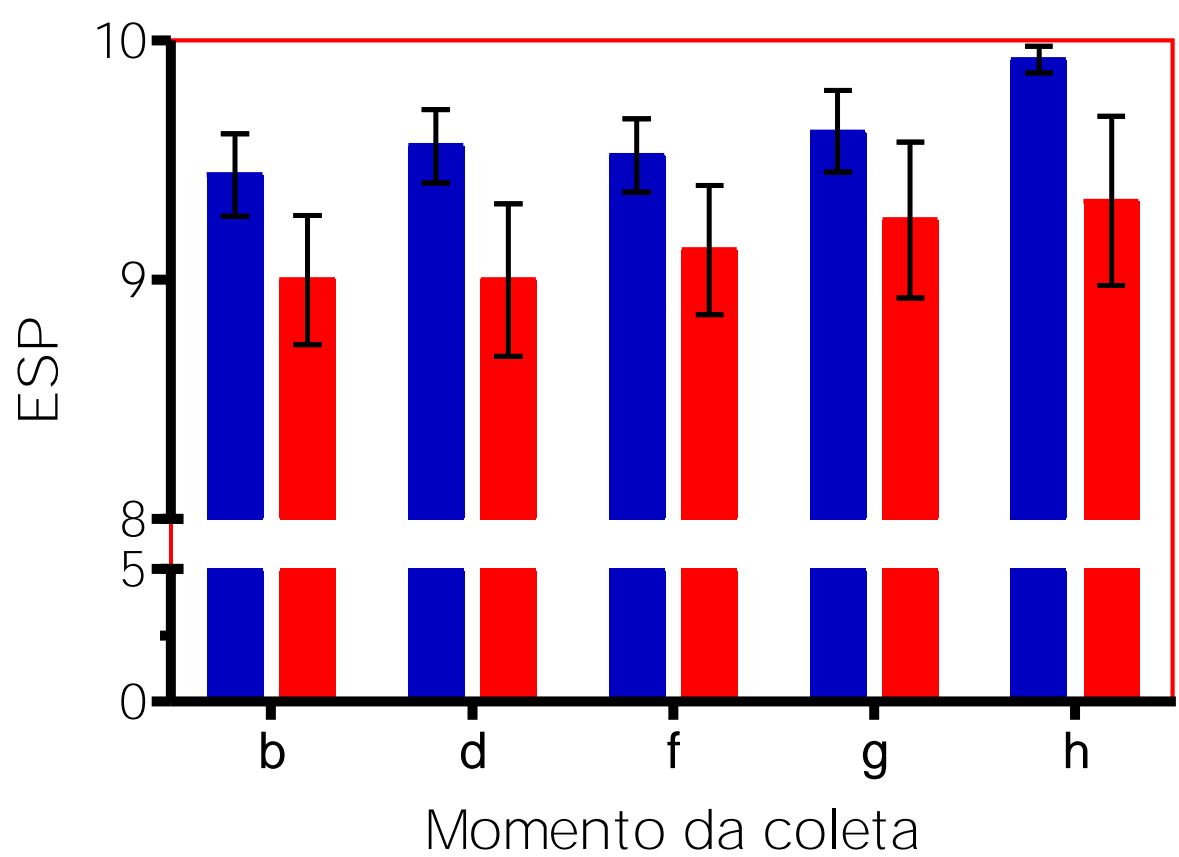

Preemptivo Placebo

Gráfico 11. Representação da média de satisfação das pacientes com o tratamento que estava sendo realizado, obtida pela ESP (Escala de Satisfação do Paciente).

$\mathrm{b}\left(3^{1 / 2} \mathrm{~h}\right.$ após a indução do bloqueio anestésico, IBA); $\mathrm{d}\left(5^{1} \frac{1}{2} \mathrm{~h}\right.$ após a IBA); $\mathrm{f}(8 \mathrm{~h}$ após a IBA); $\mathrm{g}$ (16 h após a IBA); e h (momento da alta hospitalar).

Foi utilizada a ESP, de 0 a 10.

As colunas indicam os valores da média; e as barras, o erro padrão da média.

Teste de Mann-Whitney. á = 5\%.

Não houve diferença estatística significante entre os grupos em nenhum momento de coleta da ESP.

Grupo preemptivo $(\mathrm{n}=25)$ e grupo placebo $(\mathrm{n}=24)$. 
As tabelas 7 e 8 apresentam, respectivamente, o número de vezes em que cada descritor e em que cada subcategoria do Questionário de Dor McGill (MPQ) foram selecionados pelas pacientes dos grupos preemptivo e placebo. Na tabela 9, estão expressos os descritores que melhor caracterizaram a dor incisional promovida pela colecistectomia por laparotomia, e que, de acordo com Dubuisson e Melzack (1996) e Gagliesi e Melzack (2003), seriam aqueles que fossem selecionados por pelo menos $33 \%$ dos pacientes. Todas as análises procedidas a partir do MPQ foram realizadas com 21 pacientes do grupo preemptivo e com 20 do grupo placebo. A discussão sobre a "Análise da Dor pelo Questionário de Dor McGill” (item 5.4) explica o motivo para tal.

Na tabela 10, estão apresentados os valores da média e erro padrão da média do Número de Palavras Escolhidas Total (NWC-t) e em cada categoria do MPQ e, no gráfico 12, eles estão representados. A tabela 11 apresenta uma comparação das categorias sensorial e afetiva no que se refere ao número de pacientes que selecionou mais descritores de uma ou de outra categoria, assim como o número de pacientes que os selecionaram de forma eqüitativa nessas categorias. Nota-se que os valores estão apresentados em porcentagens método recomendado por Veilleux e Melzack (1976) —, dado o número diferente de subcategorias que compõe cada uma dessas categorias (sensorial, 10; e afetiva, 5). Em ambos os grupos, houve proporcionalmente maior seleção dos descritores da categoria sensorial, principalmente no grupo preemptivo. 
Tabela 7 - Relação dos descritores do Questionário de Dor McGill selecionados pelas pacientes.

\begin{tabular}{|c|c|c|c|c|c|c|c|}
\hline Subctg & Descritores & Preemp. & Plac. & Subctg & Descritores & Preemp. & Plac. \\
\hline \multirow{6}{*}{$1 \underline{a}$} & vibração & 2 & 0 & \multirow{6}{*}{11 a } & \multirow{6}{*}{$\begin{array}{l}\text { cansativa } \\
\text { exaustiva }\end{array}$} & \multirow{6}{*}{$\begin{array}{c}17 \\
3\end{array}$} & \multirow{6}{*}{$\begin{array}{c}18 \\
2\end{array}$} \\
\hline & tremor & 1 & 1 & & & & \\
\hline & pulsante & 3 & 1 & & & & \\
\hline & latejante & 9 & 12 & & & & \\
\hline & como batida & 1 & 1 & & & & \\
\hline & como pancada & 2 & 1 & & & & \\
\hline \multirow{3}{*}{$2^{a}$} & pontada & 10 & 9 & \multirow{3}{*}{$12^{a}$} & enjoada & 17 & 18 \\
\hline & choque & 6 & 2 & & sufocante & \multirow{2}{*}{4} & \multirow{2}{*}{2} \\
\hline & tiro & 0 & 2 & & & & \\
\hline \multirow{5}{*}{ 3ạ } & agulhada & 6 & 7 & \multirow{5}{*}{$13 \underline{a}$} & castigante & 10 & 6 \\
\hline & perfurante & 5 & 1 & & atormenta & 5 & 10 \\
\hline & facada & 2 & 2 & & aterrorizante & 0 & 0 \\
\hline & punhalada & 0 & 1 & & maldita & 0 & 1 \\
\hline & em lança & 0 & 1 & & mortal & 0 & 0 \\
\hline \multirow{3}{*}{$4 \underline{a}$} & fina & 15 & 15 & \multirow{3}{*}{$14 \underline{a}$} & amedrontada & 8 & 4 \\
\hline & cortante & 5 & 1 & & apavorante & 3 & 2 \\
\hline & estraçalha & 0 & 0 & & cruel & 3 & 5 \\
\hline \multirow{5}{*}{$5 \underline{a}$} & beliscão & 3 & 6 & \multirow{5}{*}{$15 \underline{a}$} & \multirow{5}{*}{$\begin{array}{l}\text { miserável } \\
\text { enlouquecedora }\end{array}$} & & \\
\hline & pressão & 2 & 2 & & & & \\
\hline & mordida & 2 & 0 & & & 2 & 4 \\
\hline & cólica & 6 & 5 & & & 6 & 4 \\
\hline & esmagamento & 2 & 3 & & & & \\
\hline \multirow{5}{*}{ 6a } & & & & \multirow{5}{*}{$16 \underline{a}$} & chata & 1 & 5 \\
\hline & fisgada & 4 & 4 & & que incomoda & 10 & 13 \\
\hline & puxão & 10 & 6 & & desgastante & 2 & 1 \\
\hline & em torção & 3 & 6 & & forte & 4 & 0 \\
\hline & & & & & insuportável & 4 & 1 \\
\hline \multirow{4}{*}{$7 \mathfrak{a}$} & calor & 7 & 5 & \multirow{4}{*}{$17^{a}$} & espalha & 3 & 11 \\
\hline & queimação & 9 & 10 & & irradia & 0 & 1 \\
\hline & fervente & 1 & 1 & & penetra & 7 & 4 \\
\hline & em brasa & 0 & 1 & & atravessa & 3 & 1 \\
\hline \multirow{5}{*}{$8 \underline{a}$} & & & & \multirow{5}{*}{ 18aㅡ } & aperta & 5 & 3 \\
\hline & formigamento & 1 & 1 & & adormece & 1 & 2 \\
\hline & coceira & 1 & 3 & & repuxa & 11 & 11 \\
\hline & ardor & 16 & 11 & & espreme & 1 & 0 \\
\hline & ferroada & 2 & 1 & & rasga & 2 & 1 \\
\hline & mal-localizada & 1 & 2 & & & & \\
\hline & dolorida & 12 & 9 & & fria & 4 & 4 \\
\hline 9ạ & machucada & 3 & 2 & 19aa & gelada & 0 & 2 \\
\hline & doída & 1 & 4 & & congelante & 0 & 2 \\
\hline & pesada & 3 & 3 & & & & \\
\hline & sensível & 4 & 3 & & aborrecida & 11 & 8 \\
\hline & esticada & 13 & 5 & & dá náusea & 6 & 8 \\
\hline $10 \mathrm{a}$ & esfolante & 0 & 2 & $20 \mathrm{a}$ & agonizante & 1 & 0 \\
\hline & rachando & 2 & 3 & & pavorosa & 0 & 1 \\
\hline & & & & & torturante & 2 & 2 \\
\hline
\end{tabular}

Subctg. (subcategoria do Questionário de Dor McGill); Preemp. (preemptivo, $n=21$ ); Plac. (placebo, $n=20$ ). 
Tabela 8 - Número de pacientes que selecionou cada subcategoria do Questionário de Dor McGill.

\begin{tabular}{|c|c|c|c|c|c|c|c|}
\hline Subcat. & Preemptivo & Placebo & $p$ & Subcat. & Preemptivo & Placebo & $p$ \\
\hline $1 \underline{a}$ & 18 & 16 & 0,626 & 11aㅡ & 20 & 20 & 0,323 \\
\hline 2 & 16 & 13 & 0,431 & $12^{\mathrm{a}}$ & 21 & 20 & 1 \\
\hline 3 & 13 & 12 & 0,900 & $13 \underline{a}$ & 15 & 17 & 0,294 \\
\hline $4 \underline{a}$ & 20 & 16 & 0,136 & $14^{a}$ & 14 & 11 & 0,444 \\
\hline 5 & 15 & 16 & 0,522 & 15a & 8 & 8 & 0,900 \\
\hline $6 \mathrm{a}$ & 17 & 16 & 0,938 & $16 \mathrm{a}$ & 21 & 20 & 1 \\
\hline $7 \underline{a}$ & 17 & 17 & 0,730 & $17^{a}$ & 13 & 17 & 0,095 \\
\hline 8 & 20 & 16 & 0,136 & $18 \underline{a}$ & 20 & 17 & 0,269 \\
\hline 9a & 20 & 20 & 0,323 & 19a & 4 & 8 & 0,140 \\
\hline $10 \mathrm{a}$ & 19 & 13 & $0,048^{*}$ & $20 \mathrm{a}$ & 20 & 19 & 0,971 \\
\hline
\end{tabular}

Teste do $\div^{2} * \mathrm{p}<0,05$.

Grupo preemptivo $(\mathrm{n}=21)$ e grupo placebo $(\mathrm{n}=20)$. 
Tabela 9 - Descritores do Questionário de Dor McGill mais freqüentemente selecionados pelas pacientes.

\begin{tabular}{|c|c|c|c|c|}
\hline Subcategoria & Descritor & Preemptivo & Placebo & $\mathbf{p}$ \\
\hline $1^{\underline{a}}$ & latejante & $9(42,85 \%)$ & $12(60 \%)$ & 0,27 \\
\hline $2^{a}$ & pontada & $10(47,61 \%)$ & $9(45 \%)$ & 0,86 \\
\hline $3 \underline{a}$ & agulhada & $6(28,57 \%)$ & $7(35 \%)$ & 0,65 \\
\hline $4 \underline{a}$ & fina & $15(71,42 \%)$ & $15(75 \%)$ & 0,79 \\
\hline $5 \underline{a}$ & - & - & - & - \\
\hline 6a & puxão & $10(47.61 \%)$ & $6(30 \%)$ & 0,24 \\
\hline \multirow[t]{2}{*}{ 7ạ } & calor & $7(33,33 \%)$ & $5(25 \%)$ & 0,55 \\
\hline & queimação & $9(42,85 \%)$ & $10(50 \%)$ & 0,75 \\
\hline $8 \underline{a}$ & ardor & $16(76,19 \%)$ & $11(55 \%)$ & 0,15 \\
\hline 9ạ & dolorida & $12(57,14 \%)$ & $9(45 \%)$ & 0,43 \\
\hline $10 \mathrm{a}$ & esticada & $13(61,90 \%)$ & $5(25 \%)$ & $0,01 *\left(\dot{\div}^{2}=5,66\right)$ \\
\hline $11 \underline{a}$ & cansativa & $17(80,95 \%)$ & $18(90 \%)$ & 0,41 \\
\hline $12 \mathrm{a}$ & enjoada & $17(80.95 \%)$ & $18(90 \%)$ & 0,41 \\
\hline \multirow[t]{2}{*}{ 13ạ } & castigante & $10(47,61 \%)$ & $6(30 \%)$ & 0,24 \\
\hline & atormenta & $5(23,80 \%)$ & $10(50 \%)$ & 0,08 \\
\hline $14 \underline{a}$ & amedrontada & $8(38,09 \%)$ & $4(20 \%)$ & 0,20 \\
\hline 15ạ & - & - & - & - \\
\hline $16 \mathrm{a}$ & que incomoda & $10(47,61 \%)$ & $13(65 \%)$ & 0,26 \\
\hline \multirow[t]{2}{*}{$17 \underline{a}$} & espalha & $3(14,28 \%)$ & $11(55 \%)$ & $0,006^{*}\left(\div^{2}=7,55\right)$ \\
\hline & penetra & $7(33,33 \%)$ & $4(20 \%)$ & 0,33 \\
\hline $18 \mathrm{a}$ & repuxa & $11(52,38 \%)$ & $11(55 \%)$ & 0,86 \\
\hline $19 \underline{a}$ & - & - & - & - \\
\hline \multirow[t]{2}{*}{20 a } & aborrecida & $11(52,38 \%)$ & $8(40 \%)$ & 0,42 \\
\hline & dá náusea & $6(28,57 \%)$ & $8(40 \%)$ & 0,44 \\
\hline
\end{tabular}

Foi considerado como descritor mais freqüentemente selecionado aquele que assim o fosse por pelo menos 33\% das pacientes de cada grupo, em cada subcategoria. Os valores entre parêntesis correspondem à porcentagem de pacientes do referido grupo, que selecionou tal descritor.

Teste utilizado: $\stackrel{2}{-}^{2} * \mathrm{p}<0,05$. á $=5 \%$.

Grupo preemptivo $(\mathrm{n}=21)$ e grupo placebo $(\mathrm{n}=20)$. 
Tabela 10 - Índice do Número de Palavras Escolhidas (NWC) total e em cada categoria do Questionário de Dor McGill.

\begin{tabular}{lccc}
\hline \multicolumn{1}{c}{ Categoria } & Preemptivo & Placebo & \\
\hline Sensorial (NW C -s) & $8,19 \pm 0,38$ & $7,65 \pm 0,50$ & 0,449 \\
Afetiva (NW C -af) & $3,71 \pm 0,25$ & $3,75 \pm 0,20$ & 0,958 \\
A valiativa (NW C -av) & $1,00 \pm 0$ & $1,00 \pm 0$ & 1 \\
M iscelânea (NW C - m) & $2,76 \pm 0,18$ & $3,15 \pm 0,21$ & 0,155 \\
Total (NW C -t) & $15,61 \pm 0,61$ & $15,40 \pm 0,84$ & 0,937
\end{tabular}

SEM — erro padrão da média. $\mathrm{s}$ — sensorial; af — afetiva; av — avaliativa; $\mathrm{m}$ — miscelânea; e $\mathrm{t}$ total.

Teste de Mann-Whitney. á = 5\%.

Grupo preemptivo $(\mathrm{n}=21)$ e grupo placebo $(\mathrm{n}=20)$.

Tabela 11 - Relação do Número de Palavras Escolhidas nas categorias sensorial (NWCs) e afetiva (NWC-af), entre os grupos preemptivo e placebo.

\section{Categoria Número de pacientes que selecionou:}

\begin{tabular}{cccccc}
\hline \multicolumn{1}{c}{ G rupo } & Sensorial & A fetiva & $\% \mathbf{S}>\mathbf{~ A f}$ & $\% \mathbf{S ~ = ~ \% ~ A f ~}$ & $\%$ Af $>$ \% S \\
\hline Preemptivo & 8,19 & 3,71 & 12 & 4 & 5 \\
& $(81,9 \%)$ & $(74,28 \%)$ & & & \\
Placebo & 7,65 & 3,75 & 6 & 8 & 6 \\
& $(76,50 \%)$ & $(75 \%)$ & & &
\end{tabular}

Nas colunas referentes à categoria, estão expressos os valores da média do NWC nas categorias sensorial e afetiva e, entre parêntesis, os valores em taxas percentuais, que foram assim transformados porquanto essas categorias possuem um número diferenciado de subcategorias — a sensorial contém 10 subcategorias e a afetiva, 5 - para que assim fosse possível uma comparação entre essas categorias, o que é recomendado por Veilleux e Melzack (1976).

$\mathrm{S}$ - categoria sensorial; Af - categoria afetiva. Nas últimas 3 colunas da tabela, estão expressos o número absoluto de pacientes que selecionou, proporcionalmente, mais uma categoria do que a outra; assim como o daqueles que selecionou de forma semelhante as duas categorias.

Teste do $\div$.

Não houve diferença significante entre os grupos $(\mathrm{p}=0,182)$.

Grupo preemptivo $(n=21)$ e grupo placebo $(n=20)$. 


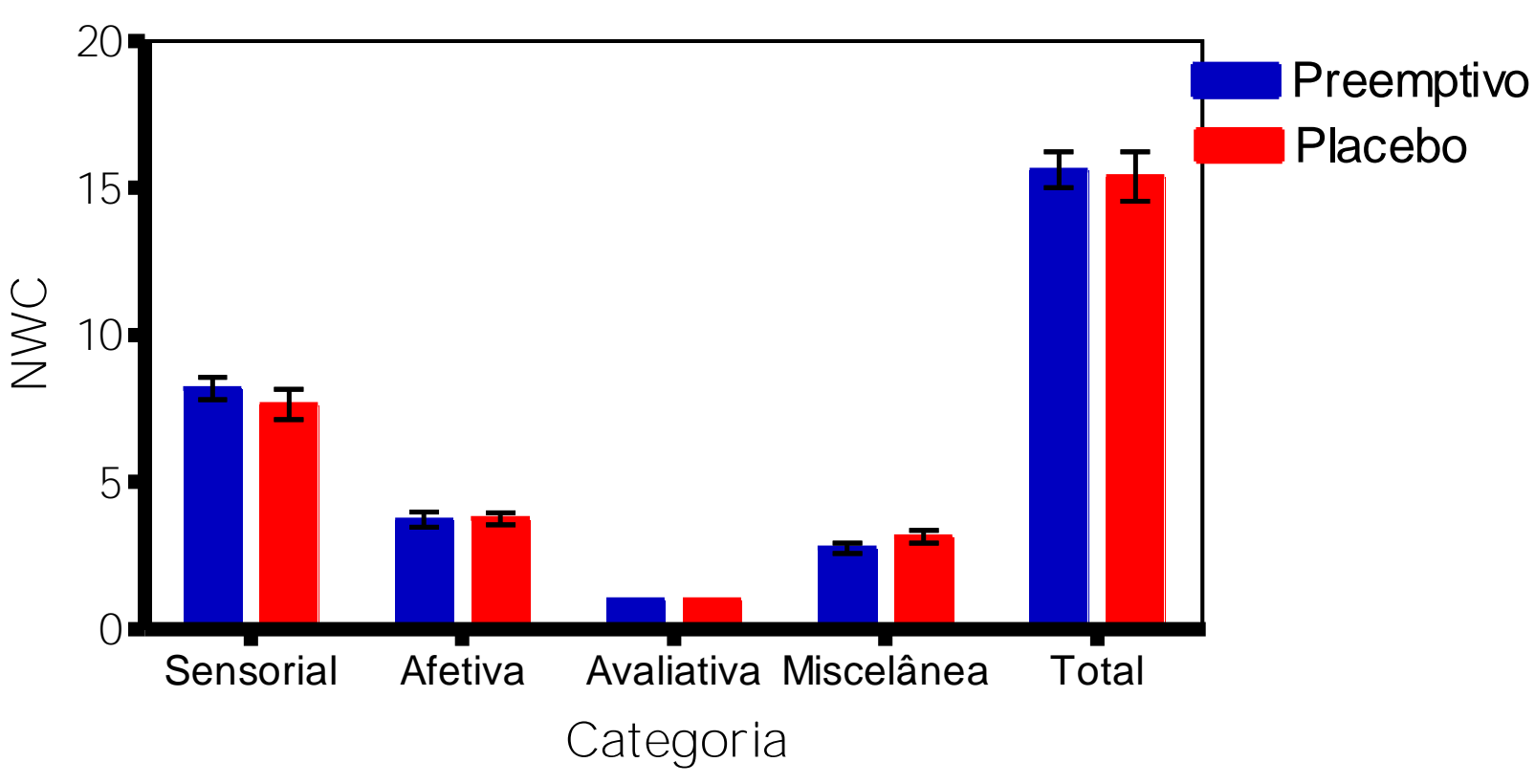

Gráfico 12. Representação da média do Número de Palavras Escolhidas (NWC) total e em cada categoria do Questionário de Dor McGill, nos grupos preemptivo e placebo.

As colunas indicam o valor da média; e as barras, o erro padrão da média.

Teste de Mann-Whitney. á = 5\%.

Não houve diferença estatística significante entre os grupos em nenhuma das categorias, assim como no índice total.

Grupo preemptivo $(\mathrm{n}=21)$ e grupo placebo $(\mathrm{n}=20)$. 
A tabela 12 apresenta os valores da média e erro padrão da média do Índice Quantitativo da Dor (PRI) Total e em cada categoria do MPQ, e o gráfico 13 ilustra tais valores. Não houve, de acordo com o Teste de Mann-Whitney, diferença estatística significante entre os grupos no que se refere ao PRI-t; todavia, ao analisá-lo, pelo mesmo teste, separadamente em cada categoria, houve diferença estatística significante na categoria avaliativa ( $\mathrm{p}=0,019)$, em que o grupo preemptivo apresentou maior valor.

Tabela 12- Índice Quantitativo da Dor (PRI) total e em cada categoria do Questionário de Dor McGill, nos grupos preemptivo e placebo.

\begin{tabular}{lccc}
\hline & Preemptivo & Placebo & \\
\hline \multicolumn{1}{c}{ Categoria } & M édia SE M & M édia e SE M & P \\
\hline Sensorial (PRI-s) & $18,42 \pm 0,92$ & $18,75 \pm 1,45$ & 0,896 \\
A fetiva (PRI-af) & $5 \pm 0,45$ & $5,40 \pm 0,41$ & 0,473 \\
A valiativa (PRI-av) & $3 \pm 0,28$ & $2,05 \pm 0,22$ & $0,019^{*}$ \\
M iscelânea (PRI-m) & $6,28 \pm 0,56$ & $6,57 \pm 0,71$ & 1 \\
T otal (PRI-t) & $32,71 \pm 1,63$ & $32,45 \pm 2,08$ & 0,906
\end{tabular}

SEM — erro padrão da média. $\mathrm{s}$ — sensorial; af — afetiva; av — avaliativa; $\mathrm{m}$ — miscelânea; e t - total.

Teste de Mann-Whitney. á $=5 \%$. * $p<0,05$.

Grupo preemptivo $(n=21)$ e grupo placebo $(n=20)$. 


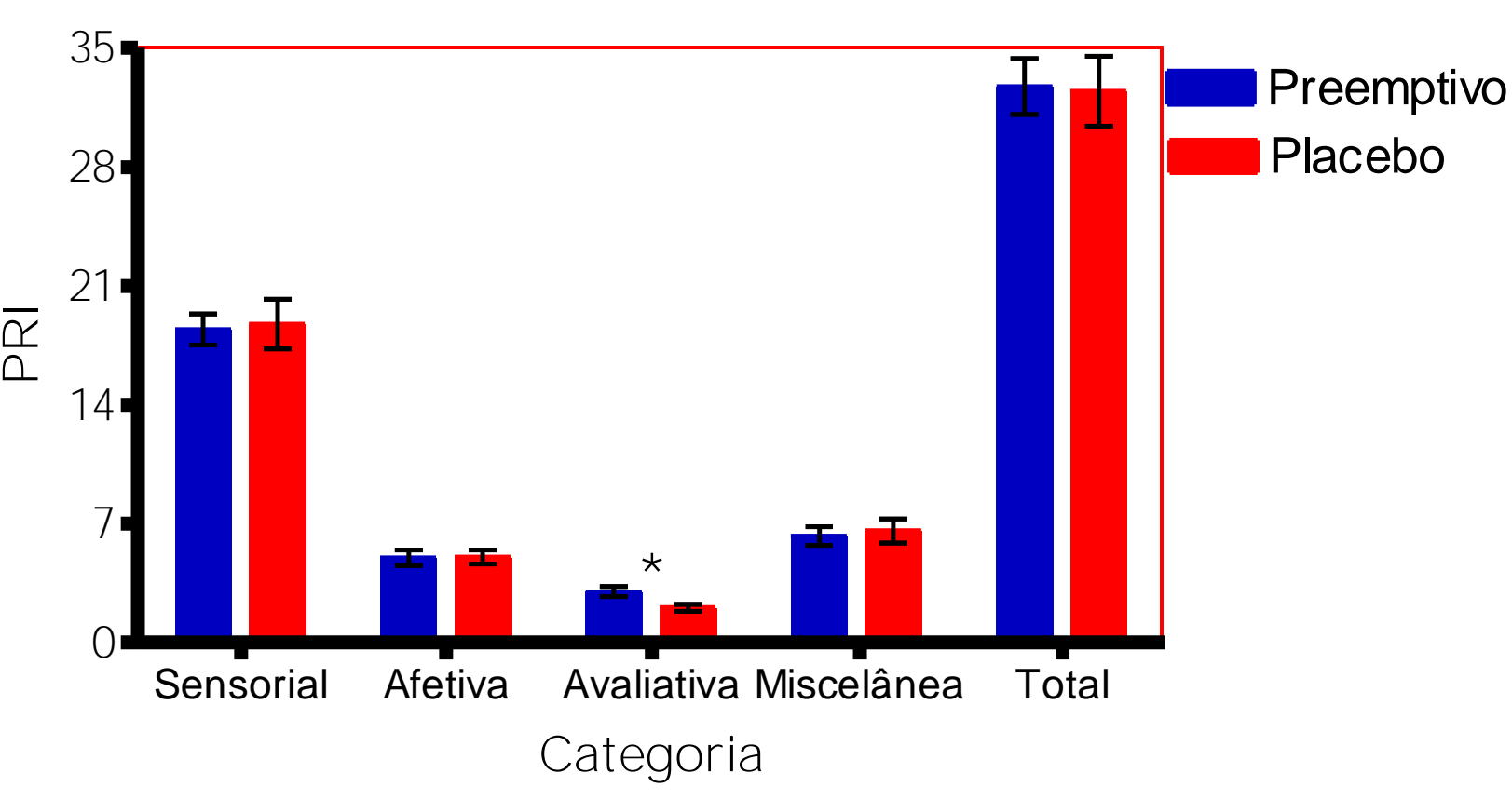

Gráfico 13. Representação da média do Índice Quantitativo da Dor (PRI) total e em cada categoria do Questionário de Dor McGill, nos grupos preemptivo e placebo.

As colunas indicam as médias; e as barras, o erro padrão da média.

Teste de Mann-Whitney. á $=5 \%$. $* \mathrm{p}<0,05$.

Grupo preemptivo $(\mathrm{n}=21)$ e grupo placebo $(\mathrm{n}=20)$. 
Das 25 pacientes do grupo preemptivo, 12 necessitaram de diclofenaco de sódio nas primeiras 16 h após a indução do bloqueio anestésico; e, das 25 do grupo placebo, 15 o utilizaram. A análise estatística, efetuada por meio do teste do $\stackrel{\circ}{-}^{2}$, demonstrou não haver diferença significante entre os dois grupos, pois o valor de p foi igual a 0,394 (gráfico 14). Avaliou-se o uso dessa droga, especificamente nas primeiras 16 h após a indução do bloqueio anestésico, haja vista que, nesse período, todas as pacientes tinham, em seus prontuários, a mesma prescrição médica — diclofenaco de sódio como medicação de resgate e dipirona, de 6 em 6 h 一, o que não ocorreu na segunda prescrição, já que ficava a critério do médico optar se seria melhor continuar com a mesma prescrição, ou mudá-la (mas sempre utilizando as mesmas duas drogas).

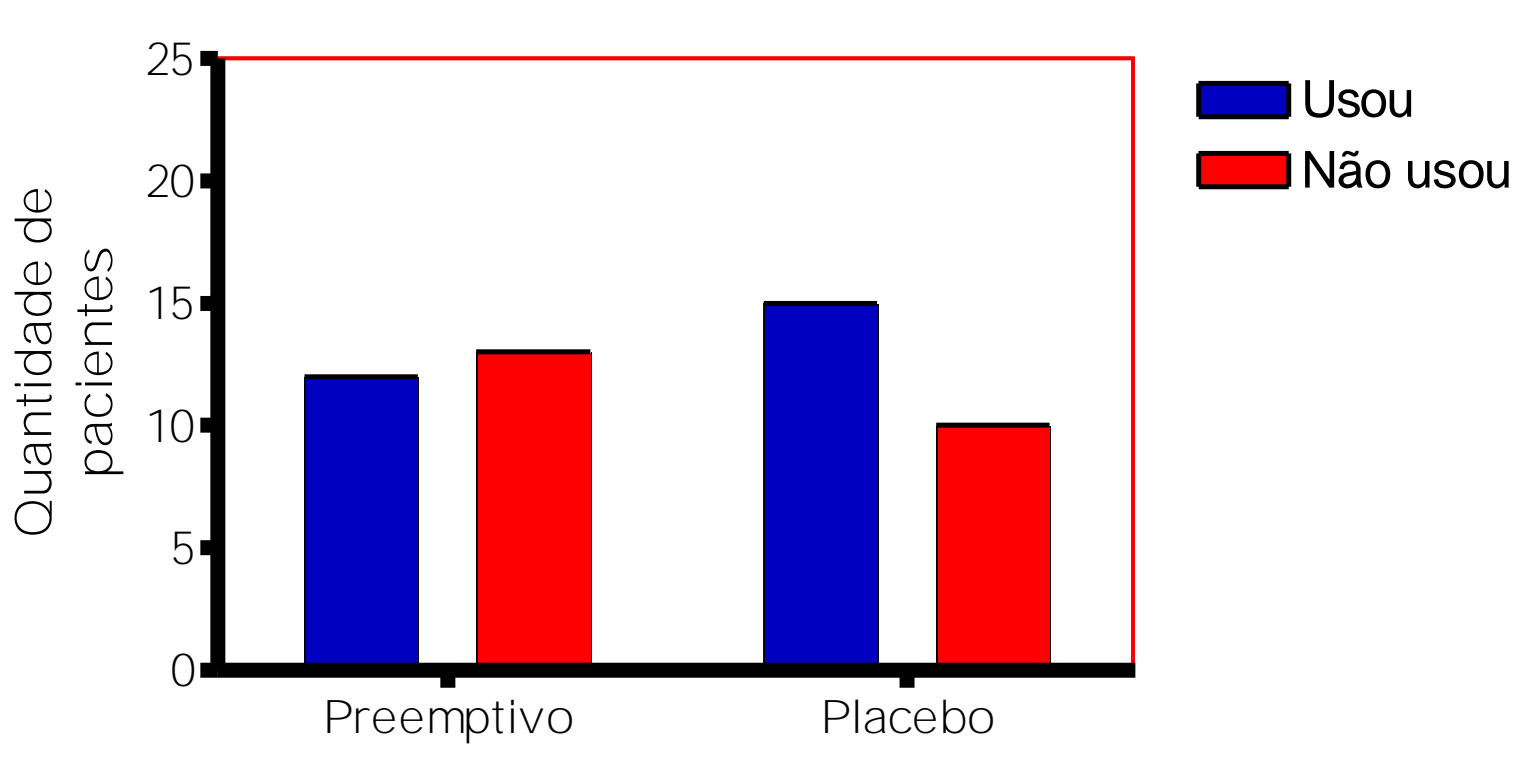

Gráfico 14. Representação do consumo de diclofenaco de sódio pelas pacientes nas primeiras 16 horas após a indução do bloqueio anestésico.

Teste do $\stackrel{\circ}{\circ}^{2}$. á $=5 \%$.

Não houve diferença significante entre os grupos $(p=0,394)$. 
Daquelas do grupo preemptivo em que foi administrado o diclofenaco de sódio nesse período, o intervalo médio para tal foi de 487,50 \53,44 min; e das do grupo placebo, 470,10 $\pm 46,19$ min, não havendo diferença significante quanto a este tempo $(p=0,807)$, de acordo com o teste $t$ de Student para amostras não pareadas (gráfico 15). O menor e maior tempo para tal administração foram, respectivamente, iguais a 224 min e 805 min (grupo preemptivo), e 25 min e 840 min (grupo placebo).

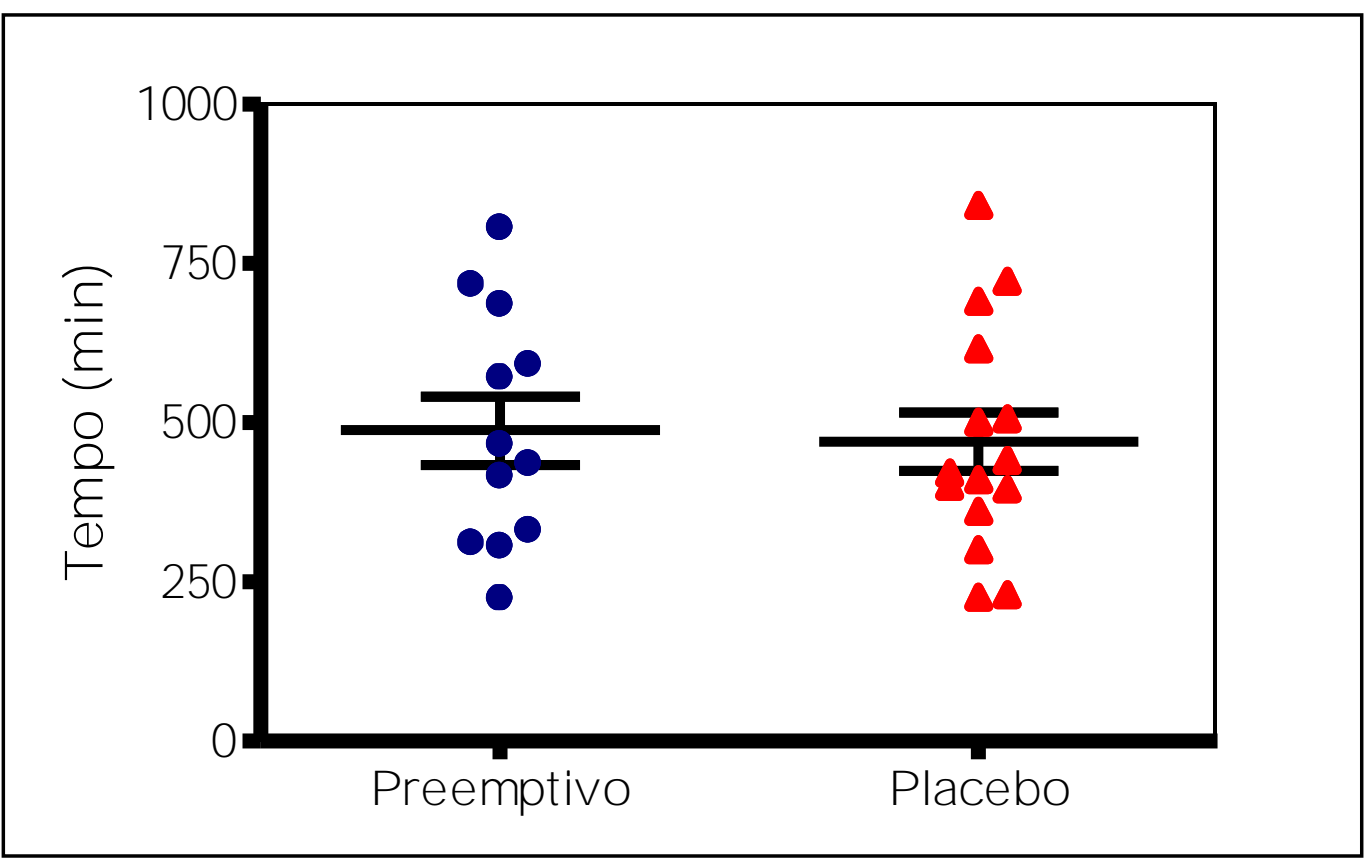

Gráfico 15. Representação dos intervalos desde a indução do bloqueio anestésico até a solicitação do diclofenaco de sódio, nas pacientes que assim a fizeram nas primeiras 16 horas após tal indução.

A barra central indica o valor da média, em cada grupo, e as barras menores indicam o erro padrão da média.

Teste $\mathrm{t}$ de Student para amostras não pareadas. á $=5 \%$.

Não houve diferença significante entre os grupos $(\mathrm{p}=0,807)$.

Grupo preemptivo $(\mathrm{n}=12)$ e grupo placebo $(\mathrm{n}=15)$. 
Em se tratando do consumo de diclofenaco de sódio (gráfico 16) e de dipirona (gráfico 17) desde o início do período pós-operatório até o momento da alta hospitalar, que ocorreu em todas as pacientes no turno da manhã, no $2^{\circ}$ dia pós-operatório, não houve, de acordo com o teste de Mann-Whitney, diferença significante entre os grupos.

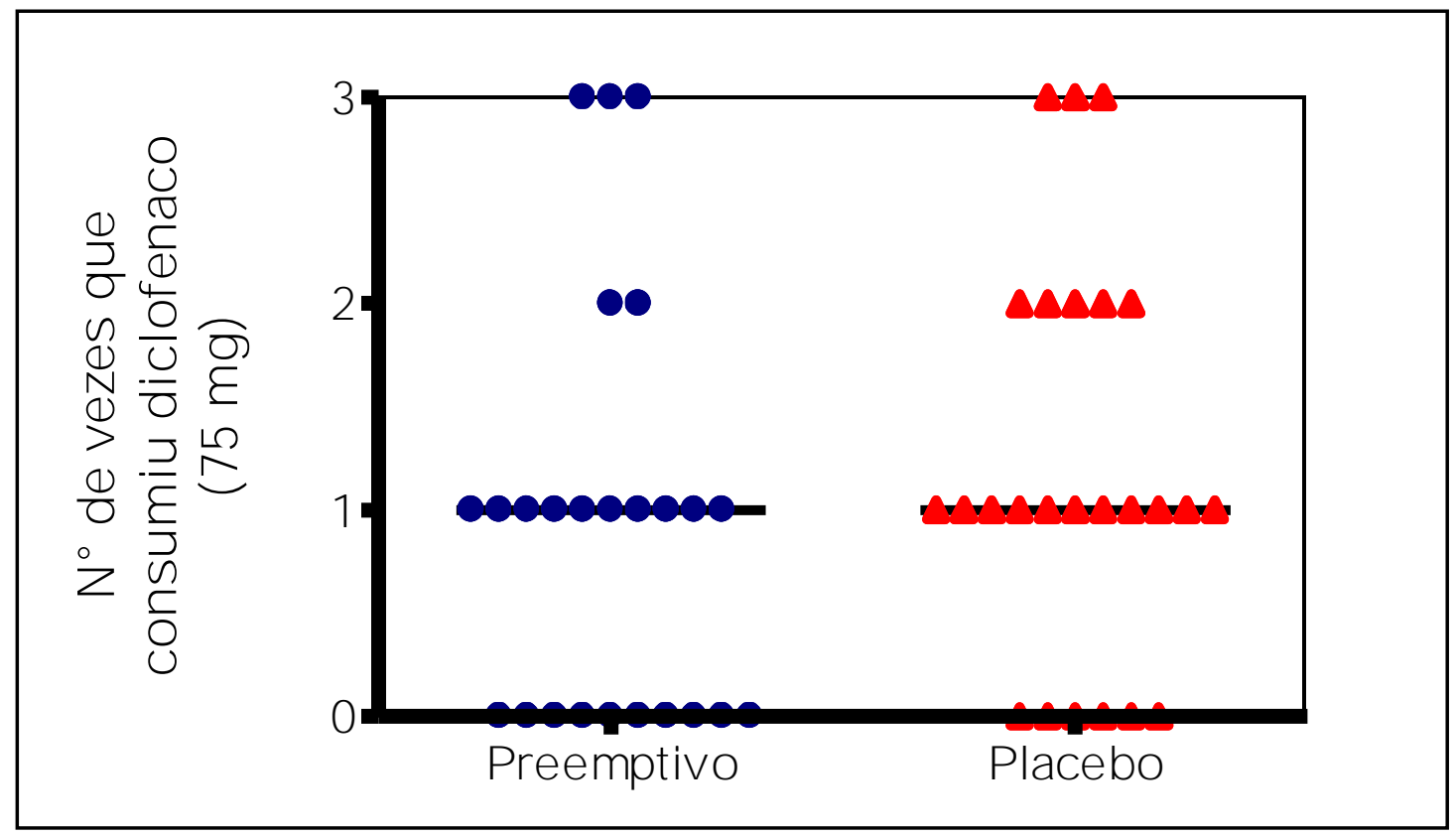

Gráfico 16. Número de vezes que as pacientes consumiram diclofenaco desde o início do período pós-operatório até o momento da alta hospitalar. A barra indica o valor da mediana.

O diclofenaco de sódio foi administrado via intra-muscular.

A alta hospitalar ocorreu no $2^{\circ}$ dia pós-operatório, no turno da manhã.

Teste de Mann-Whitney. á $=5 \%$.

Não houve diferença significante entre os grupos $(p=0,260)$. 


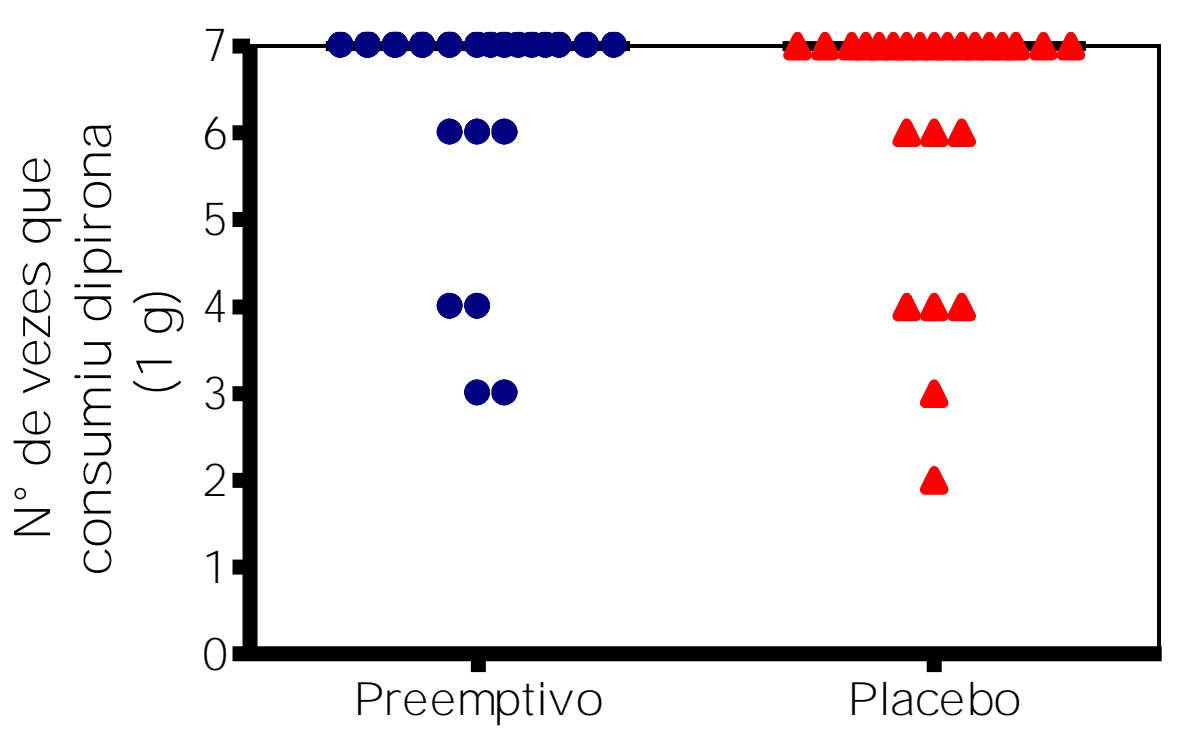

Gráfico 17. Número de vezes que as pacientes consumiram dipirona desde o início do período pós-operatório até o momento da alta hospitalar.

A barra indica o valor da mediana.

A alta hospitalar ocorreu no $2^{\circ}$ dia pós-operatório, no turno da manhã.

A dipirona foi administrada via intra-venosa.

Teste de Mann-Whitney. á = 5\%.

Não houve diferença significante entre os grupos $(p=0,788)$. 
Foi também analisada a ocorrência de dor referida no ombro direito das pacientes em algum momento do período pós-operatório. Das 25 pacientes do grupo preemptivo, 10 relataram dor nessa região; e, das pacientes do outro grupo, um total de 8 relataram a ocorrência de tal dor. Essa diferença não foi estatisticamente significante ( $p=0,555)$, segundo o teste do $\div^{2}$ (gráfico 18$)$.

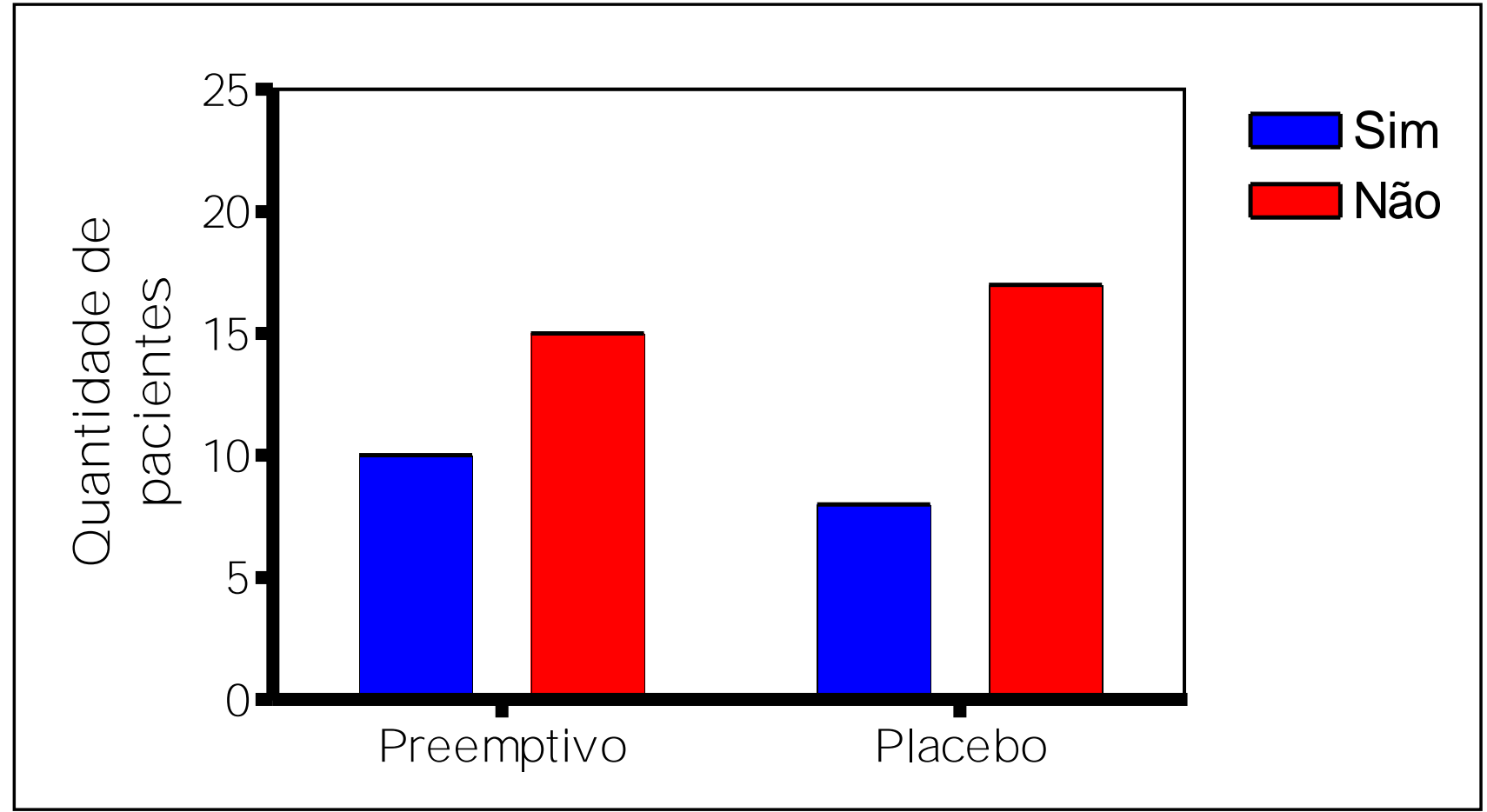

Gráfico 18. Ocorrência de dor referida no ombro direito das pacientes, em algum momento do período pós-operatório, durante a internação hospitalar.

Teste do $\div^{2}$. á $=5 \%$.

Não houve diferença significante entre os grupos $(\mathrm{p}=0,555)$. 
O uso de metoclopramida foi avaliado durante todo o período de internação hospitalar. Cinco pacientes do grupo preemptivo fizeram uso de tal droga, enquanto 8 do grupo placebo a consumiram, não havendo diferença estatística significante entre os grupos (p $=0,333)$, fato verificado pelo teste do $\div^{2}$ (gráfico 19$)$.
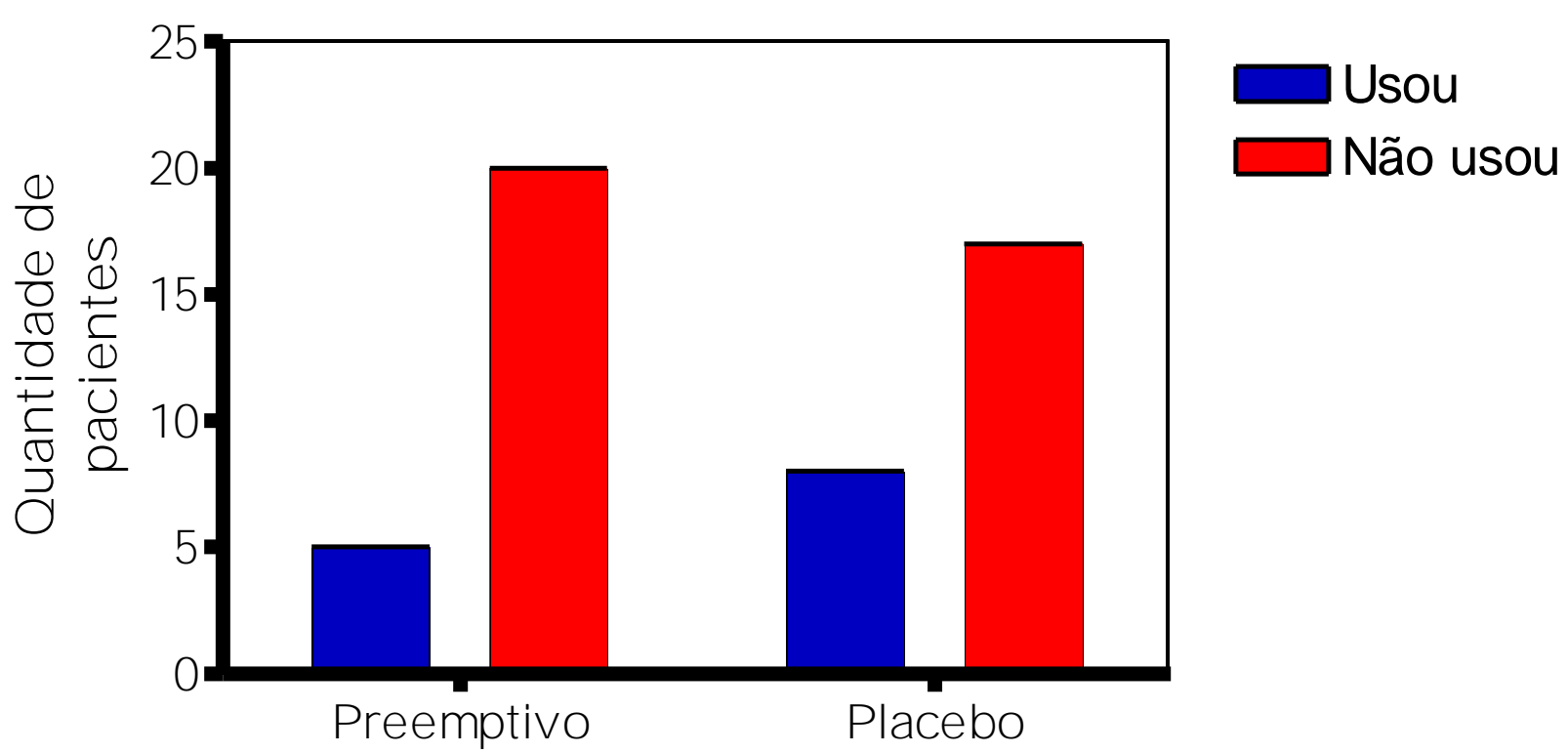

Gráfico 19. Uso de metoclopramida pelas pacientes, durante o período de internação hospitalar.

Teste do $\div^{\circ}$. á $=5 \%$.

Não houve diferença significante entre os grupos $(p=0,333)$. 
Os 2 gráficos seguintes estão relacionados ao questionário que foi aplicado no momento da alta hospitalar. Devido ao fato de o mesmo ter sido elaborado no decorrer da coleta de dados, não foi aplicado em toda a amostra, restringindo-se a 19 pacientes do grupo preemptivo, e a 17 do placebo. Em relação à aplicação da TENS no grupo preemptivo, $26,31 \%$ das pacientes disseram que esta não incomodou; $57,89 \%$, que a mesma incomodou um pouco; e 15,78\% que incomodou razoavelmente. No grupo placebo, 88,24\% relataram que não incomodou; e 11,76\% que incomodou um pouco (gráfico 20). Logo, houve diferença estatística significante entre os grupos, de acordo com o teste do $\div^{2}(p=0,0008)$. No grupo preemptivo, 94,73\% das pacientes relataram que, em uma próxima cirurgia, iriam preferir usar a TENS e os medicamentos analgésicos para o tratamento de suas dores; enquanto apenas $5,26 \%$ fizeram a assertiva de que gostariam de usar apenas a TENS. Das do outro grupo, 76,47\% gostariam de usar os dois recursos; e 23,52\% apenas os medicamentos (gráfico 21); fato que não evidencia, segundo o teste do $\stackrel{2}{\div}(\mathrm{p}=0,057)$, diferença estatística significante entre os grupos.

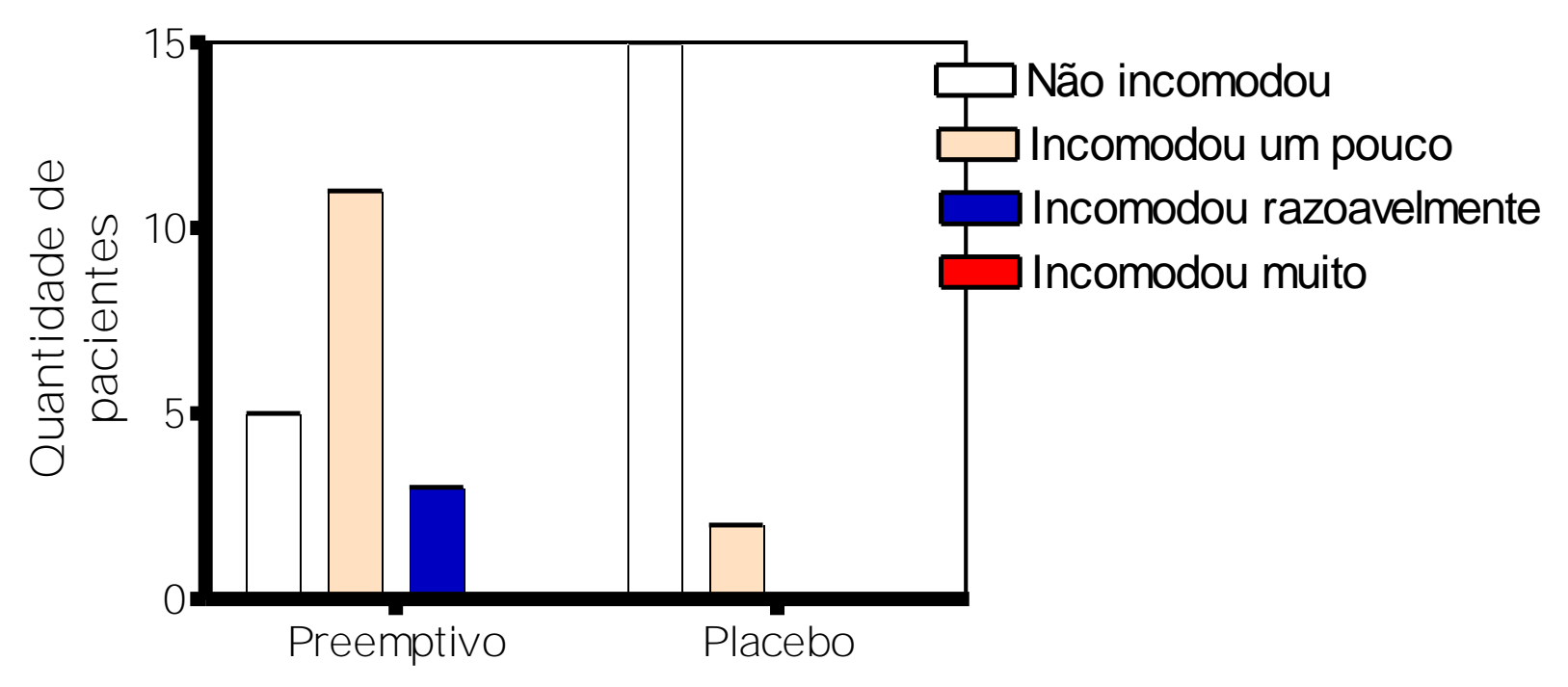

Gráfico 20. A aplicação da TENS:

Teste do $\stackrel{2}{\circ}^{2}$ á $=5 \%$.

Houve diferença estatística significante entre os grupos $(\mathrm{p}=0,0008)$.

Grupo preemptivo $(\mathrm{n}=19)$ e grupo placebo $(\mathrm{n}=17)$. 


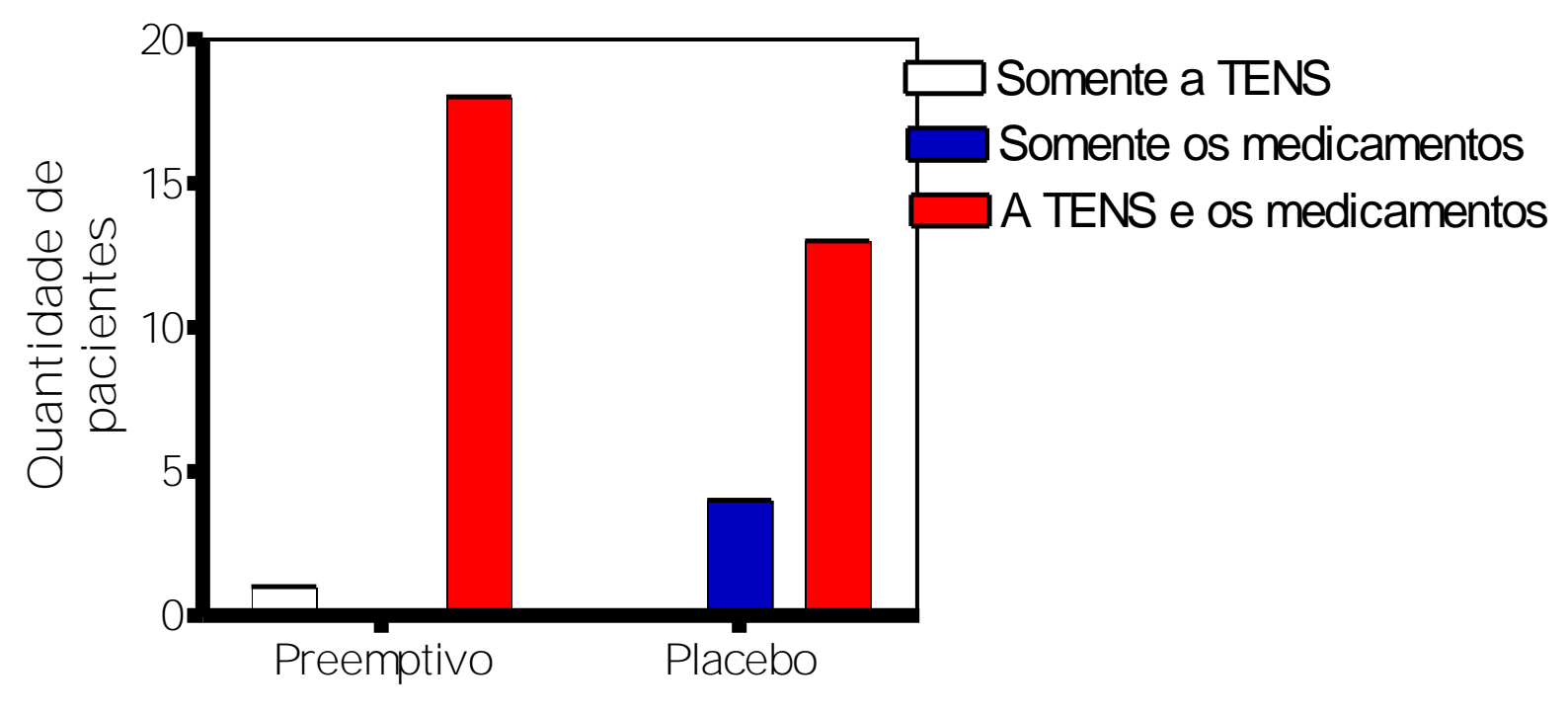

Gráfico 21. Em uma próxima cirurgia você iria preferir, para o tratamento da sua dor pósoperatória, usar:

Teste do $\stackrel{2}{\div}$. á $=5 \%$.

Não houve diferença significante entre os grupos. $(\mathrm{p}=0,057)$.

Grupo preemptivo $(\mathrm{n}=19)$ e grupo placebo $(\mathrm{n}=17)$. 
DISCUSSÃO 


\section{DISC USSÃ 0}

\subsection{Dados Demográficos e Clínicos}

A relevância da homogeneidade, entre os grupos, dos dados referentes à idade, contidos na tabela 1, consiste em evitar a possibilidade de a diferença de idade ter influenciado — dada a divergência de opiniões entre diversos autores - no relato da experiência dolorosa pelas pacientes. Para Wilkieson et al. (1993), a intensidade de dor, obtida a partir do uso de escalas unidimensionais, aumenta com o avançar da idade; para Turk, Okifuji e Scharff (1995), diminui; e para Gagliesi e Melzack (2003) e Sorkin et al. (1990), não sofre influência. Em se tratando do MPQ, Benbow, Cossins e Wiles (1996) verificaram que os índices obtidos a partir desse questionário eram menores em idosos do que em jovens, entretanto Lichtenberg, Swensen e Skehan (1986) não observaram tal diferença. Gagliesi e Melzack (1997) sugerem que as diferenças observadas com a idade podem ser dependentes do tipo de escala utilizada; e o fato de a maioria das escalas terem sido validadas em amostras de pacientes jovens pode também influenciar.

Não houve diferença significante entre os grupos quanto ao IMC, porém três pacientes do grupo preemptivo pertenciam à categoria de obesidade grau I, e duas, obesidade grau II, dados contidos na tabela 2. Como em pacientes obesos há maior impedância para a passagem da corrente elétrica, dada a maior espessura da camada de gordura - que tem menor conteúdo de água —, isso poderia talvez influenciar no efeito da TENS (STARKEY, 2001).

A semelhança quanto ao nível de escolaridade dos grupos, presente na tabela 3, é relevante, pois marcantes diferenças poderiam influenciar na compreensão das escalas e questionários utilizados. 
Não houve diferença estatística significante quanto ao diagnóstico clínico das pacientes, como pôde ser observado na tabela 4. A relevância desse dado reside no próprio conceito de dor que foi elaborado pelo comitê de taxonomia da International Association for the Study of Pain (IASP — Associação Internacional para o Estudo da Dor) em 1986, que a define como "experiência sensorial e emocional desagradável associada ou descrita em termos de lesão tecidual real ou potencial". Caso houvesse diferença quanto ao diagnóstico, isso poderia influenciar, talvez, no relato de dor das pacientes, dada suas diferentes experiências prévias e desiguais períodos em que vinham sofrendo devido à dor (BISSCHOP, G.; BISSCHOP, É.; COMMANDRÉ, 2001; KONRAD; CORDEIRO; COELI, 2001; PIMENTA; TEIXEIRA, 1997, p. 1; SPÓSITO, 1993).

Seguindo a mesma linha de raciocínio, é que se deu destaque ao tempo em que as pacientes relataram estar sentindo dor em decorrência da doença da vesícula biliar ilustrado no gráfico 5. O fato de uma paciente, v.g., estar se queixando de dor há mais de 2 anos e uma outra nunca ter tido tal queixa poderia influenciar na percepção da dor; todavia, a análise estatística possibilitou a verificação de uma amostra homogênea em relação a esse tempo.

Diferenças significantes no escore do estado físico determinado pela ASA podem influenciar na percepção da dor, v.g., pela presença de doenças associadas que não estejam sob controle. Logo, o estabelecimento como critério de inclusão de pacientes que pertencessem somente aos índices I e II, associado à ausência de diferença estatística significante entre os grupos, minimizou a possibilidade de influência na percepção dolorosa (gráfico 6).

Em se tratando do prévio uso de analgésicos para o tratamento da dor decorrente da doença da vesícula ou de outras doenças crônicas, como pôde ser observado no gráfico 7, a ausência de diferença estatística significante mostrou ser homogênea a amostra quanto ao uso 
desse tipo de droga; e a análise sobre o tempo em que as pacientes se queixavam de dor também não mostrou diferença significante (gráfico 5), o que diminui a possibilidade de as pacientes terem vivenciado grandes diferenças em relação às suas experiências dolorosas.

Também não houve diferença significante quanto ao período desde o término da aplicação da TENS até a indução do bloqueio anestésico, dados contidos no gráfico 8. A atenção despendida a esse tempo foi dada em virtude da preocupação de poder haver grande diferença no tempo entre as aplicações da TENS, o que poderia influenciar na concentração de opióides endógenos nos momentos de averiguação da intensidade de dor, sendo um considerável viés.

O fato de as cirurgias terem duração semelhante (gráfico 9) e não ter havido complicação em nenhum procedimento, pode estar eliminando a possibilidade de estas intercorrências influenciarem na transdução do estímulo doloroso - e conseqüentemente nas outras etapas da dor —, dado o maior tempo de manipulação da área cirúrgica. 
5.2 Análise da Dor pela Escala Numérica de Mensuração da Dor

De acordo com Pimenta, Cruz e Santos (1998), os instrumentos para mensuração da dor podem ser de dois tipos: unidimensionais, que consideram apenas uma única dimensão da dor; e multidimensionais, que a mensuram considerando duas ou mais dimensões.

Para Buxton (2001), Pereira e Sousa (1998), Pimenta, Cruz e Santos (1998) e Vetter e Heiner (1996), essa escala é uma das mais utilizadas em pesquisas clínicas e na prática médica diária, tanto pela praticidade de manuseio quanto pela facilidade de compreensão por parte do paciente, podendo ser utilizada várias vezes ao dia. Moiniche, Kehlet e Dahl (2002) e Ong et al. (2005), em seus artigos de revisão sobre analgesia preemptiva, a indicam como o instrumento mais freqüentemente empregado para a mensuração da intensidade de dor (CAMERON, 1999; GRIEVE, 1986; HAMZA et al., 1999; MINISTÉRIO DA SAÚDE DO BRASIL, 2001; PIMENTA; CRUZ; SANTOS, 1998; PIMENTA; TEIXEIRA, 1997; ROBINSON, 2001).

Segundo Huskisson (1983), escalas que aumentam os valores da esquerda para a direita se comportam de forma similar às que o fazem ao contrário, o que justifica o uso da escala da figura 4. A escolha dessa escala, ao invés da analógica visual (VAS), deu-se por exigir menor abstração por parte das pacientes, sendo mais fácil de ser compreendida, uma vez que Gagliesi e Melzack (1997) observaram que cerca de 30\% dos pacientes idosos não conseguem compreender a VAS. Para Ketovuori e Pöntinen (1981), muitos pacientes são incapazes de imaginar a sua dor como um ponto em uma linha reta.

O grupo preemptivo apresentou média de intensidade de dor incisional mais baixa que o placebo — à exceção da primeira observação —, sendo essa diferença estatisticamente significante nas terceira (ENDc) e quarta (ENDd) verificações, que se procederam, respectivamente, $4 \frac{1}{2} \mathrm{~h}$ e $5 \frac{1}{2} \mathrm{~h}$ após a indução do bloqueio anestésico, e cujos valores de $\mathrm{p}$ 
foram iguais a 0,042 e 0,029. Não houve diferença significante, entre os grupos, na primeira (ENDa), segunda (ENDb), quinta (ENDe), sexta (ENDf), sétima (ENDg) e oitava (ENDh) averiguações, que corresponderam a $2 \frac{1}{2} \mathrm{~h}, 3^{1 / 2} \mathrm{~h}, 7 \mathrm{~h}, 8 \mathrm{~h}$ e $16 \mathrm{~h}$ após a indução do bloqueio anestésico e momento da alta hospitalar, respectivamente. Nessas coletas, os valores de $\mathrm{p}$ foram, respectivamente, iguais a 0,$756 ; 0,171 ; 0,068 ; 0,135 ; 0,497$ e 0,145 . Todos esses dados estão contidos na tabela 5.

Nas 2 primeiras averiguações da intensidade de dor pela END, verificou-se pequenos níveis álgicos em ambos os grupos, fato que ocorreu devido à ação das drogas anestésicas - cloridrato de bupivacaína $(0,5 \%)$ e fentanil $(2 \mathrm{ml})$ - utilizadas para a realização dos procedimentos cirúrgicos, e que, quando associadas, proporcionam potencialização do efeito analgésico no pós-operatório. De acordo com Dierking et al. (1992), Pontes e Prado (2002) e Prado e Oliveira (2000), o bloqueio anestésico ocasiona depleção da sensação dolorosa, o que justifica esses diminutos níveis álgicos nessas coletas.

A conjunção do anestésico ao opióide é recomendada por Castillo [1999?], que observou, por meio da VAS, menores índices de dor nos pacientes que fizeram uso conjugado dessas duas drogas em comparação àqueles em que somente fora administrado o cloridrato de bupivacaína. Além da diminuição do quadro álgico, a sua associação possibilita menor administração de anestésicos, melhor qualidade anestésica no intra-operatório e redução da necessidade do uso de fármacos analgésicos no período pós-operatório.

À medida que houve um distanciamento em relação ao horário da indução do bloqueio anestésico, as drogas utilizadas para a realização do ato cirúrgico começaram a diminuir seu poder de ação. O cloridrato de bupivacaína — anestésico — tem uma meia-vida de aproximadamente 3 horas, e o seu efeito perdura por cerca de 4 a 5 h (RANG; DALE, 1993). 
Assim, o cloridrato de bupivacaína, em associação ao fentanil, contribuiu para que não houvesse diferença significante entre os níveis de dor incisional nas 2 primeiras coletas, o que está em concordância com outra pesquisa já realizada pelo nosso grupo em colecistectomias por laparotomia, em que Santos et al. (2004), com a mesma padronização de drogas e horários de averiguação dos níveis de dor, não observaram tal diferença, nesses momentos, entre os grupos experimental - que fazia uso da TENS de alta e baixa freqüências somente no pós-operatório - e placebo.

Isso está em concordância também com Ke et al. (1998) que, nas primeiras 4 h após a realização de laparotomias, não verificaram diferença significante nos níveis álgicos entre os grupos de pacientes que foram utilizados para a análise do efeito analgésico preemptivo do cloridrato de bupivacaína, quando aplicado pelo método de infiltração incisional.

A média de intensidade de dor do grupo preemptivo foi, a partir da ENDb, inferior à do placebo. Tal fato pode ter ocorrido devido à prévia aplicação da TENS de baixa freqüência, que pode ter estimulado a liberação de opióides endógenos, potencializando a analgesia no período pós-operatório, ao ativar o sistema descendente de controle da dor. O fato de isso não ter ocorrido na primeira investigação deve ser atribuído à ação das drogas anestésicas - como já citado anteriormente. Ademais, ao analisar a diferença estatística entre os dois grupos nessa coleta, percebe-se que esse foi o momento em que houve a menor diferença estatística, pois o valor de p foi igual a 0,756 , e as médias de 0,84 $\pm 0,34$ e 0,72 \pm 0,29 nos grupos preemptivo e placebo, respectivamente.

Quando ocorreu a transição entre a segunda (ENDb) e terceira (ENDc) verificações, o efeito do cloridrato de bupivacaína possivelmente já estava cessando, o que explicou o aumento mais acentuado do nível de dor no grupo placebo, já que provavelmente somente o fentanil estava agindo; contudo, essa grande elevação não foi observada no grupo preemptivo, o que permite a assertiva de que tenha havido, talvez, uma potencialização do efeito 
analgésico pela associação do fentanil à TENS de baixa freqüência - que estimula a liberação de opióides endógenos tanto em nível espinhal, quanto supra-espinhal -, aumentando, assim, ainda mais as concentrações de opióides. As terceira (ENDc) e quarta (ENDd) verificações foram justamente os momentos em que houve diferença estatística significante entre os dois grupos, pois as médias de intensidade de dor foram respectivamente iguais a 2,02 $\pm 0,53$ e 2,78 $\pm 0,56$ no grupo preemptivo, e $3,84 \pm 0,66$ e 4,8 $\pm 0,67$, no placebo; sendo os valores de p iguais a 0,042 e 0,029, respectivamente.

A quinta verificação (ENDe) foi o momento em que, embora não tenha havido diferença estatística significante, os valores se aproximaram bastante de tal possibilidade, visto que o valor de $\mathrm{p}<0,1$. A relevância desse momento consiste em ser o ponto a partir do qual a diferença entre os níveis de dor dos grupos diminui progressivamente, até a sétima observação (ENDg). Isso incita a assertiva de que o efeito da TENS, aplicada como método analgésico preemptivo, possivelmente seria mais evidente nas primeiras horas após o bloqueio anestésico, e seria interessante realizar aplicações da TENS também no período pós-operatório, para a obtenção de um melhor efeito analgésico, tendo como base os dados da pesquisa de Santos et al. (2004). Alguns autores sugerem que o efeito da TENS poder-seia estender por 2 a 6 h, dependendo das atividades de vida diária, posturas e níveis de dor; contudo, outros relatam um efeito ainda mais duradouro (CRÉPON, 1996; DAMIANE, C.; DAMIANE, G., 1998; SALGADO, 1999).

Esses achados estão em concordância com a maioria dos estudos, os quais revelam que a analgesia preemptiva ocorreria nas 6 primeiras horas pós-cirúrgicas; apesar de algumas pesquisas sugerirem que ela promoveria um longo tempo de analgesia que poderia perdurar por até 7 a 10 dias pós-operatórios (BRIDENBAUGH, 1994; ROSAEG et al., 2001). 
O nível álgico mais elevado do grupo placebo ocorreu na sexta (ENDf) investigação, com média igual a 4,88 \pm 0,66. Já no grupo preemptivo, o maior índice de dor foi observado na sétima verificação (ENDg), cuja média foi igual a 3,56 \pm 0,61. Esses dados sugerem que a TENS possa, talvez, ter aumentando o período de latência da dor.

Após o efeito das drogas anestésicas, em ambos os grupos, a menor média de intensidade de dor ocorreu na última coleta (ENDh), sendo de 0,96 \pm 0,33 para o preemptivo, e 1,76 \pm 0,42 para o placebo. Isso demonstra que, ao passo em que o processo inflamatório decorrente do trauma cirúrgico vai diminuindo, há, conseqüentemente, redução dos níveis álgicos; e que os maiores níveis de dor do grupo placebo em relação ao preemptivo podem ter sido responsáveis por promoverem maior memorização da dor, contribuindo, assim, para que mesmo 2 dias após a operação, as pacientes do grupo placebo ainda exibissem um maior quadro álgico, embora não diferente sob o ponto de vista estatístico. Logo, a eletroanalgesia preemptiva pode também estar influenciando na qualidade de remissão da dor.

Ao conjuminar esses dados, podemos inferir que o grupo preemptivo, em todos os momentos de análise da intensidade de dor, apresentou níveis leves; ao passo que o placebo chegou a atingir níveis moderados em 3 verificações (ENDd, ENDe, ENDf). Isso demonstra que as pacientes do grupo placebo não obtiveram analgesia tão satisfatória quanto as do outro grupo. É importante ressaltar que a colecistectomia por laparotomia gera um nível de dor severo no pós-operatório, e que esse só não deve ter sido atingido em nenhum dos grupos porque a dipirona — antiinflamatório não-esteroidal — estava sendo administrada de 6 em 6 horas.

No gráfico 10, é possível perceber que houve, no grupo preemptivo, uma ascensão do nível de dor menos íngreme que a do placebo nas primeiras coletas. Esse achado parece estar em concordância com a proposta de Melo e Santana Filho (2003) de aplicar a TENS em período pré-operatório para minimizar os picos álgicos no pós-operatório de hernioplastias 
inguinais, pois, apesar de eles terem obtido satisfatória analgesia com o seu uso no pósoperatório, verificaram que havia picos dolorosos assim que ocorria o término do efeito anestésico, e que os mesmos poderiam, talvez, serem atenuados com a aplicação da TENS antes do ato cirúrgico.

Essa atenuação do pico álgico, obtida com a aplicação da TENS já no período préoperatório, pode ser realmente observada ao confrontamos os nossos resultados com os de Santos et al. (2004) — trabalho já citado anteriormente —, tendo em vista que percebemos que, nas quinta e sexta coletas, as médias de intensidade de dor do grupo preemptivo [pertencente ao nosso trabalho] foram inferiores às do experimental [pertencente à pesquisa de Santos et al. (2004)], que tiveram valores de 3,79 $\pm 2,84$ e 3,70 $\pm 3,29$, respectivamente, o que pode ter decorrido do fato de a TENS ter promovido um efeito anti-nociceptivo. Mariano e Ben (1998) obtiveram resultados satisfatórios também com a aplicação da TENS no pósoperatório de colecistectomias, no entanto, não podemos comparar diretamente os resultados devido às diferenças de métodos empregados.

Não estão expressas, na literatura pesquisada, publicações sobre analgesia preemptiva induzida pela TENS em humanos, apenas trabalhos com a utilização de drogas e eletroacupuntura com esse propósito, e que tiveram início, principalmente, a partir da década passada. Dessa forma, a nossa discussão será sempre cotejada às pesquisas envolvendo esses dois recursos de forma preemptiva, tal como trabalhos que empregaram a TENS no pósoperatório.

Apenas um trabalho, realizado por Javier et al. (1999), sobre o uso da TENS como recurso analgésico preemptivo, foi encontrado na literatura pesquisada, entretanto, foi procedido em ratos. Eles observaram que a TENS, mormente em sua modalidade de baixa freqüência, proporcionou efeito anti-nociceptivo em procedimentos cirúrgicos realizados nesses animais, o que corrobora nossos achados. Mesmo sendo aplicados a espécies 
diferentes, o trabalho de Javier et al. (1999) e o nosso estão em concordância pois ambos obtiveram analgesia preemptiva com a aplicação da TENS de baixa freqüência.

Muito embora tenha sido empregado método diferenciado, analgesia preemptiva também foi obtida por Kotani et al. (2001) com o uso da eletroacupuntura antes de cirurgias abdominais altas e baixas, sendo verificados, pela VAS, menores níveis de dor nos pacientes em que foi aplicada a eletroestimulação, em relação aos do grupo controle - não submetidos à corrente elétrica.

A grande importância em confrontar os resultados da nossa pesquisa com os de Kotani et al. (2001) baseia-se no similar mecanismo de ação da eletroacupuntura e da TENS de baixa frequiência que se daria pelo aumento dos níveis de opióides endógenos, que agiriam, ambos, em receptores $\mu$-opióides (CHEN; HAN, 1992; HAN et al., 1986). Contudo, Zhou e Xi (1986) observaram, em coelhos, que a naloxona antagonizou parcialmente o efeito da eletroacupuntura, mas não o da TENS de baixa freqüência.

A administração de fármacos analgésicos em período pré-operatório proporcionou bons resultados na diminuição do quadro álgico em algumas pesquisas, v.g., Pontes e Prado (2002), analisando o uso do cetoprofeno antes da realização de incisões plantares em ratos, verificaram satisfatório efeito anti-nociceptivo dessa droga; Ke et al. (1998) observaram em laparotomias - menor índice de dor (mensurado pelo MPQ) no grupo de pacientes em que a bupivacaína fora administrada antes da cirurgia, quando comparado ao dos outros dois grupos: pacientes em que ela foi administrada após a cirurgia e aqueles que receberam apenas solução salina. Diversos outros autores também relatam sobre os bons resultados obtidos com a analgesia preemptiva (AIDA et al., 1999; GOTTSCHALK; OCHROCH, 2003; KE; PORTERA; LINCOLN, 1998; LEE, I-H.; LEE, I-O., 2005; WALL, 1988). Na revisão sistemática de Ong et al. (2005), analisando 66 artigos, a analgesia peridural com opióides destacou-se por ser a técnica mais eficiente para promover analgesia preemptiva, conclusão 
também obtida por Moiniche, Kehlet e Dahl (2002).

Na literatura, existem pesquisas, principalmente com a utilização de fármacos, em que não se obteve analgesia preemptiva. Pontes e Prado (2002), e.g., não promoveram analgesia preemptiva com o uso de dipirona, morfina e diclofenaco antes da realização de incisões plantares em ratos; e, de acordo com esses autores, em outra pesquisa, a infiltração pré-cirúrgica de anestésico local não exerceu influência nos níveis álgicos nem de pacientes submetidos a colecistectomias, nem herniorrafias. Assim como esses, muitos outros estudos também obtiveram resultados negativos; e, naqueles em que foi observada analgesia preemptiva, a mesma ocorreu em pequena magnitude (KISSIN, 1994, 2000, 2002; MAESTRONI et al., 2002; ONG et al., 2005; SINATRA, 2002; WOOLF; CHONG, 1993). Entretanto, os bons resultados já obtidos, tanto clínicos quanto experimentais, são provavelmente suficientes para indicar que a analgesia preemptiva é um fenômeno válido e que um maior efeito poderá ser obtido com o desenvolvimento de novas e mais específicas técnicas (KISSIN, 2000, 2002).

As pesquisas têm restringido o uso da TENS, em humanos, apenas ao período póscirúrgico. Os resultados, na sua grande maioria, têm demonstrado gratificante alívio do quadro álgico, sobretudo naqueles procedimentos em que a dor gerada tem intensidade de leve a moderada.

Guerra et al. (2003) verificaram menores níveis álgicos, por meio da END, nos pacientes que foram submetidos à aplicação da TENS no pós-operatório de hernioplastia inguinal, em relação aos que não o foram; assim como Chiu et al. (1999), em hemorroidectomias; Chen et al. (1998), em histerectomia abdominal total e miomectomia; Carrol et al. (1996), em 786 pacientes submetidos a diversos procedimentos cirúrgicos; Castro e Carlos (1986), em laparotomias, com 22\% de redução da queixa de dor, sendo os melhores resultados obtidos nas histerectomias e os piores, nas gastrectomias; o que pode ser atribuído, 
talvez, ao fato de a gastrectomia ser um procedimento cirúrgico abdominal alto e ocasionar, então, maiores níveis de dor.

Os nossos resultados não podem ser diretamente confrontados aos dessas pesquisas, tendo em vista o grande número de variáveis existentes, destacando-se o diferente modelo de dor que cada procedimento cirúrgico ocasiona e o fato de a TENS ter sido empregada sempre após as cirurgias. O que se pode e deve ser discutido é que, talvez, os resultados das pesquisas em que a TENS foi bem sucedida como recurso analgésico pudessem ser ainda melhores caso a tivessem empregado também antes das cirurgias; e os das que não obtiveram sucesso com a TENS, pudessem ter tido com essa prévia aplicação, pois as respostas analgésicas poderiam ser potencializadas.

A maior concentração de opióides endógenos após a aplicação da TENS de baixa frequiência é relatada por diversos autores (JOHNSON; ASHTON; THOMPSOM, 1991; MERKEL; GUSTEIN; MALVIYA, 1999; SLUKA; WALSH, 2003; THOMSON; SKINNER; PIERCY, 1994; TOYOTA; STATAKE; AMAKI, 1999). Eriksson, Sjolund e Neilzen (1979) e Salar, Job e Mingrino (1981) demonstraram um aumento da concentração de opióides no liquor lombar, após a TENS. De acordo com Starkey (2001), essa modalidade de corrente elétrica estimularia a glândula hipófise a liberar ACTH e â-lipotropina (molécula precursora da â-endorfina) na corrente sangüínea. Crielaard et al. ([s.d.] apud TRIBIOLI, 2003) observaram amento de $22 \%$ da taxa de â-endorfina após aplicação da TENS de baixa freqüência, com intensidade elevada a ponto de produzir contração muscular ritmada, na região lombar de pacientes. Entretanto, O’Brien et al. (1984 apud TRIBIOLI, 2003) não verificaram incremento dos níveis de â-endorfina no sangue após aplicação da TENS — tanto de baixa freqüência $(2 \mathrm{~Hz})$, quanto de alta $(80 \mathrm{~Hz})$. 
Chandran e Sluka (2003) observaram, assim como Chen e Han (1992), Kalra, Urban e Sluka (2001), King e Sluka (2001), Sluka et al. (1999) e Sluka et al. (2000), que a TENS de baixa freqüência estimulava a liberação de opióides que agiam sobre os receptores $\mu$, localizados tanto em nível espinhal $(\mu 2)$, quanto supra-espinhal $(\mu 1)$, fato ratificado por Han et al. (1991), que observaram que a endomorfina-1, ligante opíoide para os receptores $\mu$ opióides, mediava o efeito dessa modalidade de TENS. Em alguns desses estudos, concluiuse que a ação da TENS se dava sobre esse tipo de receptor, ao conseguir inibir o seu efeito pela prévia administração de baixas doses de naloxona - antagonista desses receptores. Hansson et al. (1986), Lundeberg, Bondesson e Lundstron (1985) e Olausson et al. (1986) verificaram que a TENS de baixa freqüência não foi eficiente na redução da dor nos pacientes em que foi previamente administrada a naloxona.

Apesar de a maioria dos autores apontar a ação da TENS de baixa freqüência como sendo sobre os receptores $\mu$-opióides, Chen e Han (1992) observaram que ela também agiria sobre os receptores ä-opióides. Outros autores, como Han et al. (1991) e Hughes et al. (1984), também relataram sobre um aumento da concentração de â-endorfina na circulação sangüínea de indivíduos saudáveis, após aplicação da TENS de baixa ou alta freqüências; e, no liquor lombar, concentrações elevadas de metionina-encefalina (agonista ä-opióide) e dinorfina A (agonista ê-opióide) após aplicação da TENS de alta e baixa frequiência, respectivamente. Para Basford (1994), seria mais evidente a liberação de opióides com a aplicação da TENS de baixa frequiência.

Algumas controvérsias quanto ao uso da TENS ainda persistem: a) se haveria liberação de outras substâncias capazes de modular a dor; b) se sujeitos com e sem dor diferem na resposta à estimulação; c) e, caso sejam liberados neurotransmissores para a modulação da dor, quais seriam os parâmetros de estimulação mais efetivos para tal (BASFORD, 1994). 
A eletroanalgesia preemptiva pode ter sido obtida, nessa pesquisa, por meio da inibição, pela TENS, da hipersensibilidade central, o que está em concordância com a assertiva de King e Sluka (2001) e Sluka (2000) de que a TENS de baixa freqüência reduz significantemente a hiperalgesia secundária, porém não tem efeito sobre a primária. 
5.3 Análise da Satisfação das Pacientes com o Tratamento

No grupo preemptivo, a média de satisfação das pacientes com o tratamento que estava sendo realizado, obtida a partir dos dados coletados com o uso da Escala de Satisfação do Paciente (ESP), foi sempre superior à do placebo em todos os momentos de coleta, entretanto, não houve, em nenhuma das verificações, diferença estatística significante entre os grupos, como pôde ser evidenciado na tabela 6. O intuito de aplicar tal escala foi tentar observar se haveria um grau de satisfação significantemente mais elevado no grupo preemptivo em relação ao placebo, tendo em vista o papel da dor como fator de grande influência na qualidade do tratamento pós-operatório. Porém, isso não ocorreu nem na ESPd, verificação que coincidia com o horário da ENDd, em que houve nível de dor significantemente menor no grupo preemptivo.

Rosaeg et al. (2001) relatam sobre a ausência de correlação entre a analgesia preemptiva e o grau de satisfação dos pacientes. Isso ocorreria porquanto diversos fatores, além da dor pós-operatória, contribuem para determinar o grau de satisfação dos pacientes. Nos dois grupos, os níveis de satisfação sempre se mostraram bastante elevados. Levando-se em consideração que todas as pacientes que participaram da presente pesquisa foram assistidas pelo SUS e que, comumente — até por fatores culturais —, estão mais habituadas a um "frio" relacionamento profissional de saúde-paciente, esse alto grau de satisfação talvez possa ter sido atribuído à intensa assistência dada aos dois grupos dês o período pré-cirúrgico, em que foram fornecidas informações a respeito da cirurgia que seria realizada, da dor incisional - e porventura, visceral —, do tratamento proposto, dos métodos de mensuração da dor, bem assim orientações para que as mesmas evitassem falar após a cirurgia porque não se acumulassem gases; até o momento da alta hospitalar, com os questionamentos sobre os níveis álgicos. Além disso, as pacientes podem ter se sentido constrangidas ou terem 
apresentado receio em relatar sobre a sua real satisfação, podendo supor que isso viria a influenciar nos cuidados que a equipe médica estaria despendendo para as mesmas (BARROS, 2001; JACHUCK, 1982).

Caso tivesse sido realizada a coleta da ESP em todos os horários da END, talvez fosse possível observar diferença significante entre os grupos em algum momento. Entanto, preferiu-se realizar 5 averiguações da ESP, aos invés de 8, com o intuito de não somente abordar as pacientes um menor número de vezes, perturbando-as, dessa forma, um pouco menos; como também minimizar a possibilidade de elas confundirem as duas escalas, logo que ambas são constituídas de números, embora uma seja aplicada por meio de uma régua e a outra de forma verbal, o que, em princípio, diminuiria a possibilidade de confusão.

Em ambos os grupos, a coleta em que houve a maior média de satisfação com o tratamento foi a última, sendo os valores, nos grupos preemptivo e placebo, respectivamente, de 9,92 \pm 0,05 e 9,33 \pm 0,35. Esses dados, ao serem confrontados com os da END nesse horário de coleta, mostram que o maior grau de satisfação, após o pico álgico, deu-se justamente no momento em que as pacientes estavam sentido uma menor intensidade de dor.

Diferentemente dos nossos achados, o uso da TENS no pós-operatório de hernioplastia inguinal promoveu médias de satisfação com o tratamento — também mensurada pela ESP — significantemente superiores às do grupo placebo (MELO; SANTANA FILHO, 2003).

Em pesquisa realizada por Hamza et al. (1999), em cirurgias abdominais baixas, observou-se também maior satisfação por parte dos pacientes que usaram a TENS de baixa freqüência no pós-operatório, visto que $76 \%$ desses pacientes apresentaram alto grau de satisfação com o emprego de tal aparato para o controle da dor pós-cirúrgica; enquanto apenas 24\% dos pacientes do grupo placebo apresentaram tal grau de satisfação. 


\subsection{Análise da Dor pelo Questionário de Dor McGill}

A linguagem da dor, repetidamente enfatizada por Merskey (1980), fornece relevantes indícios sobre o sofrimento e a dor das pessoas. Melzack (1975) desenvolveu um método sistemático que incorporou descritores verbais para a expressão da dor, o MPQ, que se tornou o instrumento de pesquisa mais empregado no mundo para a mensuração das propriedades multidimensionais da dor, abordando os componentes sensoriais, afetivos e de intensidade, segundo Fernandez e Boyle (2001) e Fernandez e Towery (1996).

O MPQ adaptado foi utilizado apenas uma vez - 16 h após a indução do bloqueio anestésico — no primeiro dia pós-operatório. A opção por tal horário deu-se a partir da experiência obtida no estudo piloto, em que o mesmo era administrado 7 h após a indução do bloqueio. A dificuldade para conseguir a atenção e concentração das pacientes, condições essenciais para responder de forma adequada ao mesmo, foi muito grande, fato que pode ser atribuído ao relato de cansaço por parte das pacientes, porquanto as mesmas eram submetidas ao procedimento cirúrgico em torno das 16:00, e assim o MPQ no estudo piloto era aplicado aproximadamente às 23:00, momento em que elas normalmente estavam dormindo, ou então tentando dormir, mas relatando grande desconforto, que pôde ser observado não apenas por meio de avaliação clínica durante a coleta de dados, como também pelos níveis álgicos nesse período, mensurados pela END, e contidos na tabela 5.

Apesar de alguns pesquisadores utilizarem o MPQ para a mensuração de dores passadas, e relatarem que o mesmo possa ser usado para a análise de dores de até uma semana atrás; optou-se, para evitar maiores vieses, por usá-lo para mensurar a dor incisional que a paciente estava relatando naquele momento, pois muitos pacientes apresentam dificuldade em abstrair e sumariar experiências dolorosas passadas (PIMENTA; TEIXEIRA, 1997). Para 
isso, elas eram instruídas a respondê-lo com base na dor que estavam vivenciando naquele momento.

De acordo com Melzack (1975), esse instrumento somente deve ser aplicado para os pacientes que estejam relatando dor. Em virtude disso, não foram utilizados, para a realização da análise estatística dos índices do MPQ, os dados das 50 pacientes, mas os de 41 (21 do grupo preemptivo e 20 do placebo), pois 9 pacientes estavam relatando nível de dor igual a zero, mensurado pela END, no momento da aplicação do MPQ.

Veilleux e Melzack (1976) relatam que o MPQ é suficientemente sensível para detectar diferenças entre métodos de tratamento da dor e proporciona informações a respeito do efeito de determinada terapia antálgica sobre as dimensões sensorial, afetiva e avaliativa da dor. Optou-se pela não utilização da forma reduzida do MPQ, dado o pequeno número de descritores, e cujos significados estão mais freqüentemente relacionadas à dor crônica do que à aguda (MELZACK, 1987).

A utilização do MPQ foi relevante porque esse instrumento, multidimensional, fornece informações mais ricas sobre a experiência dolorosa - envolvendo também componentes psicológicos e emocionais —, não se limitando apenas à mensuração da intensidade de dor, como o são a END, VAS, de fácies, e tantas outras. Para Prieto e Geisinger (1983), apesar de a intensidade global da dor ser importante condição para compreender a experiência dolorosa, medidas que refletem apenas essa característica são insensíveis a variações nos diferentes aspectos qualitativos da dor (KELLY; AHMAD; BRULL, 2001).

A categoria sensorial refere-se às propriedades mecânicas, térmicas, temporais e espaciais da dor; a afetiva-motivacional, à dimensão afetiva nos aspectos de tensão, medo e propriedades autonômicas; a avaliativa possibilita que o paciente expresse uma avaliação global da sua experiência dolorosa; e a miscelânea, que engloba descritores das outras 
categorias, não se refere a nenhuma propriedade específica (KETOVUORI; PÖNTINEN, 1981; MELZACK, 1975; PIMENTA; TEIXEIRA, 1997; TEIXEIRA et al., 1999).

A partir da sua utilização, pudemos obter o Índice do Número de Palavras Escolhidas (NWC) e o Índice Quantitativo da Dor (PRI). O gráfico 12 apresenta a comparação do NWC total, obtido por meio da soma do número de descritores selecionados pelas pacientes nas 4 categorias que compõem o MPQ, entre os grupos preemptivo e placebo, assim como o NWC em cada categoria do MPQ (tabela 10). De acordo com Pimenta e Teixeira (1997), quanto maior o valor do NWC, maior também será o nível de dor dos pacientes.

É possível observar que não houve diferença significante quanto ao NWC total entre os grupos, haja vista que o valor de $\mathrm{p}$ foi igual a 0,937 , tendo o grupo preemptivo selecionado em média 15,62 \pm 0,61 palavras; e o placebo, 15,40 \pm 0,84. Vale ressaltar que o máximo valor possível do NWC total é 20, pois cada paciente não pode escolher mais do que um descritor em cada subcategoria.

O grupo preemptivo selecionou em média $3,71 \pm 0,25$ e 2,76 $\pm 0,18$ descritores nas categorias afetiva e miscelânea, respectivamente; e o placebo, 3,75 $\pm 0,20$ e 3,15 $\pm 0,21$. Na categoria sensorial, diferentemente dessas duas, o grupo preemptivo $(8,19 \pm 0,38)$ selecionou mais palavras que o placebo $(7,65 \pm 0,50)$. Na avaliativa, ambos os grupos selecionaram em média uma palavra. É importante ressaltar que em nenhum desses índices houve diferença significante, o que já era esperado, pois o NWC não é eficiente para mostrar o malogro ou sucesso de uma terapia analgésica para um alívio parcial da dor. De acordo com Melzack (1975), o paciente que tem um alívio parcial da dor, não necessariamente deveria ter um menor NWC, pois haveria uma tendência em selecionar um descritor que indicasse um menor índice de dor, mas não a recusa por parte desse paciente em selecionar determinada subcategoria. Dessa forma, apenas o PRI poderia apresentar variação. 
Apesar de não ter havido diferença significante, a maior utilização — em termos proporcionais - dos descritores da categoria sensorial em relação aos da afetiva, conforme foi observada na tabela 11, em ambos os grupos, está de acordo com Pimenta (1995), Reading (1983) e Teixeira et al. (1999), que verificaram que os pacientes que sofriam de dores agudas tinham preferência por tais descritores; enquanto aqueles que padeciam de dor crônica, pelos da afetiva. Todavia, talvez exista uma tendência maior para a escolha dos descritores da categoria sensorial, pois a mesma engloba 53,9\% (42 palavras) dos descritores do MPQ, enquanto que a afetiva, 17,9\% (14 palavras). Portanto, a categoria sensorial apresenta o triplo de descritores da afetiva, apesar de possuir somente o dobro de subcategorias.

É interessante observar a importância da categoria avaliativa (16 ${ }^{\mathrm{a}}$ subcategoria), pois todas as pacientes a utilizaram para selecionar um descritor (tabela 8). Melzack (1975) descreveu que $95 \%$ dos 248 pacientes — de diversas doenças — analisados em seu estudo selecionaram um descritor dessa categoria, o que está em concordância com nossos dados. Outras subcategorias muito utilizadas foram a $9^{\mathrm{a}}, 11^{\mathrm{a}}, 12^{\mathrm{a}}$ e $20^{\mathrm{a}}$. De forma inversa, a $19^{\mathrm{a}}$ subcategoria foi a menos selecionada (4 pacientes do grupo preemptivo e 8 do placebo), o que é justificado por se tratarem de descritores que abordam os aspectos relacionados à sensação de frio, sendo mais freqüentemente utilizados para a descrição de dores de dente, de acordo com Gagliesi e Melzack (2003) e Melzack (1975).

Em ambos os grupos, os descritores mais selecionados foram "cansativa" e “enjoada", que pertencem à categoria afetiva. 80,95\% das pacientes do grupo preemptivo selecionaram esses descritores, e $90 \%$ das do placebo assim o fizeram. Na categoria sensorial, ambos os grupos selecionaram mais freqüentemente o descritor "fina": 71,42\% das pacientes do grupo preemptivo e $75 \%$ das do placebo. Na miscelânea, $55 \%$ das pacientes do grupo placebo optaram mais comumente pelos descritores "espalha" e "repuxa", e 52,38\% das do preemptivo, por "repuxa" e "aborrecida". 
Ao considerar os descritores mais apropriados para caracterizar a dor incisional nessa pesquisa (tabela 9) - considerados por Gagliesi e Melzack (2003) como aqueles que tenham sido selecionados por pelo menos $33 \%$ dos pacientes - , os que foram escolhidos de forma comum aos dois grupos foram: na categoria sensorial (latejante, pontada, fina, queimação, ardor e dolorida); afetiva (cansativa e enjoada); avaliativa (que incomoda); e na miscelânea (repuxa e aborrecida). Houve diferença significante, entre os dois grupos, na freqüência de seleção dos descritores "esticada", da 10a subcategoria, e "espalha", da $17^{\mathrm{a}}$ subcategoria, que é justificada pelo fato de, na $10^{\text {a }}$ subcategoria, das 19 pacientes do grupo preemptivo que a utilizaram, 13 selecionaram o descritor "esticada"; e, das 13 do grupo placebo, apenas 5. Em se tratando da $17^{\text {a }}$ subcategoria, apenas 3 das 13 pacientes que indicaram essa subcategoria selecionaram o descritor "espalha"; enquanto 11 do grupo placebo o selecionou, das 17 que optaram por tal subcategoria.

No gráfico 13, há a comparação do PRI total, obtido pela soma dos valores que são atribuídos a cada descritor escolhido pelas pacientes nas 4 categorias do MPQ — podendo atingir um máximo valor de 78 — , entre os dois grupos; assim como do PRI para cada uma das categorias do MPQ. Para Pimenta e Teixeira (1997), quanto maior o valor desse índice, maior a percepção dolorosa das pacientes. Não houve diferença significante quanto ao PRI total, assim como para as categorias sensorial, afetiva e miscelânea. O grupo preemptivo apresentou PRI total igual a $32,74 \pm 1,63$ e o placebo, $32,45 \pm 2,08$. A categoria avaliativa foi a única em que houve diferença significante entre os grupos, pois o PRI do grupo preemptivo foi igual a $3 \pm 0,28$ e o do placebo, a 2,05 $\pm 0,22$, sendo o valor de p igual a 0,019

A ausência de diferença estatística significante entre os dois grupos, tanto no NWC total, quanto no PRI total, está em concordância com os resultados obtidos pela ENDg, 16 h após a indução do bloqueio anestésico, pois em nenhum desses índices houve diferença significante entre os grupos. 
Apesar das dificuldades existentes — tempo de aplicação e compreensão de alguns descritores pelas pacientes —, a aplicação desse questionário possibilitou ao investigador uma experiência muito produtiva, pois permitiu a visualização da satisfação — seja por palavras ou expressões faciais - da maioria das pacientes em encontrar palavras que as auxiliassem a transmitir sua experiência dolorosa. Em pesquisa realizada por Pimenta e Teixeira (1997), 96\% dos pacientes disseram que o MPQ ajudou, ou ajudou muito, na descrição de seu quadro doloroso.

Os dados obtidos a partir do MPQ, infelizmente, tornam-se um pouco limitados para a comparação com outras pesquisas, dadas as diferenças da língua. Esse é um dos motivos pelos quais as escalas unidimensionais são mundialmente mais usadas, possibilitando o cotejo dos resultados obtidos em diferentes países e línguas.

Sabe-se que os aspectos econômicos, culturais e sociais têm influência sobre o relato da dor pelos pacientes - embora em menor magnitude nas dores de caráter agudo, v.g., a pós-operatória, do que nas de caráter crônico, segundo Pimenta e Teixeira (1997) —, mas Katz e Melzack (1999) e Melzack (1975) demonstraram que o MPQ possui elevado nível de fidedignidade e transcende a tais diferenças, talvez por ter sido elaborado com base no referencial teórico sobre a fisiologia da dor. No Brasil, 95\% dos entrevistados em uma pesquisa disseram ser capazes de compreender o inventário sem grande dificuldade, mas os estudos não avaliam a magnitude dessa dificuldade, mormente quando se trata de indivíduos de baixa escolaridade ou idosos (PIMENTA, 1995; PIMENTA; TEIXEIRA, 1997; TEIXEIRA, 2001).

Entretanto, essa talvez não seja a realidade desse questionário no Brasil — um dos líderes mundiais em desigualdade social e que possui diferenças marcantes quanto às expressões idiomáticas regionais —, o que permite supor que os resultados de uma pesquisa realizada com uma amostra extraída de uma população rica de uma capital brasileira possam, 
talvez, diferenciar significantemente dos daqueles obtidos em uma pobre cidade do sertão nordestino, dada a complexidade na compreensão de alguns descritores (BARROS, 2001).

Em decorrência dessas questões, é que foi dada atenção, nessa pesquisa, ao nível de escolaridade das pacientes - que é ressaltado por Melzack (1987) como um dos fatores limitantes para o seu uso; assim como foram estabelecidos como critérios de inclusão, v.g., somente a participação de pacientes que fossem assistidas pelo SUS e que fossem operadas no Hospital São Domingos Sávio. 


\subsection{Tempo para a Primeira Administração do Diclofenaco de Sódio}

Em contraposição a Moininche, Kehlet e Dahl (2002), Ong et al. (2005) relatam que o tempo para o primeiro requerimento de analgésicos tem menor acurácia para verificar o efeito da analgesia preemptiva do que a intensidade de dor e o consumo de drogas analgésicas, e que esse não seria o objetivo principal da analgesia preemptiva; todavia, sua importância clínica reside no fato de que, ao prolongá-lo, estaria havendo maior efeito do recurso analgésico utilizado antes da cirurgia — em nosso caso, a TENS —, podendo traduzir em menor índice de dor e consumo total de analgésicos, bem assim maior conforto à paciente.

As pacientes do grupo preemptivo que consumiram diclofenaco de sódio - droga que estava prescrita como medicação de resgate — nas primeiras 16 h após a indução do bloqueio anestésico, solicitaram-no em média 487,50 \53,44 min após esta; já as do grupo placebo, 470,10 \pm 46,19 min, não havendo diferença significante entre os grupos, porquanto o valor de $\mathrm{p}$ foi igual a 0,807 , o que pode ser visualizado no gráfico 15 que ilustra esse tempo. Esperava-se que, com a prévia aplicação da TENS de baixa freqüência, o tempo para a solicitação dessa droga pudesse ser significantemente maior, dado o possível aumento do período de latência da dor devido à eletroanalgesia preemptiva.

Por meio da END, foi verificado que as pacientes do grupo placebo apresentaram no pós-operatório imediato um pico álgico alcançado no momento da sexta coleta de dor, o que coincide com o tempo para a requisição do diclofenaco de sódio por essas pacientes.

Como não se conhecem pesquisas averiguando esse consumo com o uso da TENS de forma pré-operatória, a discussão a seguir far-se-á a partir de pesquisas que empregaram métodos diferenciados. Assim, Benedetti et al. (1997), analisando esse tempo em pacientes submetidos a toracotomias póstero-laterais, também verificaram diferença estatística nãosignificante entre os pacientes que fizeram uso da TENS no pós-operatório, e os que não a 
utilizaram; tal como Garcia (2000), ao analisar o efeito preemptivo do fentanil em histerectomias.

Já no estudo de Lin et al. (2002), que avaliou a eletroacupuntura de forma preemptiva em cirurgias abdominais baixas, foi demonstrado que o tempo para o primeiro requerimento de morfina foi de 10, 18, 28 e $28 \mathrm{~min}$, respectivamente, nos grupos: A (preemptivo controle); B (preemptivo placebo), C (preemptivo de baixa freqüência, $2 \mathrm{~Hz}$ ) e D (preemptivo de alta, $100 \mathrm{~Hz}$ ); e no de Ke et al. (1998) foi demonstrado que a bupivacaína exerceu efeito preemptivo em laparoscopias, ao retardar o tempo para o requerimento do primeiro analgésico entre os 3 grupos da pesquisa: A (pacientes em que a bupivacaína foi administrada antes do ato cirúrgico, e solução salina após), 486,7 \pm 435,3 min; B (solução salina antes e bupivacaína depois), 229,4 \pm 330,4 min; e C (solução salina antes e depois), $143,1 \pm 156,7 \mathrm{~min}$

Benedetti et al. (1997) obtiveram aumento do tempo para o primeiro requerimento de analgésicos nos pacientes que usaram a TENS no pós-operatório de costotomias, esternotomias, toracotomias com afastamento muscular e vídeo toracoscopias. 


\subsection{Análise do Consumo de Analgésicos no Pós-operatório}

Em $48 \%$ das pacientes do grupo preemptivo (12 pacientes), foi administrado o diclofenaco de sódio nas primeiras 16 h após a indução do bloqueio anestésico, enquanto que no grupo placebo isso ocorreu em 60\% (15 pacientes), diferença não estatisticamente significante (gráfico 14). Para Kissin (1996), o consumo de analgésicos é possivelmente uma variável não fidedigna para averiguar a analgesia preemptiva, e pode ser influenciado por vários fatores psicológicos. Todavia, Konrad, Cordeiro e Coeli (2001), Moiniche, Kehlet e Dahl, (2002) e Ong et al. (2005) ressaltam a relevância desse consumo para analisar a analgesia preemptiva.

Ao analisar o consumo de diclofenaco de sódio e dipirona durante todo o período de internação, também não houve diferença significante entre os grupos, como pôde ser observado nos gráficos 16 e 17, respectivamente. Quanto ao consumo de dipirona, esse resultado era previsto, pois essa droga estava prescrita de 6 em 6 h. E, quanto à administração de diclofenaco de sódio, a ausência de diferença foi um resultado natural, haja vista que nem nas primeiras 16 h após a indução do bloqueio anestésico — período em que haveria maior efeito da analgesia preemptiva — houve diferença significante.

Cotejando nossos resultados aos de pesquisas envolvendo a aplicação da eletroacupuntura de forma preemptiva em procedimentos cirúrgicos para avaliação do consumo de medicamentos analgésicos, nossos achados divergem dos de Lin et al. (2002) que, em cirurgias abdominais baixas, observaram redução de $22 \%$ desse consumo, nas primeiras $24 \mathrm{~h}$ pós-cirúrgicas, nos pacientes que fizeram uso da modalidade de baixa freqüência, em relação aos do grupo placebo. Kotani et al. (2001) conseguiram, ao aplicar a eletroacupuntura antes de cirurgias abdominais altas e baixas, reduzir em 50\% o consumo de morfina pelos pacientes. 
Ao analisar o consumo de analgésicos no pós-operatório com o método de analgesia preemptiva induzida por drogas, Levent (2001), em histerectomias abdominais totais e salpingo-ooforectomias bilaterais, não verificou diferença significante desse consumo entre as pacientes em que a morfina fora administrada antes do ato cirúrgico, e após o fechamento do peritônio; e Garcia (2000) também não observou diferença significante entre as que fizeram uso do fentanil 30 min antes das histerectomias, e as que o utilizaram após o ato cirúrgico. Maestroni et al. (2002), embora tenham verificado analgesia preemptiva em colecistectomias laparoscópicas, mensurada pela VAS, também não observaram diferença significante quanto ao consumo de analgésicos no pós-operatório, o que está de acordo com os nossos achados.

Os nossos resultados divergem dos de diversos autores, como Hamza et al. (1999), que demonstraram a efetividade da TENS na diminuição do consumo de analgésicos no período pós-operatório, senão, nessas pesquisas, a TENS foi aplicada somente após a cirurgia.

Destarte, não estamos em concordância com os resultados da pesquisa de Guerra et al. (2003), em que houve significante redução do consumo de analgésicos com o uso da TENS no pós-operatório de hernioplastia inguinal. Apenas 1 dos 9 pacientes do grupo experimental — que usou a TENS — solicitou, uma única vez, medicação analgésica; ao passo que todos os pacientes do grupo placebo $(n=9)$ solicitaram esse tipo de medicação, 2,55 vezes em média. Essa diferença em relação aos achados é fruto dos métodos usados: tipos de cirurgia; drogas anestésicas e analgésicas; níveis e tipos de dor; parâmetros de estimulação; tempo de aplicação; e horários de aplicação da TENS.

Algumas pesquisas obtiveram satisfatórios resultados com o uso da TENS no período pós-operatório, como: a de Chiu et al. (1999), em hemorroidectomias, cirurgias que geram um quadro álgico intenso, em que houve redução significante do consumo de morfina; Chen et al. (1998), em histerectomias e miomectomias, que observaram redução de $37 \%$ da administração de opióides com o uso da TENS de forma pericicatricial, e de 39\%, quando 
aplicada nos pontos de acupuntura; Bjordal, Johnson e Ljungreen. (2003), que analisaram 1350 pacientes submetidos a diferentes procedimentos cirúrgicos e verificaram redução de 35,5\% do consumo de analgésicos; Nuñez e Carrasco (2000), que minimizaram esse consumo em cesáreas, sem, no entanto, diminuir a intensidade e o período de remissão da dor; Benedetti et al. (1997) que conseguiram minimizar a intensidade de dor em costotomias, esternotomias, toracotomias com afastamento muscular e vídeo toracocospias; e Castro e Carlos (1986), em laparotomias, que o minimizaram em $63 \%$ naqueles que fizeram uso desse recurso, sendo mais significante nos que foram submetidos a histerectomias, e menos, a gastrectomias.

Embora a redução do consumo de diclofenaco não tenha sido significante, os nossos achados são muito relevantes, haja vista que, ao serem confrontados com os da análise da intensidade de dor pela END, possibilita a verificação do mais importante aspecto desse trabalho, que foi conseguir manter o nível de dor do grupo preemptivo inferior ao do placebo, sem haver, no entanto, um maior consumo de drogas analgésicas para tal. Ou seja, se as pacientes do grupo preemptivo tivessem consumido mais drogas que as do placebo, seria inviável inferir sobre a ocorrência de analgesia preemptiva.

\subsection{Dor Referida}


A ocorrência de dor referida no ombro direito - condição que sugere irritação do diafragma ou diretamente do nervo frênico — deu-se em 40\% (10 pacientes) das pacientes do grupo preemptivo e em 32\% (8 pacientes) daquelas do placebo (gráfico 18). Essa incidência está em concordância com os achados na literatura que a indicam em cerca de um terço dos pacientes submetidos a colecistectomia por laparotomia (ORLOFF, 1970; SCHWARTZ; SHIRES; SPENCER, 1996; WAY; DUNPHY, 1993).

Não se objetivou, nessa pesquisa, analisar a intensidade de dor referida no ombro apesar de os dados também terem sido coletados. Objetivou-se apenas verificar a sua incidência que, com a aplicação da TENS de baixa freqüência, não apresentou diferença significante entre as pacientes que a usaram e as que não.

De acordo com Antunes et al. (2002), a TENS tem eficácia já bastante comprovada para o tratamento das dores de origem cutânea, mas não é necessariamente eficiente para as de origem visceral; o que corrobora a pesquisa de Nuñez e Carrasco (2000), que usaram a TENS no pós-operatório de cesáreas. 
Em um total de $20 \%$ das pacientes (5 pacientes) do grupo preemptivo houve administração dessa droga; enquanto que em $32 \%$ (8 pacientes) isso ocorreu (gráfico 19). O consumo dessa droga — que não tem ação analgésica — foi verificado para auxiliar a avaliar a qualidade de recuperação pós-cirúrgica, logo que um dos preditores de náuseas e êmesis é a dor. E, como a TENS é um recurso analgésico, poderia, então, também minimizar o consumo dessa substância.

Nossos resultados são semelhantes aos de Zárate et al. (2001) que não obtiveram significante redução do consumo de drogas anti-eméticas com o uso da eletroacupuntura antes de colecistectomias por laparoscopia. Todavia, Chen et al. (1998) conseguiram reduzir a incidência de náuseas e vômitos em aproximadamente um terço das mulheres que se submeteram a histerectomia abdominal total ou miomectomia com o uso da TENS, todavia, esse recurso foi aplicado no pós-operatório; Kotani et al. (2001) observaram redução de 20\% a $30 \%$ da incidência de náuseas em cirurgias abdominais altas e baixas, com a analgesia preemptiva induzida pela eletroacupuntura; e Lin et al. (2002), em cirurgias abdominais baixas. 
Durante a coleta dos dados, observou-se que algumas pacientes do grupo preemptivo relataram que a aplicação da TENS ocasionava determinado incômodo. Assim, para a obtenção de dados mais concretos sobre esses relatos, resolveu-se acrescentar esse questionário (Apêndice H) — mesmo com a coleta de dados já em andamento.

Os resultados obtidos, ilustrados no gráfico 20 , confirmam o que foi evidenciado na prática clínica a respeito do relato das pacientes sobre o incômodo da estimulação elétrica de baixa freqüência e alta intensidade, pois a maioria $(57,89 \%)$ das pacientes do grupo preemptivo disse que a TENS incomodava um pouco e $15,78 \%$ que incomodava razoavelmente. Esses dados foram significantemente diferentes dos do grupo placebo, em que $88,24 \%$ relataram que a TENS não incomodava, e $11,76 \%$, que incomodava um pouco. O fato de ter havido queixa por parte de 2 pacientes do grupo placebo pode ter ocorrido, talvez, por essas permanecerem durante $60 \mathrm{~min}$ deitadas, com os eletrodos posicionados sobre o abdome, sem terem liberdade para deambular ou realizar atividades que solicitassem grande movimentação.

Pesquisas recentes, realizadas por Sluka et al. (2000), têm demonstrado que a TENS de alta frequiência também estimula a liberação de opióides endógenos; e, diante da experiência clínica, sabe-se que o uso de tal freqüência é mais confortável que o da de baixa, que normalmente é aplicada em nível motor de estimulação, com a máxima intensidade suportada pelo paciente. Logo, poder-se-ia utilizar a TENS de alta freqüência em pesquisas, para observar a possível ocorrência de analgesia preemptiva, comparando com os resultados da de baixa freqüência, e selecionar qual seria a mais adequada para tal, dando grande ênfase, em tal escolha, ao conforto e satisfação do paciente. 
A maioria das pacientes de ambos os grupos relatou que gostaria de, em uma próxima cirurgia, usar a TENS e os medicamentos (gráfico 21). Esses dados parecem refletir a satisfação das pacientes em receber uma melhor assistência da equipe de saúde, assim como terem à sua disposição alguns recursos diferentes para o tratamento do quadro álgico, o que reforça a relevância e a aceitação da analgesia multimodal. 
CONCLUSÃO 


\section{CONCLUSÃO}

A aplicação da modalidade de baixa freqüência da estimulação elétrica transcutânea do nervo, durante 60 minutos, no período pré-operatório de pacientes do sexo feminino submetidas a colecistectomia por laparotomia promoveu analgesia preemptiva. 
REFERÊNCIAS BIBLIOGRÁFICAS 


\section{REFERÊ NCIAS BIBLIOGRÁFICAS}

AIDA, S. et al. The effectiveness of preemptive analgesia varies according to the type of surgery: a randomized, double-blind study. Anesthesia and A nalgesia, Baltimore, v. 89, n. 3, p. 711 , Set. 1999.

ANDRADE, R. F. A. Comportamento da litíase biliar no E stado de Sergipe. 2002. Monografia (graduação em medicina) — Departamento de Medicina da Universidade Federal do Estado de Sergipe, Aracaju, 2002.

ANTUNES, A. A. M. et al. Os efeitos da estimulação elétrica nervosa transcutânea no pósoperatório de cirurgias torácicas e abdominais — revisão de literatura e relato de casos. Revista de Fisioterapia da Universidade de São Paulo, São Paulo, v. 9, n. 1, p. 23-25, jan./jun. 2002.

BARROS, N. Qualidade de vida - conceito e métodos de avaliação. In: ANDRADE FILHO, A. C. de C. Dor: diagnóstico e tratamento. Roca: São Paulo, 2001. 53-61 p.

BASFORD, J. R. Eletroterapia. In: KOTTKE, F. J.; LEHMANN, J. F. Tratado de medicina física e reabilitação de K rusen. 4. ed. São Paulo: Manole, 1994, 363-388 p.

BENBOW, S. J.; COSSINS, L.; WILES, J. R. A comparative study of disability, depression and pain severity in young and chronic pain in patients. VIIIth World Congress on Pain. Vancouver. 1996.

BENEDETTI, F. et al. Control of postoperative pain by transcutaneous electrical nerve stimulation after thoracic operations. Ann Thoracic Surgery, Torino, v. 63, n. 3, p. 773-776, Mar. 1997.

BISSCHOP, G. de; BISSCHOP, É. de; COMMANDRÉ, F. TENS. In: BISSCHOP, G. de; BISSCHOP, É. de; COMMANDRÉ, F. Eletrofisioterapia. São Paulo: Santos, 2001. 5-62 p.

BJORDAL, J. M.; JOHNSON, M. I.; LJUNGREEN, A. E. Transcutaneous electrical nerve stimulation (TENS) can reduce postoperative analgesic consumption. A meta-analysis with assessment of optimal treatment parameters postoperative pain. E uropean J ournal of Pain, Erlangen, v. 7, n. 2, p. 181-188, Apr. 2003.

BLUMGART, L. H. Cirugía del hígado y de las vías biliares. Buenos Aires: Editoria Médica Panamericana, 1988. 655-665 p.

BONICA, J. J. et al. Biochemistry and the modulation of nociception and pain. In: BONICA, J. J. The management of pain. Phyladelphia: Lea \& Febiger, 1990. 95-121 p.

BRENTANO, L. Colecistectomia. [s.1.]: ABC da Saúde, 2003. Disponível em: http://www.abcdasaude.com.br/artigo.php?86. Acesso em: 30 de agosto de 2004.

BRIDENBAUGH, P. O. Preemptive analgesia - is it clinically relevant? Anesthesia \& Analgesia, Baltimore, v. 78, n. 2, p. 203-4, Feb. 1994. 
BUTTON, B.; SAWYER, S. Fisioterapia do aparelho respiratório do adolescente. In: BURNS, Y. R.; MCDONALD, J. Fisioterapia e crescimento na infância. São Paulo: Santos, 1999. 247-261 p.

BUXTON, B. P. A fisiologia e a psicologia da dor. In: STARKEY, C. Recursos Terapêuticos em Fisioterapia. São Paulo: Manole, 2001. 37-69 p.

CAMERON, M. H. Physical agents in rehabilitation -- from research to practice. Phyladelphia: W. B. Saunders Company, 1999. 31-54 p.

CARROLL, D. et al. Randomization is important in studies with pain outcomes: systematic review of transcutaneous electrical nerve stimulation in acute postoperative pain. British J ournal of A naesthesia, Oxford, v. 77, n. 6, p. 798-803, Dec. 1996.

CARROL, E. N.; BADURA, A. S. Focal intense brief transcutaneous electric nerve stimulation for treatment of radicular and posthoracotomy pain. Archives of Physical M edicine and Rehabilitation, Cleveland, v. 82, n. 2, p.262-264, Feb. 2001.

CASTILLO, G. L. B. Estudio comparativo entre bupivacaina + fentanyl vs. bupivacaina sola por vía peridural para el control del dolor obstétrico. Tesis para obtener el diploma universitario en la especialidad de anestesiología, Querétaro, [1999?].

CASTRO, M. L.; CARLOS, E. S. Post-laparotomy pain control by transcutaneous electrical nerve stimulation: preliminary report. R evista B rasileira de Anestesiologia, Rio de Janeiro, v. 36, n. 3, p. 207-14, mar. 1986.

CHANDRAN, P.; SLUKA, K. A. Development of opioid tolerance with repeated transcutaneous electrical nerve stimulation administration. Pain, Seattle, v. 102, n. 1-2, p. 195-201, Mar. 2003.

CHEN, L. et al. The effect of location of transcutaneous electrical nerve stimulation on postoperative opioid analgesic requirement: acupoint versus nonacupoint stimulation. Anesthesia \& Analgesdia, Baltimore, v. 87, n. 5, p. 1129-1134, Nov. 1998.

CHEN, L.; HAN, J. S. Analgesia induced by electroacupuncture of different frequencies is mediated by different types of opioid receptors: another cross-tolerance study. Behavioral B rain Research, Amsterdam, v. 47, n. 2, p. 143-149, Apr. 1992.

CHESTERTON, L. S. et al. Effects of TENS frequency, intensity and stimulation site parameter manipulation on pressure pain thresholds in healthy human subjects. Pain, Seattle, v. 106, n. 1-2, p. 73-80, Nov. 2003.

CHIU, J. H. et al. Effect of transcutaneous electrical nerve stimulation relief on patients undergoing hemorrhoidectomy: prospective, randomized, controlled trial. Diseases of the Colon \& Rectum, New York, v. 42, n. 2, p. 180-185, Feb. 1999.

CREPON, F. E letrofisioterapia e R eeducação F uncional. São Paulo: Lovise, 1996. 80-101 p. 
CRIELAARD et al apud TRIBIOLI, R.A. Análise crítica atual sobre a TE NS envolvendo parâmetros de estimulação para o controle da dor. Ribeirão Preto, SP, 2003. 85f. Dissertação (mestrado em bioengenharia). Escola de Engenharia de São Carlos; Faculdade de Medicina de Ribeirão Preto; e Instituto de Química de São Carlos da Universidade de São Paulo, Ribeirão Preto, 2003.

DAMIANE, C.; DAMIANE, G. TENS: eletroanalgesia. In: RODRIGUES, E. M.; GUIMARÃES, C. S. M anual de recursos fisioterapêuticos. Rio de Janeiro: Revinter, 1998. 53-80 p.

DIERKING, G. et al. Effect of pre vs post-operative inguinal field block on postoperative pain after herniorraphy. British J ournal of Anaesthesia, Oxford, v. 68, n. 4, p. 344-348, Apr. 1992.

DUBUISSON, D.; MELZACK, R. Classification of clinical pain descriptors by multiple group discriminant analysis. Experimental Neurology, Michigan, v. 51, n. 2, p. 480-487, May 1976.

DuGAS, B. W. Medicações. In: Enfermagem prática. 4. ed. Rio de Janeiro: Guanabara, 1988. 465-487 p.

EISENBAUER, L. A.; MURPHY, M. A. Pharmacotherapeutics \& advanced nursing practice. San Diego: McGraw Hill Companies, 1998. 253 p.

ERIKSSON, M. B. E.; SJOLUND, B. H.; NEILZEN, S. Long term results of peripheral conditioning stimulation as an analgesic measure in chronic pain. Pain, Seattle, v. 6, n. 3, p. 335-347, Jun. 1979.

FERNANDEZ, E.; BOYLE, G. J. Affective and evaluative descriptors of pain in the McGill Pain Questionnaire: reduction and reorganization. The J ournal of Pain, Philadelphia, v. 2, n. 6, p. 318-325, Dec. 2001.

FERNANDEZ, E.; TOWERY, S. A parsimonious set of verbal descriptors of pain sensation derived from the Mcgill Pain Questionnaire. Pain, Seattle, v. 66, n. 1, p. 31-37, Jul. 1996.

FORTH, W.; BEYER, A.; PETER, K. Highly potent analgesics: opiates and opioids. In: FORTH, W.; BEYER, A.; PETER, K. Alívio da dor: uma visão analítica das vantagens e desvantagens da moderna administração da dor. São Paulo: Hoechest, 1995. 40-49 p.

FRAMPTON, V. Estimulação Nervosa Elétrica Transcutânea. In: KITCHEN, S.; BAZIN, S. E letroterapia de Clayton. 10. ed. São Paulo: Manole, 1998. 276-294 p.

GAGLIESI, L. MELZACK, R. Age differences in the quality of chronic pain: a preliminary study. Pain R esearch \& M anagement, Oakville, v. 2, n.3, p. 157-162, Winter 1997.

GAGLIESE, L.; MELZACK, R. Age-related differences in the qualities but not the intensity of chronic pain. Pain, Seattle, v. 104, n. 3, p. 597-608, Aug. 2003. 
GARCIA, J. B. dos S. Preemptive analgesia with epidural bupivacaine plus fentanyl in hysterectomy: serum interleukin-6 implications. 2000. Tese para obtenção do título de doutorado - Escola Paulista de Medicina - Universidade Federal de São Paulo, São Paulo, 2000 .

GOFFI, F. S.; GOFFI JÚNIOR, P. S.; SORBELLO, A. A. Cirurgia das vias biliares. In: GOFFI, F. S. Técnica cirúrgica: bases anatômicas, fisiopatológicas e técnicas da cirurgia. 4. ed. São Paulo: Atheneu, 1996, 691-694 p.

GOTTSCHALK, A.; OCHROCH, E. A. Preemptive analgesia: what do we do now? A nesthesiology, Philadelphia, v. 98, n.1, p. 280-281, Jan. 2003.

GRAHAM, C. et al. Use of the McGill Pain Questionnaire in the assessment of cancer pain: replicability and consistency. Pain, Seattle, v. 8, n. 3, p. 377-387, Jun. 1980.

GRIEVE, G. P. Modern manual therapy of the vertebral column. New York: Churchill Livingstone, 1986. 233-249 p.

GUERRA, D. R. et al. A Utilização da TENS no pós-operatório imediato de pacientes submetidos a cirurgia de hérnia inguinal. In: $\mathrm{V}$ CONGRESSO DE INICIAÇÃO CIENTÍFICA. PIBIC/UFS, 2003, Universidade Federal de Sergipe. Anais.... São Cristóvão: Universidade Federal de Sergipe, 2003. 215 p.

HAMZA, M. A. et al. Effect of the frequency of transcutaneous electrical nerve stimulation on the postoperative opioid analgesic requirement and recovery profile. Anesthesiology, Philadelphia, v. 91, n. 5, p. 1232-1238, Nov. 1999.

HAN, J. S. et al. Frequency as the cardinal determinant for electroacupuncture analgesia to be reversed by opioid antagonists. Chinese M edical J ournal, Peking, v. 38, n. 5, p. 475-482, Oct. 1986.

HAN, J. S. et al. Effect of low and high frequency TENS on met-enkephalin-arg-phe and dynorphin. A immunoreactivity in human lumbar CSF. Pain, Seattle, v. 47, n. 3, p. 295-298, Dec. 1991.

HANSSON, B. et al. Influence of naloxone on relief of acute oro-facial pain by transcutaneous electrical nerve stimulation (TENS) or vibration. Pain, Seattle, v. 24, n. 3, p. 323-329, Mar. 1986.

HEPNER, D. L. Preemptive analgesia: what does it really mean? Anesthesiology, Philadelphia, v. 93, n. 5., p. 1368, nov. 2000.

HUGHES, G. S. et al. Response of plasma beta-endorphins to transcutaneous electrical nerve stimulation in healthy subjects. Physical Therapy, Alexandria, v. 64, n. 7, p. 1062-1066, Jul. 1984.

HUSKISSON, E. C. Visual Analogue Scales. In: MELZACK, R. Pain measurement and assessment. New York: Raven Press, 1983. 33-37 p. 
IMAMURA, M. et al. Eletroestimulação nervosa transcutânea. In: LEITÃO, V. A. Clínica de reabilitação. São Paulo: Atheneu, 1995. 301-309 p.

JACHUCK, S. J. et al. The effect of hypotensive drugs on the quality of life. The British J ournal of the Royal College General Practitioners, London, v. 32, n. 235, p. 103-105, Feb. 1982.

JAFFE, J. H.; MARTIN, W. R. Analgésicos opióides e antagonistas. In: GILMAN, A. G. et al. Goodman e Gilman. As Bases farmacológicas da terapêutica. 8. ed. Rio de Janeiro: Guanabara Koogan, 1991. 320-343 p.

JAVIER, G. P. et al. Analgesia preventiva en un modelo experimental de dolor visceral. R evista M exicana de Anestesiologia, v. 22, n. 2, p. 116-121, abr-jun. 1999.

JOHNSON, M. I. et al. Analgesic effects of different frequencies of transcutaneous electrical nerve stimulation on cold-induced pain in normal subjects. Pain, Seattle, v. 39, n. 2, p. 231236, Nov. 1989.

JOHNSON, M. I.; ASHTON, C. H.; THOMPSOM, J. W. An in depth study of long term users of transcutaneous electrical nerve stimulation (TENS). Implications for clinical use of TENS. Pain, Seattle, v. 44, n. 3, p. 221-229, Mar. 1991.

KALRA, A. B.; URBAN, M. O.; SLUKA, K. A. Blockade of opiod receptors in rostral ventral medulla prevents antihyperalgesia produced by transcutaneous electrical nerve stimulation (TENS). The J ournal of Pharmacology and Experimental Therapeutics, Bethesda, v. 298, n. 1, p. 257-263, Jul. 2001.

KATZ, J.; MELZACK, R. Measurement of pain. Surgery Clinical North American, v. 79, n. 2, p. 231-252, Apr. 1999.

KE, R. W.; PORTERA, S. G.; LINCOLN, S. R. A randomized blinded trial of preemptive local anesthesia in laparoscopy. Primary Care U pdate for $\mathbf{O}$ bstetric and G ynecology, v. 5, n. 4, p. 197-198, Jul. 1998.

KE, R. W. et al. A randomized double-blinded trial of preemptive analgesia in laparoscopy. O bstetrics \& G ynecology, Denver, v. 92, n. 6, p. 972-5, Dec. 1998.

KELLY, D. J.; AHMAD, M.; BRULL, S. Preemptive analgesia I: physiological pathways and pharmacological modalities. Canadian J ournal of Anesthesia, Toronto, v. 48, n. 10, p. 1000-1010, Nov. 2001.

KETOVUORI, H.; PÖNTINEN, P. J. A pain vocabulary in finnish - the finnish pain questionnaire. Pain, Seattle, v. 11, n. 1, p. 247-253, Aug. 1981.

KING, E. W.; SLUKA, K. A. The effect of varying frequency and intensity of transcutaneous electrical nerve stimulation on secundary mechanical hyperalgesia in an animal model of inflammation. The J ournal of Pain, Philadelphia, v. 2, n. 2, p. 128-133, Apr. 2001.

KISSIN, I. Preemptive analgesia: terminology and clinical relevance. Anesthesia and analgesia, Baltimore, v. 79, n. 4, p. 809, Oct. 1994. 
Preemptive analgesia - Why its effect is not always obvious. Anesthesiology, Philadelphia, v. 84, n. 5, p. 1015-1019, May 1996.

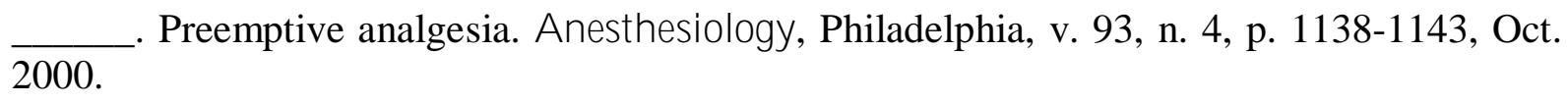

Study design to demonstrate clinical value of preemptive analgesia: is it commonly used approach valid? Regional Anesthesia and Pain Medicine, Seattle, v.27, n.3, p. 242244, May-Jun. 2002.

KONRAD, K.; CORDEIRO, S. M.; COELI, M. Dor. Fisiopatologia e tratamento. In: LIANZA, S. M edicina de R eabilitação. Rio de Janeiro: Guanabara Koogan, 2001. 137-150 p.

KOTANI, N. et al. Preoperative intradermal acupuncture reduces postoperative pain, nausea and vomiting, analgesic requiriment, and sympathoadrenal responses. Anesthesiology, Philadelphia, v. 95, n. 2, p. 349-356, Aug. 2001.

LABRADA, A.; JIMÉNEZ-GARCIA, Y. Preventive multimodal analgesia: a comparative study. Revista de la Sociedad E spañola del Dolor, Madrid, v. 11, n. 3, p. 122-128, abr. 2004.

LEE, I-H.; LEE, I-O. Preemptive effect of intravenous ketamine in the rat: concordance between pain behavior and spinal fos-like immunoreactivity. Acta Anaesthesiologica Scandinavica, Oxford, v. 49, n. 2, p. 160-165, Feb. 2005.

LEVENT, K. The effect of preemptive intravenous morphine on postoperative analgesia and surgical stress response. R evista Brasileira de A nestesiologia, Rio de Janeiro, v. 51, n. 6, p. 503-510, dez. 2001.

LICHTENBERG, P. A.; SWENSEN, C. H.; SKEHAN, M. W. Further investigation of the role of personality, lifestyle and arthritic severity in predicting pain. Journal of Psychosomatic Research, New York, v. 30, n. 3, p. 327-337, maio 1986.

LIN, J. et al. The effect of high and low frequency eletroacupuncture in pain after low abdominal surgery. Pain, Seattle, v. 99, n. 3, p. 509-514, out. 2002.

LOMBARD, B., et al. Evaluation de l'électrostimulation transcutanée dans la prise en charge des douleurs post-amygdalectomie chez l'adulte. R evue Laryngologie Otologie R hinologie, Bordeaux Cédex, v. 117, n. 2, p. 89-92, abr. 1996.

LOW, J.; REED, A. E letroterapia explicada. 3. ed. São Paulo: Manole, 2001. 472 p.

LUNDEBERG, T.; BONDESSON, L.; LUNDSTRON, V. Relief of primary dysmenorrhea by transcutaneous electrical nerve stimulation. Acta Obstetetricia et Gynecologica Scandinavica, Gothenburg, v. 64, n. 6, p. 491-497, ago. 1985.

MACHADO, M. C. C.; RAIA, A. A. Anatomia - Histologia - Embriologia - Fisiologia da vesícula e vias biliares - Fisiologia da bile. In: CORRÊA NETTO, A.; RAIA, A. A.; ZERBINO, E. de J. Clínica Cirúrgica. 4. ed. São Paulo: Sarvier, 1994. 785-789 p. 
MAESTRONI, U. et al. A new method of preemptive analgesia in laparoscopic cholecystectomy. Surgical Endoscopy, New York, v. 16, n. 9, p. 1336-1340, Sep. 2002.

MARIANO, T. F.; BEN, V. F. G. Efeitos da eletroestimulação transcutânea (TE NS) em indivíduos adultos no pós-operatório imediato de colecistectomia. 1998. Trabalho de Conclusão de Curso - Universidade Católica Dom Bosco (UCDB), Campo Grande, 1998.

MARIN, L. I.; CASTRO, C. E. S. Post laparotomy pain control by transcutaneous electrical nerve stimulation: preliminary report. R evista Brasileira de Anestesiologia, Rio de Janeiro, v. 36, n. 3, p. 207-214, maio-jun. 1986.

MCQUAY, H. J. Pre-emptive analgesia: a systematic review of clinical studies. Annals of Medicine, Stockholm, v. 27, n. 2, p. 249-56, Apr. 1995.

MELO, J. N.; SANTANA FILHO, V. J. E feito da TE NS convencional no requerimento de analgésicos no pós-operatório imediato de herniorrafia inguinal. 2003. Monografia apresentada ao curso de fisioterapia para título de bacharel, Universidade Tiradentes, Aracaju, 2003.

MELZACK, R. The McGill Pain Questionnaire: major properties and scoring methods. Pain, Seattle, v. 1, n. 3, p. 277-299, Sep. 1975.

MELZACK, R.; WALL, P. 0 desafio da dor. Lisboa: Fundação Calouste Gulbenkian, 1987. $189-250 \mathrm{p}$.

MERINO, C. S. Colecistectomía laparoscópica comparada con colecistectomía clásica en colecistitis aguda. R evista Chilena de Cirurgia, Santiago, v. 53, n. 1, p. 53-59, 2001.

MERKEL, S. I.; GUSTEIN, H. B.; MALVIYA, S. Use of transcutaneous electrical nerve stimulation in a young child with pain from open perineal lesions. J ournal of Pain and Symptom M anagement, New York, v. 18; n. 5, p. 376-81, Nov. 1999.

MERSKEY, H. Some features of the history of the idea of pain. Pain, Seattle, v. 9, n. 1, p. 38, Aug. 1980.

MINISTÉRIO DA SAÚDE DO BRASIL. C uidados paliativos oncológicos: controle da dor. Rio de Janeiro: INCA, 2001. 16-32 p.

MOINICHE, S.; KEHLET, H.; DAHL, J. B. A qualitative and quantitative systematic review of preemptive analgesia for postoperative pain relief. Anesthesiology, Philadelphia, v. 96, n. 3, p. 725-41, Mar. 2002.

MORIN, C. et al. Differences between the sexes in post-surgical pain. Pain, Seattle, v. 85, n. 1-2, p. 79-85, Mar. 2000.

MOTAMED, C. et al. Preemptive intravenous morphine-6-glucuronide is ineffective for postoperative pain relief. Anesthesiology, Philadelphia, v. 92, n. 2, p. 355-360, Feb. 2000. 
NUÑEZ, C. N.; CARRASCO, M. P. Estimulación eléctrica transcutánea (EET) para reducir el dolor después de la cesárea. G inecología y O bstetricia de M éxico, Ciudad del México, v. 68, n. 1, p. 60-63, fev. 2000.

O’BRIEN et al. apud TRIBIOLI, R.A. Análise crítica atual sobre a TENS envolvendo parâmetros de estimulação para o controle da dor. Ribeirão Preto, SP, 2003. 85f. Dissertação (mestrado em bioengenharia). Escola de Engenharia de São Carlos; Faculdade de Medicina de Ribeirão Preto; e Instituto de Química de São Carlos da Universidade de São Paulo, Ribeirão Preto, 2003.

OLAUSSON, B. et al. Effects of naloxone on dental pain threshold following muscle exercises and low frequency transcutaneous nerve stimulation: a comparative study in man. Acta Physiologica Scandinavica, Stockholm, v. 126, n. 2, p. 299-305, Sep. 1986.

ONG, C. K.-S. et al. The efficacy of preemptive analgesia for acute postoperative pain management: a meta-analysis. Anesthesia \& Analgesia, Baltimore, v. 100, n. 3, p. 757-773, Mar. 2005.

ORLOFF, M. J. Fígado e sistema biliar. In: DAVIS, I. C hristopher C línica Cirúrgica. 2. ed. Rio de Janeiro: Guanabara Koogan, 1970. 772-783 p.

PATIÑO, J. F.; LONDOÑO, E.; GARCÍA, L. G. Colecistectomia mini-traumática: hospitalización de corta estancia. R evista Colombiana de Cirurgia, Bogotá, v. 6, n. 2, p. 7075, ago. 1991.

PEREIRA, L. V.; SOUSA, F. A. E. F. Mensuração e avaliação da dor pós-operatória: uma breve revisão. R evista L atino-americana de Enfermagem, Ribeirão Preto, v. 6., n. 3, p. 7784, jul. 1998.

PÉREZ-AYUSO, R. M. et al. Historia natural de la colelitiasis. Incidencia de colescistectomía en un área urbana y una rural mapuche, en la última década. R evista Médica de Chile, Santiago, v. 130, n. 7, p. 723-730, jul. 2002.

PIMENTA, C. A. M. Avaliação da experiência dolorosa. R evista de M edicina, São Paulo, v. 74, n. 2, p. 69-75, ago-set. 1995.

PIMENTA, C. A. de M.; CRUZ, D.de A. L. M. da C; SANTOS, J. L. F. dos. Instrumentos para avaliação da dor. O que há de novo no nosso meio. Arquivo Brasileiro de Neurocirurgia, São Paulo, v. 17, n. 1, p. 15-24, jun. 1998.

PIMENTA, C. A.; TEIXEIRA M. J. Questionário de Dor Mcgill: proposta de adaptação para a língua portuguesa. R evista B rasileira de Anestesiologia, Rio de Janeiro, v. 47, n. 2, p. 177186, ago. 1997.

PONTES, R. M. C.; PRADO, W. A. Presurgical ketoproten, but not morphine, dipyrone, diclofenac, preempts post-incisional mechanica allodynia in rats. Brazilian Journal of M edical and Biological R esearch, Ribeirão Preto, v. 35, n. 1, p. 11-119, jan. 2002. 
PRADO, W. A.; OLIVEIRA, R. Anti-hyperalgesic effect of electroacupuncture in a model of post-incisional pain in rats. Brazilian Journal of Medical and Biological Research, Ribeirão Preto, v. 33, n. 8, p. 957-960, ago. 2000.

PRIETO, E. J.; GEISINGER, K. F. Factor-analytic studies of the McGill Pain Questionnaire. In: MELZACK, R. Pain measurement and assessment. New York: Raven Press, 1983. 63$70 \mathrm{p}$.

RANG, H. P.; DALE, M. M. Farmacologia. 2. ed. Rio de Janeiro: Guanabara Koogan, 1993. $460 \mathrm{p}$.

READING, A. E. The McGill Pain Questionnaire: an appraisal. In: MELZACK, R. Pain measurement and assessment. New York: Raven Press, 1983. 55-61 p.

RIVERA, A. R. F. Incisión transversa contra incisión media en colecistectomía, Cuál es menos dolorosa? Cirurgía G eneral, v. 18, n. 3, p. 178-181, jul-set. 1996.

ROBINSON, A. J. Instrumentação para eletrotrerapia. In: ROBINSON, A. J.; SNYDERMACKLER, L. E letrofisiologia clínica: eletroterapia e teste eletrofisológico. 2. ed. Porto Alegre: Artmed, 2001. 43-83 p.

ROSAEG, O. P. et al. Effect of preemptive multimodal analgesia for arthroscopic Knee Ligament repair. Regional Anesthesia and Pain Medicine, Seattle, v. 26, n. 2, p. 125-130, Mar-Apr. 2001.

ROSLYN, J. J.; ZINNER, M. J. Gallbladder and extra-hepatic billiary system. In: SCHWARTZ, S. I.; SHIRES, G. T.; SPENCER, F. C. 6. ed. Principles of surgery. Estados Unidos: Mc Graw Hill, 1996. 1367-1399 p.

SALAR, G.; JOB, I.; MINGRINO, S. et al. Effects of transcutaneous electrotherapy on CSF b-endorphin content in patients without pain problems. Pain, Seattle, v. 10, n. 2, p. 169-172, apr. 1981.

SALGADO, A. S. I. M anual clínico de eletrofisioterapia. Londrina: Midiograf, 1999. 112$147 \mathrm{p}$.

SANTIESTEBAN, A. J. Agentes físicos e dor músculo-esquelética. In: GOULD, J. A. Fisioterapia na ortopedia e na medicina do esporte. 2. ed. São Paulo: Manole, 1993. 181$193 \mathrm{p}$.

SANTOS et al. Aplicação da TENS de alta e baixa freqüências no pós-operatório imediato de colecistectomia convencional. In: VI CONGRESSO DE INICIAÇÃO CIENTÍFICA. PIBIC/UFS, 2004, Universidade Federal de Sergipe. Anais... São Cristóvão: Universidade Federal de Sergipe, 2004. p.242

SCHWARTZ, S. I.; SHIRES, G. T.; SPENCER, F. C. Princípios de cirurgia. 6.ed. México: Interamericana, 1996. 416-449 p. 
SEKAR, C. et al. Preemptive analgesia for postoperative relief in lumbosacral spine surgeries: a randomized controlled trial. The Spine J ournal, La Grange, v. 4, n. 3, p. 261-264, MayJun. 2004.

SILVA, P. Anestésicos locais e outros fármacos que afetam os canais iônicos. In: RANG, H. P.; DALE, M. M.; RITTER, J. M. Farmacologia. 5. ed. Rio de Janeiro: Guanabara Koogan, 1998. 485-505 p.

SILVEIRA, I. A. M; LIMA, P. A. L. Estudo da redução de custo no hospital São Domingos Sávio com a utilização da TE NS no pós-operatório de hernioplastia inguinal. 2004. Monografia para obtenção do título de bacharel em fisioterapia, Universidade Tiradentes, Aracaju, 2004.

SINATRA, R. Role of COX-2 inhibitors in the evolution of acute pain management. J ournal of Pain and Sympton M anagement, New York, v. 24, n. 1S, p. S18-27, Jul. 2002.

SLUKA, K. A. Systemic morphine in combination with TENS produces an increase antihyperalgesia in rats with acute inflamation. The J ournal of Pain, Philadelphia, v. 1, n. 3, p. 204-211, Sep. 2000.

SLUKA, K. A. et al. Spinal blockade of opiod receptors prevents the analgesia produced by TENS in arthritic rats. The J ournal of Pharmacology and Experimental Therapeutics, Bethesda, v. 289, n. 2, p. 840-846, May. 1999.

SLUKA, K. A. et al. Low frequency TENS is less effective than high frequency TENS at reducing inflammation-induced hyperalgesia in morphine-tolerant in rats. E uropean J ournal of Pain, Erlangen, v. 4, n. 2, p. 185-93, Jun. 2000.

SLUKA, K. A.; WALSH, D. Transcutaneous electrical nerve stimulation: basic science mechanisms and clinical effectiveness. The J ournal of Pain, Philadelphia, v. 4, n. 3, p. 109121, Apr. 2003.

SOFAER, B. Assessing pain. In: Pain: a handbook for nurses. 2. ed. New York: Chapman \& Hall, 1994. 44-57 p.

SORKIN, B. A. et al. Chronic pain in young and old patients: differences appear less important than similarities. J . G erontol. Psychol. Sci. Washington, v. 45, n. 2, p. 64-68, Mar. 1990.

SPÓSITO, M. M. M. M anual de medicina física e de reabilitação. São Paulo: [s.n.], 1993. 73-93 p.

STARKEY, C. Agentes elétricos. In: Recursos terapêuticos em físioterapia. São Paulo: Manole, 2001. 176-276 p.

TAYLOR, D. New ways to contain post-op pain. 2002. Disponível em: <http:// www. outpatientsurgery.net/2002/os08/f2.shtml>. Acesso em: 22 de outubro de 2004.

TEIXEIRA, M. J. Fisiopatologia da dor neuropática. In: ANDRADE FILHO, A. C. de C. Dor: diagnóstico e tratamento. Roca: São Paulo, 2001. 7-42 p. 
TEIXEIRA, M. J.; SOUZA, A. C. F. Dor - evolução histórica dos conhecimentos. In: TEIXEIRA, M. J.; FIGUEIRÓ, J. A. B. Dor: epidemiologia, fisiopatologia, avaliação, síndromes dolorosas e tratamento. São Paulo: Grupo Editorial Moreira Jr., 2001. 8-13 p.

TEIXEIRA, M. J. et al. Avaliação da dor: fundamentos teóricos e análise crítica. Revista de M edicina, São Paulo, v. 78, n. 2 (pt. 1), p. 85-114, abr. 1999.

THOMSON, A.; SKINNER, A.; PIERCY, J. Habilidades da fisioterapia. In: Fisioterapia de Tidy. 12. ed. São Paulo: Santos, 1994. 417-465 p.

TORRE, A. et al. Analgesia Preventiva. Revista Venezuelana de Anestesiologia, Caracas. v. 7, n. 1, p. 15-26, jun. 2002.

TOYOTA, S.; STATAKE, T.; AMAKI, Y. Transcutaneous electrical nerve stimulation as an alternative therapy for microlaryngeal endoscopic surgery. Anesthesia \& Analgesia, Baltimore, v. 89, n. 5, p. 1236-8, Nov. 1999.

TRIBIOLI, R.A. Análise crítica atual sobre a TENS envolvendo parâmetros de estimulação para o controle da dor. Ribeirão Preto, SP, 2003. 85f. Dissertação (mestrado em bioengenharia). Escola de Engenharia de São Carlos; Faculdade de Medicina de Ribeirão Preto; e Instituto de Química de São Carlos da Universidade de São Paulo, Ribeirão Preto, 2003.

TURK, D. C.; OKIFUJI, A.; SCHARFF, L. Chronic pain and depression: role of perceived impact and perceived control in different ages cohorts. Pain, Seattle, v. 61, n. 1, p. 93-101, Apr. 1995.

VALE, F. M. Dor. Novos aspectos fisiopatológicos e conseqüentes estratégias farmacológicas. Revista da Faculdade de Medicina de Lisboa, Lisboa, v. 5, n. 5, p. 291304, set-out. 2000.

VEILLEUX, S.; MELZACK, R. Pain in psychotic patients. Experimental Neurology, Michigan, v. 52, n. 1, p. 535-543, Jul. 1976.

VETTER, T. R.; HEINER, E. J. Discordance between patient self-reported visual analog scale pain scores and observed pain-related behavior in older children after surgery. J ournal of Clinical Anesthesia, New York, v. 8, n. 5, p. 371-375, Aug. 1996.

WALL, P. D. The prevention of postoperative pain. Pain, Seattle, v. 33, n. 2, p. 289-90, May. 1988.

WALSH, D. M. et al. Transcutaneous electrical nerve stimulation: effect of peripheral nerve conduction, mechanical pain threshold, and tactile threshold in humans. A rchives of Physical Medicine and R ehabilitation, Philadelphia, v. 79, n. 9, p. 1051-8, Sep. 1998.

WANG, B. et al. Effect of the intensity of transcutaneous acupoint electrical stimulation on the postoperative analgesic requirement. Anesthesia \& Analgesia, Baltimore, v. 85, n. 2, p. 406-413, Aug. 1997. 
WARNCKE, T.; STUBHAUG, A.; JORUM, E. Preinjury treatment with morphine or ketamine inhibits the development of experimentally induced secondary hyperalgesia in man. Pain, Seattle, v. 86, n. 1-2, p. 293-303, Mar. 2000.

WAY, L. W.; DUNPHY, J. E. Biliary tract. In: WAY, L. W.; DUNPHY, J. E. Cirurgia: diagnóstico e tratamento. 9. ed. Rio de Janeiro: Guanabara koogan, 1993. 525-552 p.

WILKIESON, C. A. et al. Toleration, side-effects an efficacy of sulphasalazine in rheumatoid arthritis patients of different ages. Q uarterly J ournal of M edicine, Oxford, v. 86, n. 8, p. 501-505, Aug. 1993.

WOOD, L. Fisiologia da dor. In: KITCHEN, S.; BAZIN, S. Eletroterapia de Clayton. 10. ed. São Paulo: Manole, 1998. 80-85 p.

WOOLF, C. J.; CHONG, M.-S. Preemptive analgesia: treating postoperative pain by preventing the establishment of central sensitization. Anesthesia \& Analgesia, Baltimore, v. 77, n. 2, p. 362-379, Aug. 1993.

WU, W.-P et al. The very-high-efficacy 5-HT $1 \mathrm{~A}$ receptor agonist, F 13640 preempts the development of allodynia-like behaviors in rats with spinal cord injury. E uropean J ournal of Pharmacology, Utrecht, v. 478, n. 2-3, p. 131-137, Oct. 2003.

YENG, L. T. et al. Medicina física e reabilitação em doentes com dor crônica. In: TEIXEIRA, M. J.; FIGUEIRÓ, J. A. B. Dor: epidemiologia, fisiopatologia, avaliação, síndromes dolorosas e tratamento. São Paulo: Grupo Editorial Moreira Jr., 2001. 131-140 p.

ZÁRATE, E. et al. The use of transcutaneous acupoint electrical stimulation for prevening nausea and vomiting after laparoscopic surgery. A nesthesia \& Analgesia, Baltimore, v. 92, n. 3, p. 629-35, Mar. 2001.

ZHOU, G. Z; XI, G. F. Comparison between transcutaneous nerve stimulation analgesic effect and electroacupuncture. Analgesic effect in rabbits. Acupuncture and Electrotherapeutics R esearch, Oxford, v. 11, n. 2, p. 119-125, May 1986. 


\section{APÊNDICE}




\section{APÊ NDICE}

\section{APÊ NDICE A -- Ficha de identificação da paciente}

Número do estudo:

Leito:

Data da cirurgia:

Hospital:

Nome:

Prontuário da paciente:

Idade:

Peso:

Estatura:

Sexo: ( ) M ( ) F

Diagnóstico clínico:

Profissão:

Naturalidade:

Nível de escolaridade: ( ) Nunca estudou ( ) $1^{\circ}$ grau incompleto ( ) $1^{\circ}$ grau completo

( ) $2^{\circ}$ grau incompleto ( ) $2^{\circ}$ grau completo ( ) $3^{\circ}$ grau incompleto ( ) $3^{\circ}$ grau completo

Possui: ( ) Hepatopatia ( ) Nefropatia ( ) Algum tipo de enfermidade maligna

( ) Hipertensão arterial ( ) Diabetes Outra:

Sentia dor? Em caso de sim, há quanto tempo?

Utilizava algum medicamento para combatê-la? ( ) Sim （ ) Não

Qual?

Faz ou fez uso de algum outro tipo de medicação para combater essa dor? Em caso de sim, qual e há quanto tempo? 


\section{APÊ NDICE B -- Termo de consentimento livre e esclarecido}

A senhora será submetida a uma cirurgia, na qual o tratamento pós-cirúrgico é feito com remédios para aliviar a dor. A nossa pesquisa, intitulada "ESTIMULAÇÃO ELÉTRICA TRANSCUTÂNEA DO NERVO: ANALGESIA PREEMPTIVA EM COLECISTECTOMIA POR LAPAROTOMIA", usará, antes da realização da cirurgia, durante 60 minutos um aparelho chamado TENS. Queremos saber, no período pós-operatório, o seu nível de dor e a sua satisfação com o tratamento. Esse tipo de tratamento por nós proposto não promove danos lesivos à sua saúde e não oferece fatores de risco. O fato de você concordar em participar desse estudo não implica prejuízo à saúde, bem assim não alterará de nenhuma forma o tratamento já estabelecido.

$\mathrm{Eu}$, $\mathrm{RG}$ fui informada dos objetivos da pesquisa acima de maneira clara e detalhada. Recebi informações a respeito do tratamento proposto e esclareci minhas dúvidas. Sei que a qualquer momento poderei solicitar novas informações e modificar minha decisão se assim o desejar. Sei também que todos os dados dessa pesquisa ficarão em sigilo e terei a liberdade de retirar meu consentimento de participação na pesquisa.

\section{Paciente}

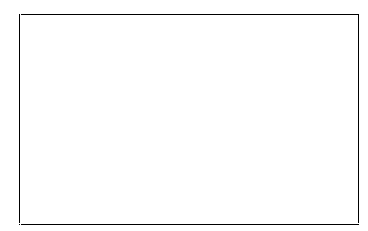

Digital (para caso de pacientes não letrados)

\section{Pesquisador}




\section{APÊ NDICE C -- Ficha de aplicação da TE NS e do ato cirúrgico}

\section{APLICAÇÃO DA TENS:}

Número do estudo: Leito:

Grupo a que pertence a paciente: ( ) Preemptivo ( ) Placebo

Parâmetros de aplicação da TENS: duração de pulso $(T)=250 \mu$ s; freqüência $(F)=4 \mathrm{~Hz}$; e tempo $=60 \mathrm{~min}$.

Início da aplicação: $\mathrm{h}$

Término da aplicação: h

Obs:

\section{ATO CIRÚRGICO:}

\section{ASA: I ( ) II ( )}

Horário de indução do bloqueio anestésico: h

Medicação anestésica:

Horário da cirurgia: Início: h Término: h

Duração da cirurgia: $\min$.

Médico cirurgião:

Médico anestesista:

Houve alguma intercorrência cirúrgica? ( )Sim （ ) Não

Horário da intercorrência: $\mathrm{h}$

OBS:

Obs: Lembrar de solicitar ao cirurgião que a dipirona seja prescrita de 6 em 6 h, e o diclofenaco de sódio e a metoclopramida, como medicação de resgate. Informá-lo que essa prescrição deverá ser procedida durante todo o período de internação hospitalar. 


\section{APÊ NDICE D -- Ficha de avaliação da dor pela Escala Numérica de M ensuração da D or}

Número do estudo:

Data da cirurgia:

Nome da paciente:

Horário da indução do bloqueio Anestésico:
Leito:

Prontuário:

1) Horário:

ENDa na cicatriz:

ENDa em outra região:

h (2 1/2 h após a indução do bloqueio anestésico)

Obs:

2) Horário:

h (3 $1 \frac{1}{2} \mathrm{~h}$ após a indução do bloqueio anestésico)

ENDb na cicatriz:

ENDb em outra região:

Qual (is) região (ões)?

Obs:

3) Horário:

ENDc na cicatriz:

ENDc em outra região:

Qual (is) região (ões)?

Obs:

4) Horário:

ENDd na cicatriz:

h (5 1/2 h após a indução do bloqueio anestésico)

ENDd em outra região:

Qual (is) região (ões)?

Obs:

5) Horário:

ENDe na cicatriz:

ENDe em outra região:

h (7 h após a indução do bloqueio anestésico)

Obs:

6) Horário:

h ( 8 h após a indução do bloqueio anestésico)

ENDf na cicatriz:

ENDf em outra região:

Qual (is) região (ões)?

Obs:

7) Horário:

ENDg na cicatriz:

ENDg em outra região:

Qual (is) região (ões)?

Obs:

8) Horário:

h (às 07:00 h do dia de alta hospitalar)

ENDh na cicatriz:

ENDh em outra região:

Qual (is) região (ões)?

Obs:

Sentiu dor no ombro em algum momento do período pós-operatório? 


\section{APÊ NDICE E -- Questionário de Dor M CG ill}

Número do estudo:

Leito:

Data da cirurgia:

Prontuário:

Nome da paciente:

Aplicação do MPQ (16 h após a indução do bloqueio anestésico): $\mathrm{h}$

"Algumas das palavras que eu vou ler descrevem a sua dor atual. Diga-me qual palavra de cada grupo melhor descreve a sua dor. Não escolha aquelas que não se aplicam. Escolha somente uma palavra de cada grupo, a mais adequada para a descrição de sua dor. Caso nenhuma palavra expresse a sua dor, você pode dizer nenhuma."

\begin{tabular}{|c|c|c|c|}
\hline $\begin{array}{l}1^{\mathrm{a}} \\
\text { ( ) } \text { 1.VIBRAÇÃO } \\
\text { ( ) } \text { ).TREMOR } \\
\text { ( ) } \text { 3.PULSANTE } \\
\text { ( ) 4.LATEJANTE } \\
\text { ( ) } 5 . \mathrm{COMO} \mathrm{BATIDA} \\
\text { ( } \text { ) 6.COMO PANCADA }\end{array}$ & $\begin{array}{l}2^{\mathrm{a}} \\
\text { ( ) } 1 . \text { PONTADA } \\
\text { ( ) } 2 . \mathrm{CHOQUE} \\
\text { ( ) } 3 . \mathrm{TIRO}\end{array}$ & $\begin{array}{l}3^{\mathrm{a}} \\
\text { ( ) }) \text { 1.AGULHADA } \\
\text { ( ) } 2 . \text { PERFURANTE } \\
\text { ( ) } 3 . \text { FACADA } \\
\text { ( ) } \text { 4.PUNHALADA } \\
\text { ( ) } 5 . \text { EM LANÇA }\end{array}$ & $\begin{array}{l}4^{\mathrm{a}} \\
\text { ( ) } 1 . \mathrm{FINA} \\
\text { ( ) } 2 . \mathrm{CORTANTE} \\
\text { ( ) } 3 . \mathrm{ESTRAÇALHA}\end{array}$ \\
\hline $\begin{array}{l}5^{\mathrm{a}} \\
\text { ( ) } 1 . \mathrm{BELISC} \tilde{\mathrm{A} O} \\
\text { ( ) } 2 . \mathrm{PRESS} \tilde{O} \mathrm{O} \\
\text { ( ) } 3 . \mathrm{MORDIDA} \\
\text { ( }) \text { 4.CÓLICA } \\
\text { ( }) \text { 5.ESMAGAMENTO }\end{array}$ & $\begin{array}{l}6^{\mathrm{a}} \\
\text { ( ) } 1 . \mathrm{FISGADA} \\
\text { ( ) } 2 . \mathrm{PUX} \tilde{\mathrm{A} O} \\
\text { ( ) } 3 . \mathrm{EM} \text { TORÇÃO }\end{array}$ & $\begin{array}{l}7^{\mathrm{a}} \\
\text { ( ) } 1 . \mathrm{CALOR} \\
\text { ( ) } 2 . \mathrm{QUEIMAÇÃO} \\
\text { ( ) } 3 . \text { FERVENTE } \\
\text { ( ) 4.EM BRASA }\end{array}$ & $\begin{array}{l}8^{\mathrm{a}} \\
\text { ( ) } 1 . \mathrm{FORMIGAMENTO} \\
\text { ( ) } 2 . \mathrm{COCEIRA} \\
\text { ( ) 3.ARDOR } \\
\text { ( ) 4.FERROADA }\end{array}$ \\
\hline $\begin{array}{l}9^{\mathrm{a}} \\
\text { ( ) } 1 . \mathrm{MAL} \text { LOCALIZADA } \\
\text { ( ) } 2 . \mathrm{DOLORIDA} \\
\text { ( ) 3.MACHUCADA } \\
\text { ( ) 4.DOÍDA } \\
\text { ( ) } 5 . \text { PESADA }\end{array}$ & $\begin{array}{c}10^{\mathrm{a}} \\
(\mathrm{c}) \text { 1.SENSÍVEL } \\
\text { ( }) \text { 2.ESTICADA } \\
\text { ( } \quad \text { ) 3.ESFOLANTE } \\
\text { ( } \quad \text { ) 4.RACHANDO }\end{array}$ & $\begin{array}{l}11^{\mathrm{a}} \\
\text { ( ) 1.CANSATIVA } \\
\text { ( ) 2.EXAUSTIVA }\end{array}$ & $\begin{array}{c}12^{\mathrm{a}} \\
\text { ( ) } 1 . \mathrm{ENJOADA} \\
\text { ( ) } 2 . \mathrm{SUFOCANTE}\end{array}$ \\
\hline $\begin{array}{l}13^{\mathrm{a}} \\
\text { ( ) } 1 . \mathrm{CASTIGANTE} \\
\text { ( ) } 2 . \text { ATORMENTA } \\
\text { ( ) } 3 . \text { ATERRORIZANTE } \\
\text { ( ) } 4 . \mathrm{MALDITA} \\
\text { ( ) } 5 . \mathrm{MORTAL}\end{array}$ & $\begin{array}{l}14^{\mathrm{a}} \\
\text { ( ) } 1 . \text { AMEDRONTADA } \\
\text { ( ) } 2 . \text { APAVORANTE } \\
\text { ( ) } 3 . \mathrm{CRUEL}\end{array}$ & $\begin{array}{c}15^{\mathrm{a}} \\
\text { ( ) } 1 . \text { MISERÁVEL } \\
\text { ( ) } 2 . \text { ENLOUQUECEDORA }\end{array}$ & \begin{tabular}{l}
\multicolumn{1}{c}{$16^{\mathrm{a}}$} \\
( ) ) 1.CHATA \\
( ) ).QUE INCOMODA \\
( ) 3.DESGASTANTE \\
( ) ).FORTE \\
( ) 5.INSUPORTÁVEL
\end{tabular} \\
\hline
\end{tabular}




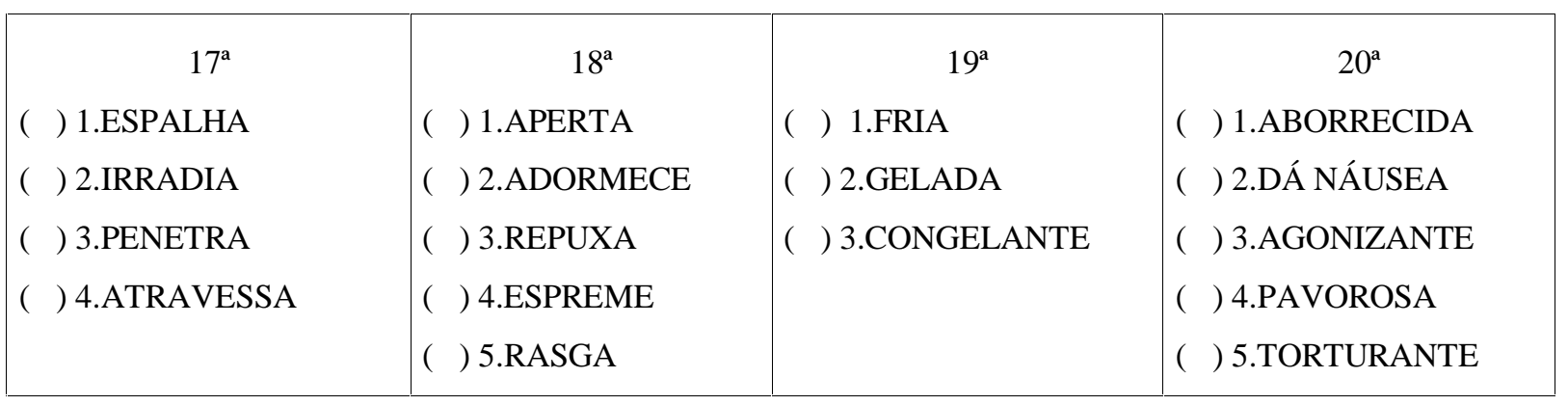

Número de Palavras Escolhidas Índice Quantitativo de Dor

Sensorial:

Afetiva:

Avaliativa:

Miscelânea:

Total:
Sensorial:

Afetiva:

Avaliativa:

Miscelânea:

Total: 


\section{APÊ NDICE F -- Ficha de avaliação da satisfação dos pacientes pela E scala de Satisfação do Paciente}

Número do estudo:

Data da cirurgia:

Prontuário:

Nome da paciente:

Horário da indução do bloqueio Anestésico: h

Leito:

1) Horário: h (3 1/2 h após a indução do bloqueio anestésico) $\mathrm{ESPb}$ :

Obs:

Responsável pela coleta:

2) Horário: h (5 1/2 h após a indução do bloqueio anestésico) ESPd:

Obs:

Responsável pela coleta:

3) Horário: _ _ h ESPf:

Obs:

Responsável pela coleta:

4) Horário: __ _ h $\mathrm{h}$ (16 h após a indução do bloqueio anestésico) ESPg:

Obs:

Responsável pela coleta:

5) Horário: h (momento da alta hospitalar) ESPh:

Obs:

Responsável pela coleta: 


\section{APÊ NDICE G -- Ficha de registro da administração de fármacos no pós- operatório}

Qual o tempo decorrido desde a indução do bloqueio anestésico até a $1^{\text {a }}$ requisição de analgésicos?

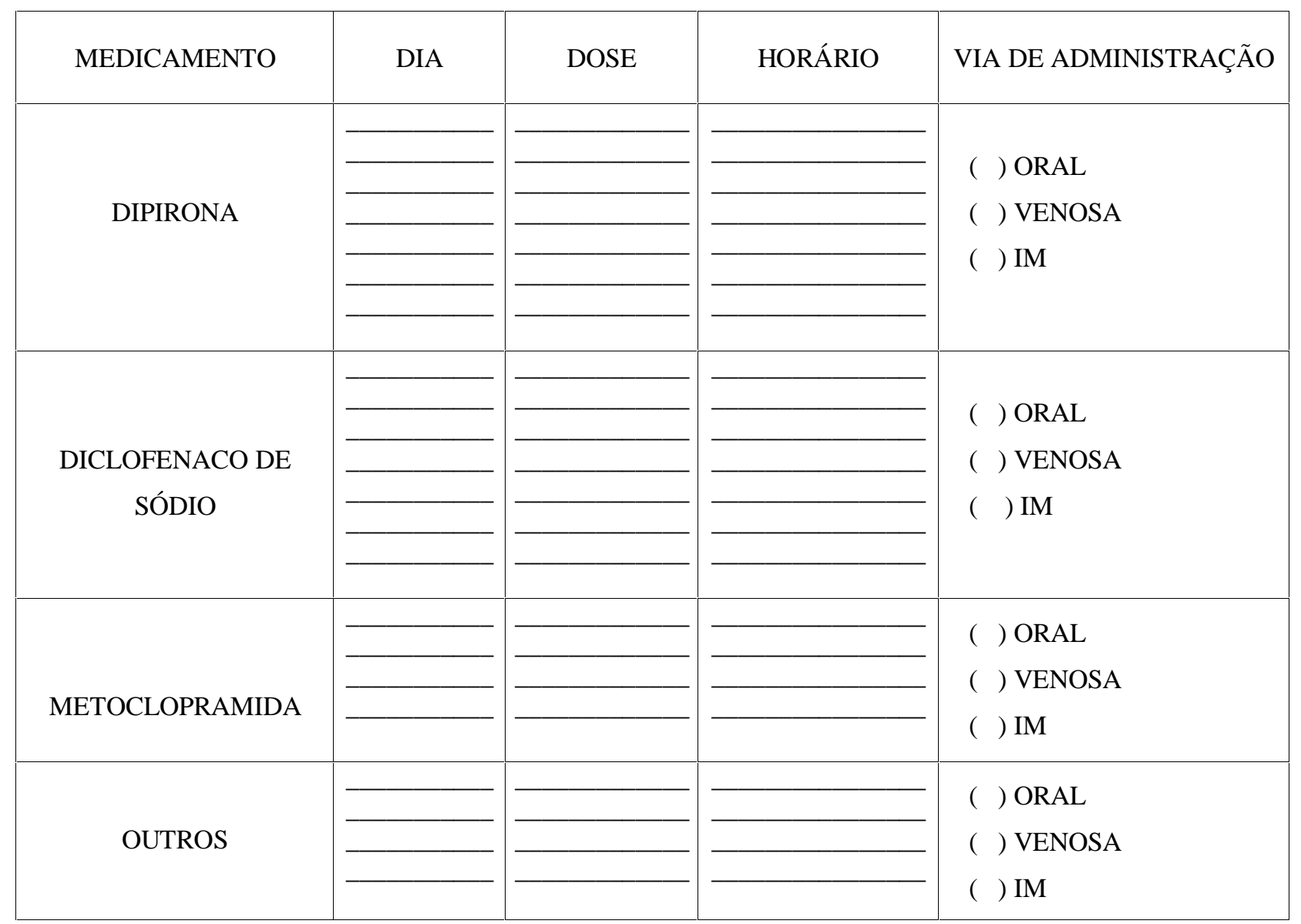

O bservações sobre náuseas e êmesis: 


\section{APÊ NDICE H -- Q uestionário sobre a aplicação da TE NS}

As perguntas que eu vou ler para a senhora referem-se à TENS (Estimulação Elétrica Transcutânea do Nervo), aquele aparelho que foi utilizado na senhora antes da cirurgia:

1) A aplicação da TENS:

( ) Não incomodou

( ) Incomodou um pouco

( ) Incomodou razoavelmente

( ) Incomodou muito

2) Em uma próxima cirurgia você iria preferir, para o tratamento da sua dor pós-operatória, usar:

( ) Somente a TENS

( ) Somente os medicamentos

( ) A TENS e os medicamentos 


\section{APÊ NDICE I -- Lista de tabelas com os resultados da pesquisa}

Tabela 13 - Valores da intensidade de dor incisional, obtidos pela Escala Numérica de Mensuração da Dor, das pacientes do grupo preemptivo.

\begin{tabular}{|c|c|c|c|c|c|c|c|c|}
\hline Paciente & a & b & C & d & e & $f$ & $\mathbf{g}$ & h \\
\hline $1^{\circ}$ & 4 & 3 & 4 & 4 & 3 & 3 & 2 & 2 \\
\hline $2^{\circ}$ & 0 & 0 & 0 & 0 & 0 & 0 & 3 & 0 \\
\hline $3^{\circ}$ & 5 & 5 & 5,5 & 8 & 8 & 5 & 0 & 0 \\
\hline $4^{\circ}$ & 0 & 0 & 4 & 3 & 7,5 & 7,5 & 9 & 3 \\
\hline $5^{\circ}$ & 0 & 2 & 4 & 3 & 5 & 5 & 10 & 0 \\
\hline $6^{\circ}$ & 0 & 0 & 0 & 0 & 5 & 6 & 0 & 7 \\
\hline $7^{\circ}$ & 0 & 0 & 0 & 0 & 0 & 0 & 0 & 0 \\
\hline $8^{\circ}$ & 0 & 0 & 0 & 0 & 0 & 0 & 3 & 2 \\
\hline $9^{\circ}$ & 0 & 0 & 0 & 0 & 1 & 4 & 6 & 0 \\
\hline $10^{\circ}$ & 0 & 2 & 1 & 3 & 3 & 0 & 2 & 3 \\
\hline $11^{\circ}$ & 0 & 0 & 0 & 5 & 0 & 6 & 3 & 1 \\
\hline $12^{\circ}$ & 0 & 0 & 3 & 3 & 2 & 0 & 3 & 3 \\
\hline $13^{\circ}$ & 0 & 2 & 3 & 6 & 3 & 3 & 4 & 0 \\
\hline $14^{\circ}$ & 0 & 0 & 10 & 10 & 3 & 5 & 7 & 1 \\
\hline $15^{\circ}$ & 3 & 3 & 1 & 3 & 3 & 2 & 2 & 0 \\
\hline $16^{\circ}$ & 0 & 0 & 0 & 0 & 4 & 4 & 6 & 0 \\
\hline $17^{\circ}$ & 0 & 0 & 5 & 3 & 8 & 4 & 3 & 0 \\
\hline $18^{\circ}$ & 0 & 0 & 0 & 0 & 0 & 0 & 3 & 0 \\
\hline $19^{\circ}$ & 0 & 0 & 0 & 0 & 4 & 7 & 9 & 0 \\
\hline $20^{\circ}$ & 0 & 0 & 0 & 0 & 0 & 2 & 2 & 0 \\
\hline $21^{\circ}$ & 0 & 0 & 0 & 1 & 3 & 3 & 2 & 0 \\
\hline $22^{\circ}$ & 0 & 0 & 0 & 2 & 0 & 2 & 0 & 0 \\
\hline $23^{\circ}$ & 5 & 7 & 4 & 7 & 9 & 8 & 8 & 2 \\
\hline $24^{\circ}$ & 0 & 0 & 0 & 3,5 & 6 & 6 & 1 & 0 \\
\hline $25^{\circ}$ & 4 & 5 & 6 & 5 & 3 & 3 & 2 & 0 \\
\hline
\end{tabular}


Tabela 14 - Valores da intensidade de dor incisional, obtidos pela Escala Numérica de Mensuração da Dor, das pacientes do grupo placebo.

\begin{tabular}{ccccccccc}
\hline Paciente & $\mathbf{a}$ & $\mathbf{b}$ & $\mathbf{C}$ & $\mathbf{d}$ & $\mathbf{e}$ & $\mathbf{F}$ & $\mathbf{g}$ & $\mathbf{h}$ \\
$\mathbf{1}^{\circ}$ & 0 & 0 & 0 & 1 & 5 & 10 & 4 & 4 \\
$\mathbf{2}^{\circ}$ & 1 & 1 & 0 & 2 & 3 & 1 & 4 & 2 \\
$\mathbf{3}^{\circ}$ & 0 & 0 & 3 & 5 & 10 & 10 & 5 & 5 \\
$\mathbf{4}^{\circ}$ & 3 & 5 & 3 & 3 & 3 & 3 & 0 & 2 \\
$\mathbf{5}^{\circ}$ & 0 & 0 & 0 & 0 & 4 & 8 & 7 & 4 \\
$\mathbf{6}^{\circ}$ & 5 & 5 & 8 & 8 & 3 & 3 & 0 & 0 \\
$\mathbf{7}^{\circ}$ & 0 & 0 & 4 & 5 & 9 & 9 & 6 & 0 \\
$\mathbf{8}^{\circ}$ & 5 & 10 & 10 & 0 & 0 & 0 & 7 & 1 \\
$\mathbf{9}^{\circ}$ & 0 & 2 & 4 & 10 & 8 & 9 & 3 & 8 \\
$\mathbf{1 0}^{\circ}$ & 0 & 0 & 0 & 0 & 0 & 2 & 3 & 4 \\
$\mathbf{1 1}^{\circ}$ & 0 & 0 & 1 & 4 & 5 & 8 & 7 & 4 \\
$\mathbf{1 2}^{\circ}$ & 0 & 0 & 1 & 4 & 4 & 5 & 5 & 0 \\
$\mathbf{1 3}^{\circ}$ & 0 & 6 & 7 & 4 & 4,5 & 3 & 3 & 3 \\
$\mathbf{1 4}^{\circ}$ & 0 & 1 & 9 & 9 & 6 & 6 & 4 & 2 \\
$\mathbf{1 5}^{\circ}$ & 0 & 0 & 0 & 4 & 6 & 7 & 5 & 0 \\
$\mathbf{1 6}^{\circ}$ & 0 & 0 & 6 & 10 & 2 & 3 & 4 & 0 \\
$\mathbf{1 7}^{\circ}$ & 1 & 5 & 7 & 8 & 8 & 5 & 4 & 1 \\
$\mathbf{1 8}^{\circ}$ & 0 & 0 & 5 & 8 & 2 & 2 & 3 & 0 \\
$\mathbf{1 9}^{\circ}$ & 0 & 0 & 2 & 3 & 5 & 6 & 0 & 0 \\
$\mathbf{2 0}^{\circ}$ & 0 & 0 & 0 & 10 & 9 & 2 & 6 & 0 \\
$\mathbf{2 1}^{\circ}$ & 2 & 3 & 6 & 7 & 2 & 3 & 3 & 1 \\
$\mathbf{2 2}^{\circ}$ & 0 & 5 & 7 & 2 & 4 & 0 & 0 & 0 \\
$\mathbf{2 3}^{\circ}$ & 0 & 7 & 0 & 0 & 0 & 0 & 1 & 0 \\
$\mathbf{2 4}^{\circ}$ & 0 & 3 & 8 & 8 & 8 & 9 & 8 & 3 \\
$\mathbf{2 5}^{\circ}$ & 1 & 3 & 5 & 5 & 8 & 8 & 0 & 0 \\
\hline a (21/2 h após a indução do bloqueio anestésico, IBA); b (31/2 h após a IBA); c (41/2 h após a IBA); $(51 / 2$ \\
h após a IBA); e (7 h após a IBA); f (8 h após a IBA); g (16 h após a IBA); e h (momento da alta \\
hospitalar). & & & & & & & &
\end{tabular}


Tabela 15 - Valores do grau de satisfação das pacientes do grupo preemptivo com o tratamento que estava sendo realizado, obtidos pela Escala de Satisfação dos Pacientes.

\begin{tabular}{cccccc}
\hline Paciente & $\mathbf{b}$ & $\mathbf{d}$ & $\mathbf{f}$ & $\mathbf{g}$ & $\mathbf{h}$ \\
$\mathbf{1}^{\circ}$ & 8 & 8 & 9 & 9 & 9 \\
$\mathbf{2}^{\circ}$ & 8 & 10 & 10 & 10 & 10 \\
$\mathbf{3}^{\circ}$ & 8 & 8 & 9 & 9 & 9 \\
$\mathbf{4}^{\circ}$ & 9 & 9 & 9 & 9,5 & 10 \\
$\mathbf{5}^{\circ}$ & 8 & 10 & 10 & 10 & 10 \\
$\mathbf{6}^{\circ}$ & 8 & 8 & 10 & 10 & 10 \\
$\mathbf{7}^{\circ}$ & 10 & 10 & 10 & 10 & 10 \\
$\mathbf{8}^{\circ}$ & 10 & 10 & 10 & 10 & 10 \\
$\mathbf{9}^{\circ}$ & 10 & 10 & 10 & 10 & 10 \\
$\mathbf{1 0}^{\circ}$ & 10 & 10 & 10 & 10 & 10 \\
$\mathbf{1 1}^{\circ}$ & 10 & 10 & 10 & 10 & 10 \\
$\mathbf{1 2}^{\circ}$ & 10 & 10 & 10 & 10 & 10 \\
$\mathbf{1 3}^{\circ}$ & 10 & 10 & 8 & 10 & 10 \\
$\mathbf{1 4}^{\circ}$ & 10 & 10 & 10 & 10 & 10 \\
$\mathbf{1 5}^{\circ}$ & 9 & 9 & 9 & 9 & 10 \\
$\mathbf{1 6}^{\circ}$ & 8 & 8 & 8 & 9 & 10 \\
$\mathbf{1 7}^{\circ}$ & 10 & 10 & 10 & 10 & 10 \\
$\mathbf{1 8}^{\circ}$ & 10 & 10 & 10 & 10 & 10 \\
$\mathbf{1 9}^{\circ}$ & 10 & 9 & 8 & 6 & 10 \\
$\mathbf{2 0}^{\circ}$ & 10 & 10 & 10 & 10 & 10 \\
$\mathbf{2 1}^{\circ}$ & 10 & 10 & 10 & 10 & 10 \\
$\mathbf{2 2}^{\circ}$ & 10 & 10 & 8 & 9 & 10 \\
$\mathbf{2 3}^{\circ}$ & 10 & 10 & 10 & 10 & 10 \\
$\mathbf{2 4}^{\circ}$ & 10 & 10 & 10 & 10 & 10 \\
$\mathbf{2 5}^{\circ}$ & 10 & 10 & 10 & 10 & 10 \\
\hline $\mathrm{b}\left(33^{\circ} \mathrm{h}\right.$ após a indução do bloqueio anestésico, IBA); d (51/2 hapós a IBA); f (8 h \\
após a IBA); g (16 h após a IBA); e h (momento da alta hospitalar). & \\
& & & & &
\end{tabular}


Tabela 16 - Valores do grau de satisfação das pacientes do grupo placebo com o tratamento que estava sendo realizado, obtidos pela Escala de Satisfação dos Pacientes.

\begin{tabular}{|c|c|c|c|c|c|}
\hline Paciente & b & d & $f$ & g & $\mathbf{h}$ \\
\hline $1^{\circ}$ & 8 & 10 & 7 & 10 & 8 \\
\hline $2^{\circ}$ & 8 & 8 & 9 & 9 & 9 \\
\hline $3^{\circ}$ & 10 & 10 & 10 & 10 & 10 \\
\hline $4^{\circ}$ & 10 & 10 & 10 & 10 & 10 \\
\hline $5^{\circ}$ & 10 & 10 & 10 & 10 & 10 \\
\hline $6^{\circ}$ & 10 & 10 & 10 & 10 & 10 \\
\hline $7^{\circ}$ & 9 & 6 & 8 & 8 & 9 \\
\hline $8^{\circ}$ & 8 & 8 & 8 & 4 & 3 \\
\hline $9^{\circ}$ & 5 & 5 & 5 & 8 & 10 \\
\hline$* 10^{\circ}$ & - & - & - & - & - \\
\hline $11^{\circ}$ & 10 & 10 & 10 & 10 & 10 \\
\hline $12^{\circ}$ & 7 & 7 & 7 & 5 & 5 \\
\hline $13^{\circ}$ & 9 & 9 & 9 & 9 & 10 \\
\hline $14^{\circ}$ & 8 & 6 & 9 & 9 & 10 \\
\hline $15^{\circ}$ & 10 & 10 & 8 & 10 & 10 \\
\hline $16^{\circ}$ & 10 & 9 & 10 & 10 & 10 \\
\hline $17^{\circ}$ & 8 & 10 & 10 & 10 & 10 \\
\hline $18^{\circ}$ & 10 & 10 & 10 & 10 & 10 \\
\hline $19^{\circ}$ & 10 & 10 & 10 & 10 & 10 \\
\hline $20^{\circ}$ & 8 & 10 & 10 & 10 & 10 \\
\hline $21^{\circ}$ & 8 & 10 & 10 & 10 & 10 \\
\hline $22^{\circ}$ & 10 & 10 & 10 & 10 & 10 \\
\hline $23^{\circ}$ & 10 & 10 & 10 & 10 & 10 \\
\hline $24^{\circ}$ & 10 & 8 & 9 & 10 & 10 \\
\hline $25^{\circ}$ & 10 & 10 & 10 & 10 & 10 \\
\hline
\end{tabular}


Tabela 17 - Uso de diclofenaco de sódio nas primeiras 16 horas após a indução do bloqueio anestésico e tempo decorrido desde essa indução até a primeira solicitação dessa droga, nos grupos preemptivo e placebo.

\begin{tabular}{|c|c|c|c|c|}
\hline \multirow[b]{2}{*}{ Paciente } & \multicolumn{2}{|c|}{ Uso de diclofenaco de sódio } & \multicolumn{2}{|c|}{ Tempo (min) } \\
\hline & Preemptivo & Placebo & Preemptivo & Placebo \\
\hline $1^{\circ}$ & Não & Sim & - & 230 \\
\hline $2^{\circ}$ & Não & Não & - & - \\
\hline $3^{\circ}$ & Não & Sim & - & 440 \\
\hline $4^{\circ}$ & Não & Sim & - & 225 \\
\hline $5^{\circ}$ & Sim & Sim & 224 & 690 \\
\hline $6^{\circ}$ & Não & Sim & - & 505 \\
\hline $7^{\circ}$ & Não & Não & - & - \\
\hline $8^{\circ}$ & Sim & Sim & 805 & 300 \\
\hline $9^{\circ}$ & Sim & Não & 465 & - \\
\hline $10^{\circ}$ & Não & Sim & - & 840 \\
\hline $11^{\circ}$ & Sim & Não & 435 & - \\
\hline $12^{\circ}$ & Sim & Não & 415 & - \\
\hline $13^{\circ}$ & Sim & Sim & 330 & 410 \\
\hline $14^{\circ}$ & Sim & Sim & 310 & 360 \\
\hline $15^{\circ}$ & Não & Sim & - & 722 \\
\hline $16^{\circ}$ & Sim & Não & 716 & - \\
\hline $17^{\circ}$ & $\mathrm{Sim}$ & Sim & 685 & 400 \\
\hline $18^{\circ}$ & Sim & Sim & 570 & 395 \\
\hline $19^{\circ}$ & Não & Não & - & - \\
\hline $20^{\circ}$ & Não & Sim & - & 615 \\
\hline $21^{\circ}$ & Não & Sim & - & 420 \\
\hline $22^{\circ}$ & Não & Não & - & - \\
\hline $23^{\circ}$ & Sim & Sim & 305 & 500 \\
\hline $24^{\circ}$ & Sim & Não & 590 & - \\
\hline $25^{\circ}$ & Não & Não & - & - \\
\hline
\end{tabular}


Tabela 18 - Presença de dor no ombro direito no período pós-operatório, nas pacientes dos grupos preemptivo e placebo.

\section{Relato de dor no ombro direito}

\begin{tabular}{ccc}
\hline Paciente & G rupo preemptivo & G rupo placebo \\
\hline $\mathbf{1}^{\circ}$ & Não & Sim \\
$\mathbf{2}^{\circ}$ & Sim & Não \\
$\mathbf{3}^{\circ}$ & Não & Não \\
$\mathbf{4}^{\circ}$ & Não & Sim \\
$\mathbf{5}^{\circ}$ & Sim & Sim \\
$\mathbf{6}^{\circ}$ & Não & Não \\
$\mathbf{7}^{\circ}$ & Não & Não \\
$\mathbf{8}^{\circ}$ & Não & Não \\
$\mathbf{9}^{\circ}$ & Sim & Não \\
$\mathbf{1 0}^{\circ}$ & Não & Não \\
$\mathbf{1 1}^{\circ}$ & Não & Não \\
$\mathbf{1 2}^{\circ}$ & Não & Sim \\
$\mathbf{1 3}^{\circ}$ & Não & Não \\
$\mathbf{1 4}^{\circ}$ & Sim & Sim \\
$\mathbf{1 5}^{\circ}$ & Sim & Não \\
$\mathbf{1 6}^{\circ}$ & Não & Não \\
$\mathbf{1 7}^{\circ}$ & Sim & Não \\
$\mathbf{1 8}^{\circ}$ & Não & Sim \\
$\mathbf{1 9}^{\circ}$ & Sim & Não \\
$\mathbf{2 0}^{\circ}$ & Não & Não \\
$\mathbf{2 1}^{\circ}$ & Sim & Não \\
$\mathbf{2 2}^{\circ}$ & Sim & Sim \\
$\mathbf{2 3}^{\circ}$ & Não & Não \\
$\mathbf{2 4}^{\circ}$ & Sim & Não \\
$\mathbf{2 5}^{\circ}$ & Não & Sim \\
\hline & & \\
\hline
\end{tabular}


Tabela 19 - Quantidade de vezes em que a metoclopramida, o diclofenaco de sódio e a dipirona foram administradas em cada paciente, durante todo o período pós-operatório em que elas estavam internadas.

\begin{tabular}{|c|c|c|c|c|c|c|}
\hline \multirow[b]{2}{*}{ Paciente } & \multicolumn{2}{|c|}{ M etoclopramida (10 mg) } & \multicolumn{2}{|c|}{$\begin{array}{c}\text { Diclofenaco de sódio } \\
\text { (75 mg) }\end{array}$} & \multicolumn{2}{|c|}{ Dipirona (1 g) } \\
\hline & Preemptivo & Placebo & Preemptivo & Placebo & Preemptivo & Placebo \\
\hline $1^{\circ}$ & - & - & - & 1 & 7 & 7 \\
\hline $2^{\circ}$ & 1 & - & 2 & 2 & 4 & 7 \\
\hline $3^{\circ}$ & - & - & - & 1 & 7 & 7 \\
\hline $4^{\circ}$ & - & - & 1 & 1 & 7 & 7 \\
\hline $5^{\circ}$ & - & - & 2 & 3 & 4 & 7 \\
\hline $6^{\circ}$ & - & 2 & - & 1 & 7 & 6 \\
\hline $7^{\circ}$ & 1 & 2 & - & - & 6 & 7 \\
\hline $8^{\circ}$ & 1 & - & 1 & 2 & 7 & 7 \\
\hline $9^{\circ}$ & - & - & 3 & - & 6 & 7 \\
\hline $10^{\circ}$ & 3 & - & - & 1 & 3 & 7 \\
\hline $11^{\circ}$ & - & - & 1 & - & 7 & 6 \\
\hline $12^{\circ}$ & 1 & - & 1 & - & 7 & 7 \\
\hline $13^{\circ}$ & - & - & 1 & 2 & 7 & 7 \\
\hline $14^{\circ}$ & - & 2 & 3 & 1 & 7 & 7 \\
\hline $15^{\circ}$ & - & 2 & - & 2 & 7 & 4 \\
\hline $16^{\circ}$ & - & 1 & - & - & 7 & 6 \\
\hline $17^{\circ}$ & - & 1 & 1 & 1 & 7 & 7 \\
\hline $18^{\circ}$ & - & - & 1 & 3 & 7 & 7 \\
\hline $19^{\circ}$ & - & - & - & 1 & 6 & 7 \\
\hline $20^{\circ}$ & - & - & 1 & 3 & 7 & 7 \\
\hline $21^{\circ}$ & - & - & - & 1 & 7 & 7 \\
\hline $22^{\circ}$ & - & - & 1 & 1 & 7 & 4 \\
\hline $23^{\circ}$ & - & 2 & 1 & 2 & 7 & 2 \\
\hline $24^{\circ}$ & - & 1 & 3 & - & 3 & 4 \\
\hline $25^{\circ}$ & - & - & - & 1 & 7 & 3 \\
\hline
\end{tabular}

